University of Louisville

ThinkIR: The University of Louisville's Institutional Repository

$12-2017$

\title{
Type IX secretion system : characterization of an effector protein and an insight into the role of c-terminal domain dimeration in outer membrane translocation.
}

Lahari Koneru

University of Louisville

Follow this and additional works at: https://ir.library.louisville.edu/etd

Part of the Bacteria Commons, Bacteriology Commons, Biochemistry Commons, Immunology of Infectious Disease Commons, Molecular Biology Commons, Oral Biology and Oral Pathology Commons, Periodontics and Periodontology Commons, and the Structural Biology Commons

\section{Recommended Citation}

Koneru, Lahari, "Type IX secretion system : characterization of an effector protein and an insight into the role of c-terminal domain dimeration in outer membrane translocation." (2017). Electronic Theses and Dissertations. Paper 2854.

https://doi.org/10.18297/etd/2854

This Doctoral Dissertation is brought to you for free and open access by ThinkIR: The University of Louisville's Institutional Repository. It has been accepted for inclusion in Electronic Theses and Dissertations by an authorized administrator of ThinkIR: The University of Louisville's Institutional Repository. This title appears here courtesy of the author, who has retained all other copyrights. For more information, please contact thinkir@louisville.edu. 
TYPE IX SECRETION SYSTEM:

\title{
CHARACTERIZATION OF AN EFFECTOR PROTEIN AND AN INSIGHT INTO THE ROLE OF C-TERMINAL DOMAIN DIMERIZATION IN OUTER MEMBRANE TRANSLOCATION
}

\author{
By \\ Lahari Koneru
}

\begin{abstract}
A Dissertation
Submitted to the Faculty of the

School of Interdisciplinary and Graduate Studies of the University of Louisville In Partial Fulfillment of the Requirements

for the degree of

Doctor of Philosophy in Interdisciplinary Studies

School of Interdisciplinary and Graduate Studies

University of Louisville

Louisville, Kentucky
\end{abstract}

December 2017 
(C) Copyright 2017 by Lahari Koneru

All Rights Reserved 

TYPE IX SECRETION SYSTEM:

\author{
CHARACTERIZATION OF AN EFFECTOR PROTEIN AND AN INSIGHT INTO \\ THE ROLE OF C-TERMINAL DOMAIN DIMERIZATION IN OUTER MEMBRANE \\ TRANSLOCATION \\ By \\ Lahari Koneru
}

A Dissertation Approved on

November 9, 2017

By the Following Dissertation Committee

Dr. Jan S. Potempa (mentor)

Dr. David A. Scott (committee member)

Dr. Richard J. Lamont (committee member)

Dr. Silvia M. Uriarte (committee member) 


\section{DEDICATION}

This Dissertation is dedicated to my younger sister Vineetha Koneru for all her love and support. 


\section{ACKNOWLEDGMENTS}

I would like to thank my committee Dr. Jan S. Potempa (mentor), Dr. David A. Scott, Dr. Richard J. Lamont, and Dr. Silvia M. Uriarte for their immense support and encouragement. Also, I will be extremely thankful to my lab members Ms. Barbara Potempa, Dr. Miroslaw Ksiazek and Dr. Anna Lasica, for helping me to cultivate substantial knowledge in the respective field. Finally, I am grateful, to my parents Koneru Mallikharjuna Prasad and Koneru Kumari, my younger sister Vineetha Koneru, my husband Dr. Narasimha Rao Vattikunta and all my friends for being my biggest strength. 


\begin{abstract}
TYPE IX SECRETION SYSTEM:

CHARACTERIZATION OF AN EFFECTOR PROTEIN AND AN INSIGHT INTO THE ROLE OF C-TERMINAL DOMAIN DIMERIZATION IN OUTER MEMBRANE TRANSLOCATION

Lahari Koneru
\end{abstract}

November 9, 2017

Porphyromonas gingivalis and Tannerella forsythia are two of the primary pathogens that are associated in the etiology and progression of chronic periodontitis. In T. forsythia, KLIKK proteases are the recently identified group of proteolytic enzymes that are secreted through Type IX secretion system (T9SS). Among, these KLIKK proteases a synergistic relationship was observed between karilysin and mirolysin in invading the host complement system for the survival of the bacteria [47]. Since, karilysin has been already characterized [45], in this study we propose to study about mirolysin through structural, biochemical and biological characterization. The obtained results from the experiments has shown the propensity of the proenzyme (mirolysin) to autocatalytically process itself at Xaa-Arg peptide bonds. Also, the catalytic enzyme has shown the capablity to degrade an array of physiological substrates like fibrinogen, fibronectin, insulin and LL-37 antimicrobial peptide. In $P$. gingivalis, gingipains are the major proteolytic enzymes that 
are also secreted through T9SS and possess a conserved CTD similar to KLIKK proteases. The conserved C-Terminal Domain (CTD) of the T9SS cargo proteins is found essential for the export of these proteins from the periplasm across the outer membrane. Although the mechanism of CTD as an export signal is not well understood so far, taking previous literature into consideration [95] a phenomenon of CTD dimerization has been hypothesized as a possible mechanism in translocation of the cargo proteins through T9SS. Hence, based on the structure of an already crystallized rCTD of RgpB [95] and PorZ (PG1604) [96], in which the CTD is not cleaved off during the translocation of PorZ across outer membrane, four mutations (A637R, G699R, A719R, and R721E) were incorporated into the structure of the RgpB CTD. These mutants were later characterized for their secretory phenotype by quantification of the gingipain activity and by analyzing the processing of the protein through western blots. Out of the four, G699R and A719R mutations have completely occluded the export of protein, while the proteins bearing A637R and R721E mutations were partially processed and secreted. The full-length ProRgpB (native) and its recombinant Ig-CTD tandem proteins, with and without insertion of the factor Xa cleavage site (inserted between Ig and CTD), were purified to investigate the effect of A719R and R721E mutations on CTD dimerization. Preliminary results with the glutaraldehyde crosslinking on recombinant Ig-CTD proteins with A719R and R721E mutations revealed the lack of dimer formation in contrast to the wild-type recombinant Ig-CTD protein without any mutations. In future, these studies will certainly help in understanding the mechanism of T9SS in Gram-negative bacteria. 
TABLE OF CONTENTS

Page

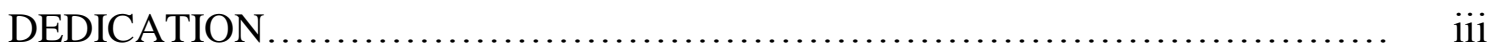

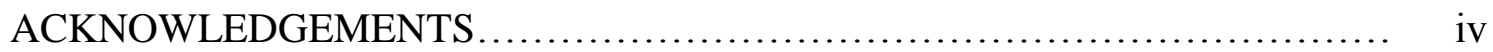

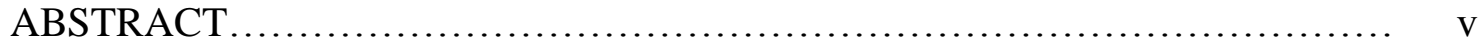

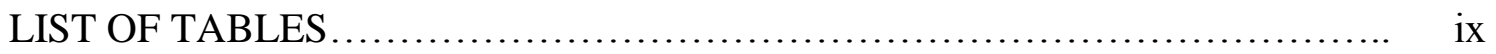

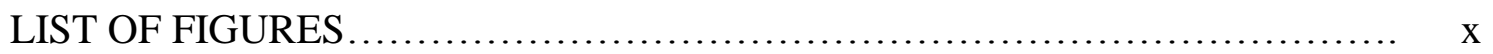

CHAPTERS:

CHAPTER 1: Introduction...................................................11

1.1 Oral Diseases

1.2 Periodontal Diseases

1.3 Virulence Factors

1.4 Gingipains

1.5 KLIKK Proteases

1.6 T9SS

1.7 CTD as an export signal

1.8 Scope of Dissertation 
CHAPTER 2: Mirolysin, a LysargiNase from Tannerella forsythia, proteolytically inactivates the human cathelicidin, LL-37. $12-45$

2.1 Introduction

2.2 Materials and Methods

2.3 Results

2.4 Discussion

CHAPTER 3: Construction of novel mirolysin mutants for crystallography analysis

3.1 Introduction

3.2 Materials and Methods

3.3 Results

3.4 Discussion

CHAPTER 4: Underlying mechanisms and important amino acid residues in the terminal domain of $\operatorname{RgpB}$ gingipain essential for the translocation of the proteins across outer membrane in T9SS.

4.1 Introduction

4.2 Materials and Methods

4.3 Results

4.4 Discussion

CHAPTER 5: Conclusion and Future Perspectives

REFERENCES

$80-86$

CURRICULUM VITAE. 87-88 


\section{LIST OF TABLES}

Table 1: The effect of inhibitors, reducing agents, and divalent cations on the proteolytic

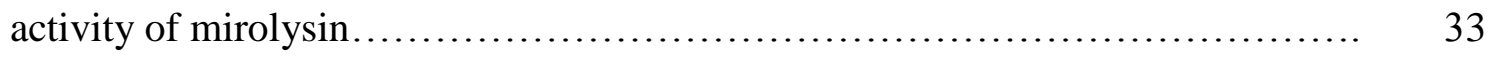

Table 2: List of primers used to generate mirolysin mutants...................... 49

Table 3: List of primers used to incorporate mutations within the CTD of RgpB... 59

Table 4: List of Porphyromonas gingivalis strains used in this study.............. $\quad 60$ 


\section{LIST OF FIGURES}

Page

Figure1: Predicted multidomain structure of KLIKK proteases of Tannerella forsythia.. 5

Figure 2: The hypothetical basic model of T9SS in P.gingivalis..................... 7

Figure 3: The structure of recombinant $\mathrm{C}$-terminal domain........................ 9

Figure 4: Alignment of mirolysin with other members of the M43B protease family... 25

Figure 5: Expression, purification, and autoprocessing of promirolysin............... 28

Figure 6: Expression, purification, and the effect of calcium on autoprocessing of mirolysin

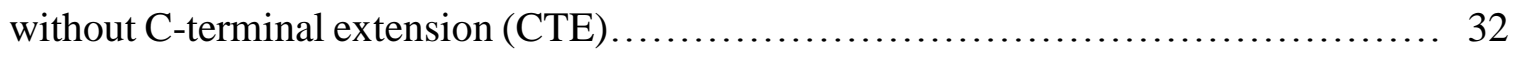

Figure 7: Determination of the dissociation constant $\left(K_{d}\right)$ of mirolysin in the presence of calcium, the effect of calcium on thermal stability, and the optimum $\mathrm{pH} \ldots \ldots \ldots \ldots \ldots . \ldots 35$

Figure 8: Mirolysin hydrolyzes a broad range of substrates and cleaves peptide bonds at arginine and lysine.

Figure 9: Mirolysin degrades LL-37 in a concentration- and time-dependent manner, abolishing its antimicrobial activity. 39

Figure 10: Mirolysin amino acid sequence and the scheme of novel mirolysin mutants generated in this study. 48 
Figure 11: Expression of the recombinant mirolysin mutants

Figure 12: The location of predicted mutations on CTD of RgpB in P.gingivalis..... 57

Figure 13: Purification of native ProRgpB and recombinant Ig-CTD tandem proteins. 66

Figure 14: Phenotype of Porphyromonas gingivalis strains on blood agar plates..... 68

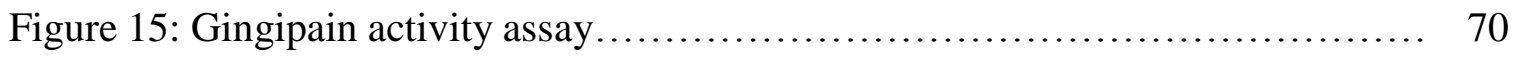

Figure 16: Comparison of RgpB phenotype in Porphyromonas gingivalis W83: wild-type

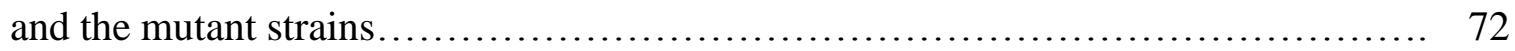




\section{CHAPTER- 1}

\section{INTRODUCTION}

1.1 Oral Diseases: Orodental diseases affect the localized tissues in the oral cavity and also exert a major impact on systemic health and well-being of individuals. According, to the Surgeon General's report on oral health in America, oral health problems not only reflect the general health conditions; they can exacerbate and sometimes even initiate them [1]. Among the most prevalent chronic diseases, periodontal disease is considered as a serious global burden in deteriorating the oral health [2].

1.2 Periodontal diseases: They comprise of bacterially induced inflammatory diseases, with inadequate or overactive localized immunological response affecting the gingiva and periodontium of the oral cavity [3]. The prevalence of a chronic form of periodontitis was notably found higher among the adult population (141 million) of United States $[4,5]$. The initial manifestations include gingivitis caused by the local immune responses, due to formation of plaque. Later, this can progress into an advanced inflammatory condition called periodontitis leading to the destruction of connective tissue attachment, alveolar bone resorption and eventually tooth loss $[6,7]$. Periodontitis has also been linked with several systemic diseases like respiratory infections [8], esophageal cancer [9], cardiovascular diseases [10], gestational diabetes [11], and rheumatoid arthritis [12]. Although plaque bacteria are considered to be the primary etiologic agent, several risk factors are involved that influence the initiation and progression of the disease. These include systemic health, trauma from occlusion, genetic factors, hormonal imbalance, 
pregnancy, smoking, malnutrition etc., which favor the primary factor by causing a state of imbalance between host response and microbial challenge [13-15].

Currently, a polymicrobial synergy and dysbiosis model is considered as the most accepted hypothesis explaining the initiation and progression of chronic periodontitis [17]. Till to date, a large number of diverse bacterial species have been detected in gingival sulcus. Along with the identification of new species and investigation of their role in the etiology and progression of the periodontal diseases have opened the doors for the current concept of polymicrobial synergy and dysbiosis in disease etiology. The above mentioned hypothesis describes, the significance of the synergism in promoting the overgrowth and virulence of the entire polymicrobial community that eventually leads to the transition in the composition of subgingival microbiome towards dysbiotic species [16-18]. Among them, Porphyromonas gingivalis, Tannerella forsythia and Treponema denticola are considered as the primary players in initiating the phenomenon of dysbiosis and hence the study of these pathogens still remains the major area of focus. $P$. gingivalis is the keystone pathogen in eliciting the pathogenesis and maintains a synergistic relation with $T$. forsythia and $T$. denticola [19-21]. Although, several studies were done so far with respect to $P$. gingivalis and $T$. denticola very few studies are done in relation to $T$. forsythia.

1.3 Virulence factors of $\boldsymbol{P}$. gingivalis, $T$. forsythia and $T$. denticola: There are several virulence factors identified in $P$. gingivalis like proteases, lipopolysaccharides, haemagglutinins, capsular material, and fimbriae. Among proteases, gingipains are considered as the major virulence factor associated with several deteriorating functions including subversion of the host defense mechanisms [22-24]. In case of $T$. denticola the virulence factors identified include cell surface proteins, lipooligosacharide, cytotoxic 
metabolites, leucine-rich repeat proteins, trypsin-like protease activity, dentilisin etc., which accentuate the periodontal disease by invasion and destruction of host tissues [2528]. So far very few virulence factors were identified with respect to T. forsythia, among which a cysteine protease named PrtH and KLIKK proteases are the only proteolytic enzymes that are well characterized [29, 30].

1.4 Gingipains: Gingipains are considered as the major virulence factors of $P$. gingivalis. Along with possessing several virulence properties pertinent to dysregulation and destruction of host defense systems they are also found implicated with development of severity in several systemic diseases. These extracellular proteolytic enzymes comprise of cysteine proteases named as Rgp and Kgp, based on the hydrolysis of peptide bonds at specific amino acid residues. Arginine-Xaa peptide bond specific gingipains are encoded by two separate genes called $\operatorname{rgpA}$ and $\mathrm{rgpB}$ while the Lysine-Xaa specific gingipain is encoded by the kgp gene. The proprotein of RgpB consists of an N-terminal prodomain, a catalytic/protease domain, and a C-terminal domain. In case of RgpA and Kgp an additional domain referred to as a hemagglutinin/adhesion domain, is present in between the catalytic domain and the CTD. Gingipains, comprising of $85 \%$ of the extracellular proteolytic activity of the keystone pathogen $P$. gingivalis [31-43], are secreted onto the bacterial surface and extracellular milieu through a unique secretion system called T9SS. 


\subsection{KLIKK Proteases:}

They are the newly identified proteolytic enzymes expressed by $T$. forsythia which comprise of three metalloproteases (karilysin, mirolysin, forsilysin) and three serine proteases (mirolase, miropsin-1, miropsin-2). These proteases (Figure 1) are also reported to be secreted into extracellular mileu through T9SS similar to gingipains. Among them metalloprotease karilysin, which belongs to M10A family and serine protease mirolase that belongs to S8A family, has been well characterized. Also, karilysin along with mirolysin exert a synergistic ability to evade the complement system of the host and thus contributing the survival of $T$. forsythia within the hostile environment of the inflamed periodontal pocket [29, 31-36, 44-47]. 


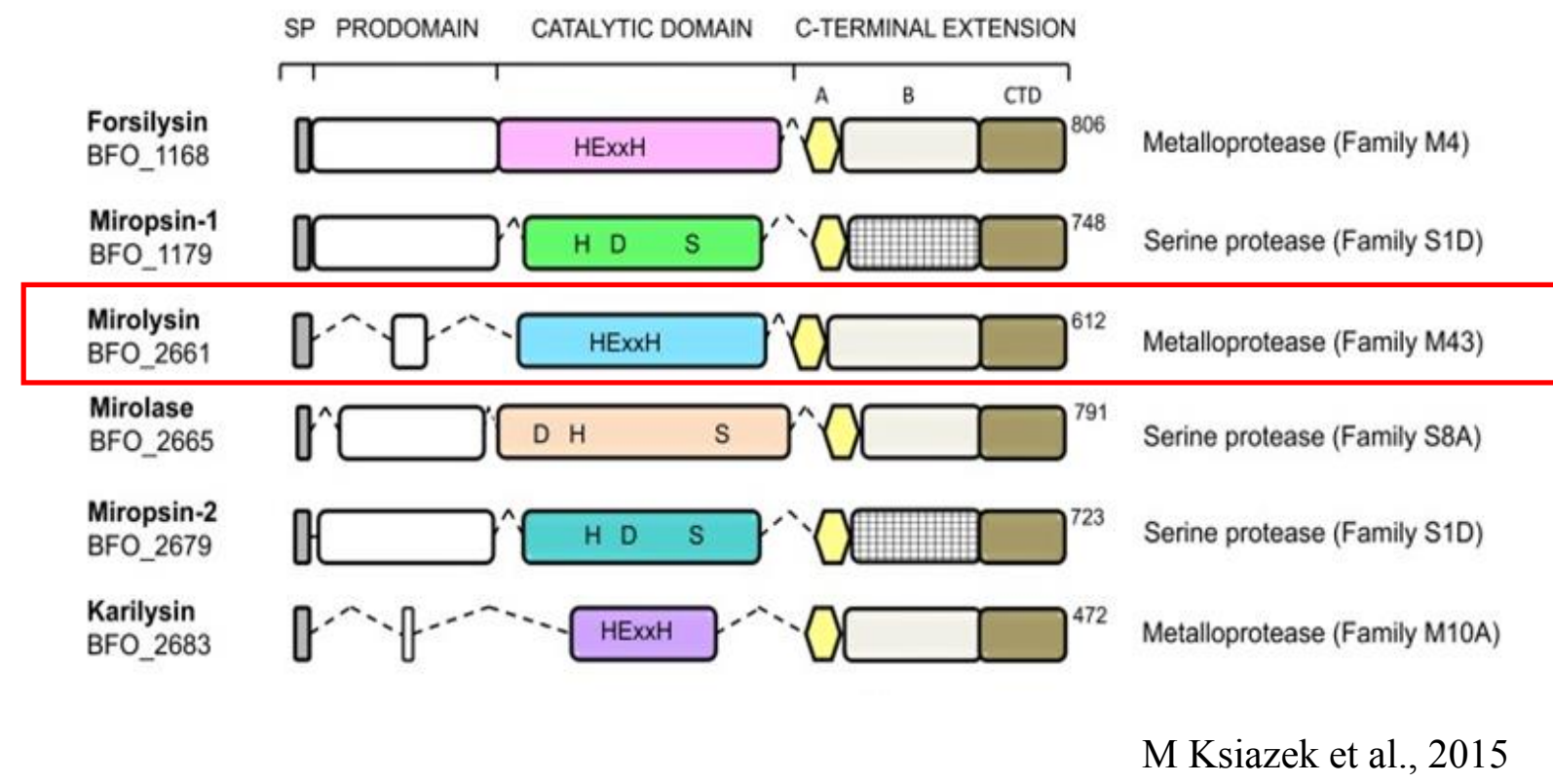

Fig 1: Predicted multi-domain structure of KLIKK proteases of Tannerella forsythia. Beginning from the N-terminus, KLIKK protease consist of: signal peptide (grey box), Nterminal prodomain (white box), catalytic domain (color boxes) containing all the amino acids directly involved in proteolysis (in black), and C-Terminal Extension containing the variable region B flanked by two conserved regions, A (30 amino acids) and the CTD (86 amino acids). 
1.6 T9SS: Till to date several secretion systems have been identified and classified in prokaryotes. The most conserved secretion systems identified in bacteria include the Sec and Tat pathways. Through these two pathways proteins are exported from the cytoplasm across the cytoplasmic membrane to the periplasm (in case of diderm Gram-negative bacteria) or into the extracellular medium (monoderm Gram-positive bacteria). Previous studies on gingipains from $P$. gingivalis have led to the discovery of a novel secretion system called T9SS. The T9SS cargo proteins are initially navigated towards the inner membrane with the help of a signal peptide. Later, the signal peptide is cleaved off by the signal peptidase releasing the protein into the periplasm. In the next step these proteins undergo a folding process to attain a final form that are ready to translocate across the outer membrane. In all the proteins that are secreted through T9SS, C-terminal domain (CTD) is found essential for their translocation. At the outer membrane the CTD is cleaved off by a PorU sortase-like peptidase. After cleavage the covalent attachment of A-LPS (glycosylation) provides a mean for the anchorage of secreted proteins to the outer leaflet of the outer membrane (Figure 2) [48-51]. 


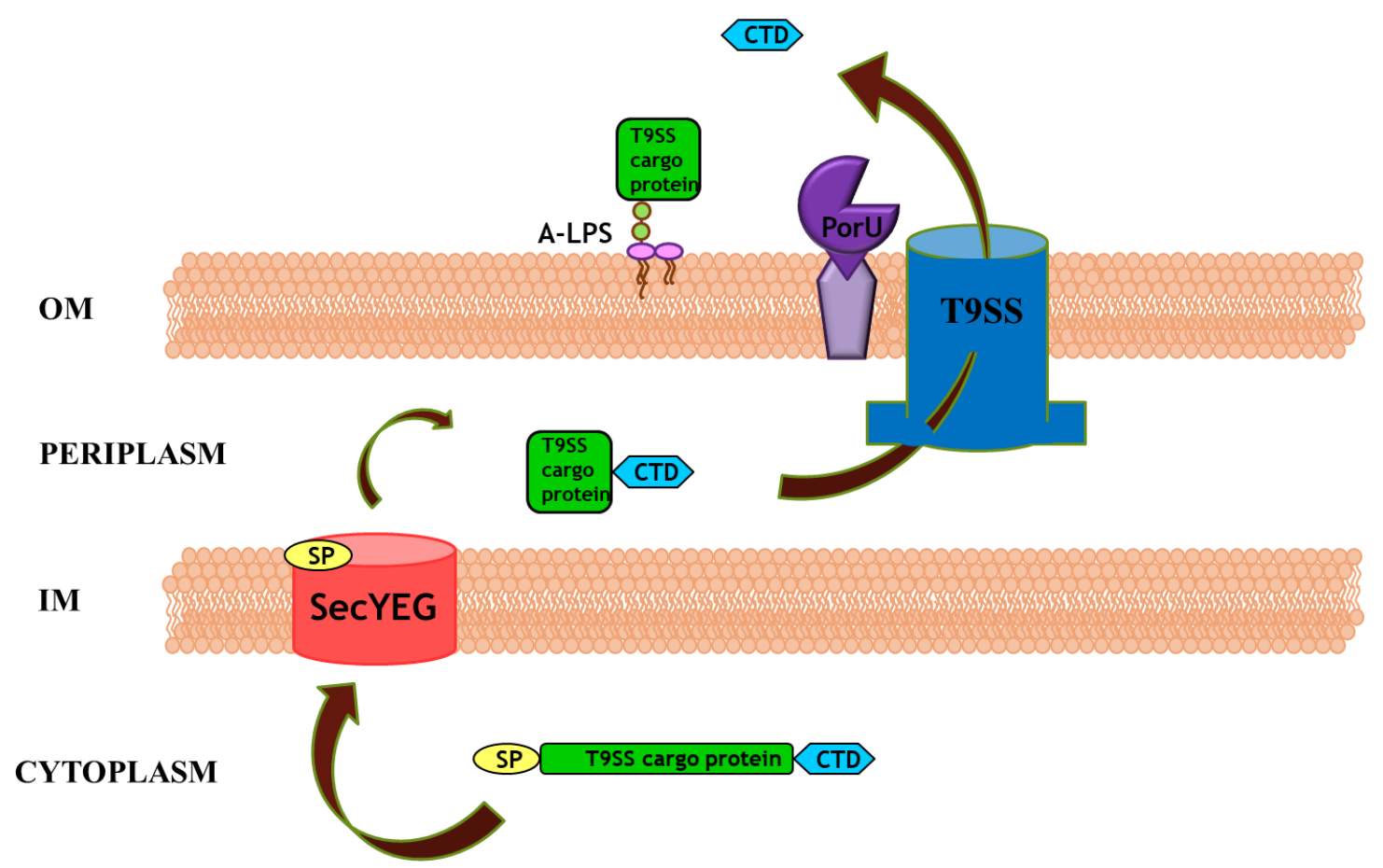

A M Lasica et al., 2017, modified

Fig 2: The hypothetical basic model of T9SS system function in $P$. gingivalis.

The T9SS cargo protein (with the intact SP and CTD) from the cytoplasm is guided by the SP towards the inner membrane and is transported into the periplasm with the SP cleaved off at the IM. Later, with the help of the CTD signal the folded protein is translocated across the outer membrane through T9SS and anchored to the OM by the attachment of A-LPS. While translocation the intact CTD of T9SS cargo protein is cleaved off at the OM by a PorU sortase.

SP - signal peptide, CTD - C terminal domain, IM - inner membrane, OM - outer membrane, A-LPS - anionic lipopolysaccharide, T9SS- Type IX secretion system. 
1.7 C-Terminal Domain (CTD) as an export signal: CTD is the carboxy-terminal end domain within the structure of a protein. This domain is found conserved within the structure of all proteins secreted through T9SS that are wide spread within the Bacteroidetes phylum. Moreover, CTD has been found to be an essential component in the translocation of these proteins across the outer membrane by functioning as an export signal. In RgpB the truncation of CTD (at the C-terminal end) by only 2 amino acids (VK) resulted in the accumulation of this protein within the periplasm. Recent crystallization studies of the recombinant CTD of RgpB has presented its structure in the form of a tightly packed $\beta$-sandwich structure that can spontaneously dimerise through $\mathrm{C}$-terminal strand swapping (Figure 3) [51-53]. 

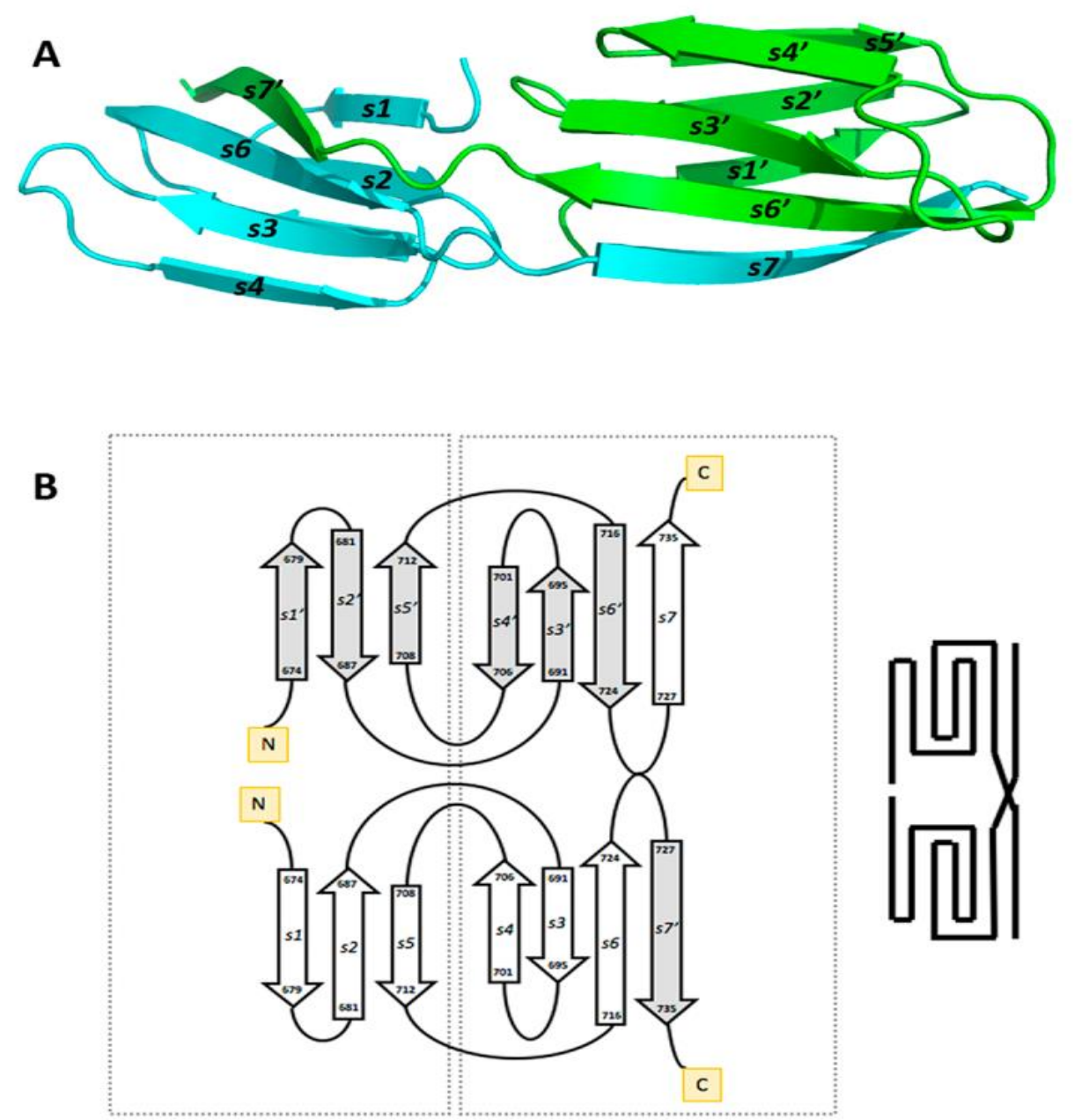

1 de Diego et al., 2016

Fig 3: The structure of recombinant C-Terminal Domain. A) The dimeric structure of purified rCTD, in cyan and green chains. B) Topology depicting the domain swap of $\mathrm{C}$ terminal strands. 
1.8 Scope of dissertation: Periodontitis is a chronic inflammatory disease affecting majority of the population worldwide. Although, the disease is considered as polymicrobial in its etiology, $P$. gingivalis, $T$. forsythia and $T$. denticola are considered as the primary pathogens in the progression of the diseases through the mechanism of synergism and dysbiosis. The major virulence factors identified in these pathogens encompass proteolytic enzymes, which are significantly involved in the pathogenesis of the diseases. Although several inhibitors were identified to combat the pathogenic effects of these enzymes the attempts were barely successful. Enzyme specificity is the major criterion in designing efficient inhibitors. Hence, it has become very important to identify specific targets for their development. For this purpose in this study, we tried to derive the knowledge about proteases through two different approaches that will help in identification of specific targets. Since, the majority of virulence properties are associated with the proteolytic enzymes secreted through T9SS from the major pathogens like $P$. gingivalis, $T$. forsythia, T. denticola our primary focus was on their virulence factors with an emphasis towards the understudied pathogen $T$. forsythia. In chapter 2 , we characterized one of the newly identified proteolytic enzymes, mirolysin, that belongs to the KLIKK group of T. forsythia. A comprehensive biochemical and biological characterization was successfully performed with respect to the protein mirolysin. Based on this we hypothesized the potential virulence mechanisms of the enzyme in the pathogenesis of periodontal diseases by T. forsythia. Due to the previous unsuccessful attempts to crystallize mirolysin, in chapter 3 we tried to expand our studies by designing the new constructs for the purification of the protein mirolysin, which will be utilized for its crystallization studies. In chapter 4 we tried to investigate the dimerization phenomenon of the CTD which is the structural domain found 
in all proteins secreted by T9SS in $P$. gingivalis, $T$. forsythia and $T$. denticola. Taking the previous studies into account in the context of the structure of the recombinant CTD we tried to investigate the significance of the dimerization phenomenon in the mechanism of protein secretion via T9SS. 


\section{CHAPTER 2}

\section{MIROLYSIN, A LYSARGINASE FROM TANNERELLA FORSYTHIA, PROTEOLYTICALLY INACTIVATES THE HUMAN CATHELICIDIN, LL-37}

2.1 Introduction: Periodontitis is arguably the most prevalent infection driven chronic inflammatory disease of humankind. It is estimated that up to $15 \%$ of adults worldwide experience severe forms of periodontitis $[54,55]$. In the US alone, nearly $47 \%$ of people aged $\geq 30$ (approximately 65 million adults) suffer from this disease [4]. The progression of periodontitis is marked by gingival bleeding, suppuration, and progressive loss of alveolar bone, resulting in the formation of deep periodontal pockets. If left untreated, the disease can even lead to tooth loss [56]. Due to its chronic inflammatory and infectious character, periodontitis is associated with the progression and/or development of systemic diseases such as rheumatoid arthritis, cardiovascular diseases, diabetes, and aspiration pneumonia $[8,57]$.

Because the etiology of periodontitis is multifactorial, it is impossible to implicate a single pathogen as responsible for development of the disease. Periodontitis begins with the formation of bacterial plaque in the subgingival space below the gum line. The plaque becomes pathogenic upon colonization by a consortium of bacteria: Porphyromonas gingivalis, Tannerella forsythia, and Treponema denticola, referred to as the "red complex" $[18,58]$. A common feature of bacteria belonging to the "red complex" is strong extracellular proteolytic activity, which is thought to be central to the virulence of these 
pathogens [59]. The role of the secretory proteases of $P$. gingivalis and T. denticola in the pathogenesis of periodontitis has been well described [60,61]. These enzymes are involved in several processes, including nutrient acquisition, immunomodulation, and corruption of the innate immune system. Until recently, our knowledge regarding the secretory proteases of T. forsythia has been very limited [40]. The only proteolytic enzyme that has been characterized in detail was PrtH, a cysteine protease of a caspaselike fold. PrtH detaches adherent cells from the substratum and increases IL-8 expression [30, 62]. Our knowledge has been increased immensely with the discovery of a novel family of six secretory proteases in T. forsythia that includes three serine proteases (mirolase, miropsin-1, and miropsin-2) and three metalloproteases (karilysin, mirolysin, and forsilysin). These proteolytic enzymes are conserved in almost all clinical strains of $T$. forsythia but absent from the sequenced but not yet assembled genomes of 12 isolates of Tannerella BU063, which is a health-associated strain relative of $T$. forsythia. The enzymes are also capable of degrading elastin, a major component of gum connective tissue. Due to the presence of the sequential K-L-I-K-K amino acids motif at the C-terminus, these proteases are referred to as KLIKK proteases. The KLIKK proteases possess a unique multidomain structure consisting of (beginning from the N-terminus) a signal peptide (SP) responsible for translocation across the inner membrane, an N-terminal profragment (NTP) responsible for enzyme latency, a catalytic domain (CD), and a C-terminal extension (CTE) encompassing a variable region flanked by two domains, which are nearly identical in all six KLIKK proteases [29]. The domain at the C-terminus shares sequence similarity with the conserved C-terminal domain (CTD), which serves as a signal for the translocation of $P$. gingivalis and $T$. forsythia proteins across the outer membrane via a type IX secretion system (T9SS) 
[51, 63, 64]. To date, only two KLIKK proteases, karilysin and mirolase, have been characterized in detail. Both proteases possess a unique mechanism responsible for their zymogenicity. Prokarilysin possesses the shortest propeptide described for metalloproteases, while in promirolase, a $19 \mathrm{kDa}$ profragment forms a stable noncovalent complex with the $\mathrm{CD}$ after being cleaved off. Degradation of fibrinogen and the antimicrobial peptide LL-37 by karilysin, as well as synergistic inhibition of all complement activation pathways by both proteases, may contribute to the virulence of $T$. forsythi7[45, 46, 65, 66]. In contrast to karilysin, very little is known regarding the biochemical properties of mirolysin in the context of its putative role in the virulence of $T$. forsythia. Here, we characterized mirolysin, which exhibits a unique specificity for XaaArg and Xaa-Lys peptide bonds and may contribute to the pathogenesis of periodontitis through inactivation of the biological activities of LL-37 and interference with complement functions. 


\subsection{Material and Methods:}

\section{Chemicals and reagents}

The restriction endonucleases BamHI and XhoI, T4 DNA ligase, dNTP, GeneJETTM Gel Extraction Kit, GeneJETTM PCR Purification Kit, Phusion DNA Polymerase, and GeneJETTM Plasmid Miniprep Kit were acquired from Thermo Scientific (Waltham, MA, USA). The QuikChange Lightning Site-Directed Mutagenesis Kit was purchased from Stratagene (La Jolla, CA, USA). All primers used in the study were synthesized by Genomed (Warsaw, Poland). The expression vector pGEX-6P-1, glutathione-Sepharose 4 Fast Flow, 3C protease (PreScission protease), HiLoad 16/600 Superdex 75 pg SEC column, and Mono Q 4.6/100 PE ion exchange column were obtained from GE Healthcare Life Sciences (Little Chalfont, UK). The Pierce Protein Concentrators 9K MWCO (7 ml and $20 \mathrm{ml}$ ) were from Thermo Scientific (Rockford, Il, USA). The protein molecular weight standards Precision Plus Protein Dual Xtra and Pageruler Unstained Low Range Protein Ladder were purchased from Bio-Rad (Hercules, CA, USA) and Thermo Scientific, respectively. Polyvinylidene difluoride (PVDF) membranes were from Bio-Rad. Spectra/Por 412000 to 14000 Dalton MWCO dialysis membranes were acquired from Spectrum Laboratories (Rancho Dominguez, CA, USA). Calbiochem Azocoll was purchased from Merck (Darmstadt, Germany). Human fibrinogen, human fibronectin, bovine casein, bovine insulin $\beta$-chain, human albumin, RPMI, and the Hank's balanced salts protease inhibitors leupeptin ( $\mathrm{N}$-acetyl-L-leucyl-Leucyl-L-argininal hemisulfate salt), E-64 (transepoxy-succinyl-1-leucyl-amido (4-guanidino) butane), IAA, Pefabloc (4-(2Aminoethyl) benzenesulfonyl fluoride hydrochloride), EDTA, and 1,10-phenanthroline (ortho-phenantrholine) were from Sigma (St. Louis, MO, USA). The human complement 
proteins C3, C4, and C5 were acquired from Complement Technology (Tyler, TX, USA). Synthetic LL-37 (LLGDFFRKSKEKIGKEFKRIVQRIKDFLRNLVPRTES) was purchased from GenScript (Piscataway, NJ, USA). All other chemical reagents were obtained from BioShop Canada (Burlington, ON, Canada).

\section{Cloning and mutant construction:}

Genomic DNA from T. forsythia was isolated from strain ATCC 43037. The coding sequences of the full-length mirolysin gene, proMir (Ser25-Lys612, BFO_2661; GenBank accession number: AEW21083.1), and mirolysin CD with NTP, Mircat (Ser25-Ser331), both without the nucleotide sequence that encodes the SP, were amplified by PCR using the following primers (restriction sites are underlined):

proMir_F: 5'-ACAGGATCCTCTGAGTTGAATATGGAAC-3'

proMir_R: 5'-CGGCTCGAGTTACTTCTTAATCAATTTCTGC-3'

Mircat_F: 5'-ACAGGATCCTCTGAGTTGAATATGGAACAAATCC-3'

Mircat_R: 5'-CGGCTCGAGTTAGGAGAAAGAAAGTGGATTCG-3'

The PCR products were purified and cloned into the pGEX-6P-1 vector, which provides the sequence for an N-terminal GST tag and inserts five additional residues (Gly-Pro-LeuGly-Ser) in the N-terminus of mirolysin. The wild-type (WT) constructs (pGEX-6P1_proMir, pGEX-6P1_Mircat) were used to obtain E225A variants (proMirE225A and MircatE225A) in which the active site Glu-225 is substituted by alanine (Figure 1B). This was achieved with the Quick Change Lightning Site-Directed Mutagenesis Kit and the following mutagenic primers: 
E225A-F (5' GGACAGCGACGCATGCAGTAGGGCATTGGTTAG3') and E225A-R (5' CTAACCAATGCCCTACTGCATGCGTCGCTGTCC 3'). All obtained plasmids were confirmed by DNA sequencing and then transformed into the E. coli strain BL21 (DE3) (New England Biolabs, Ipswich, MA, USA), which allowed expression under the control of the T7 promoter.

\section{Recombinant protein expression and purification:}

Transformed E. coli BL21 (DE3) were grown in LB Lennox media at $37^{\circ} \mathrm{C}$ to an optical density $(\mathrm{OD} 600 \mathrm{~nm})$ ranging from 0.75 to 1.0 and cooled for $30 \mathrm{~min}$ at $4{ }^{\circ} \mathrm{C}$. Expression of recombinant proteins was then induced by the addition of $0.1 \mathrm{mM}$ isopropyl $\beta$-D-1galactopyranoside (IPTG). After $6-8 \mathrm{~h}$ of cultivation at $20^{\circ} \mathrm{C}$, cells were harvested by centrifugation $\left(6000 \mathrm{~g}, 15 \mathrm{~min}, 4^{\circ} \mathrm{C}\right)$ and resuspended in PBS supplemented with $0.02 \%$ $\mathrm{NaN}_{3}$ (15 ml per pellet from 11 of culture). They were then lysed by sonication $(35 \times 0.5$ s pulses at an amplitude of 70\%) using a Branson Digital Sonifier 450 (Branson Ultrasonics, Danbury, CT, USA). The cell lysates were clarified by centrifugation (50 000 $\mathrm{g}, 50 \mathrm{~min}, 4^{\circ} \mathrm{C}$ ) followed by filtration through a $0.45 \mu \mathrm{m}$ syringe filter and then applied at $4^{\circ} \mathrm{C}$ to a glutathione-Sepharose 4 Fast Flow column (bed volume $=5 \mathrm{ml}$ ) equilibrated with PBS supplemented with $0.02 \% \mathrm{NaN}_{3}$. After extensive washing, $10 \mathrm{ml}$ of PBS supplemented with $0.02 \% \mathrm{NaN}_{3}$ containing $100 \mu \mathrm{l}$ of PreScission protease stock solution (1 U/ml) was applied to the column and incubated for $40 \mathrm{~h}$ at $4{ }^{\circ} \mathrm{C}$. The final purification of recombinant protein (Mircat and Mir-catE225A) was accomplished by SEC on a Superdex 75 pre-equilibrated with $50 \mathrm{mM}$ Tris-HCL (pH 8.0) and, for MircatE225A only, ion exchange chromatography employing Mono Q, and two buffers: $20 \mathrm{mM}$ Tris- $\mathrm{HCl}(\mathrm{pH}$ 
8.0) and $20 \mathrm{mM}$ Tris- $\mathrm{HCl}, 1 \mathrm{M} \mathrm{NaCl}(\mathrm{pH} \mathrm{8.0)}$. The total amount of purified protein was determined by measuring the absorbance at $280 \mathrm{~nm}$ using a Spectrophotometer Nano Drop 1000 and BCA assay (Thermo Scientific). Purity of the obtained protein was verified by SDS-PAGE.

\section{Gel electrophoresis and zymography:}

Mirolysin purification, autocatalytic processing, and protein substrate degradation were monitored by SDS-PAGE using NuPAGE Novex $4-12 \%$ and $4-20 \%$ gels (only for degradation of LL-37) and Bis-Tris Protein Gels with MES buffer (Thermo Scientific). Gels were stained with SimplyBlue SafeStain (Thermo Scientific) and destained in water. Zymographic analysis was performed on samples mixed $1: 1$ with sample buffer $(0.125 \mathrm{M}$ Tris- $\mathrm{HCl}, \mathrm{pH} 7.8,20 \%$ glycerol, $4 \%$ SDS, $0.1 \%$ Bromophenol Blue) for 15 min at $20^{\circ} \mathrm{C}$ and electrophoresed on $12 \%$ SDS-PAGE gels ( $\mathrm{T}: \mathrm{C}, 27.5: 1)$ containing gelatin at a final concentration of $0.1 \mathrm{mg} / \mathrm{ml}$, a substrate for proteases. Gels were incubated twice in $2.5 \%$ Triton X-100 for $30 \mathrm{~min}$, followed by incubation in developing buffer $(0.2 \mathrm{~m}$ Tris-HCl, 5 $\mathrm{mM} \mathrm{CaCl} 2,1 \mathrm{mM} \mathrm{DTT}, \mathrm{pH} 7.8$ ) for $3 \mathrm{~h}$ at $37^{\circ} \mathrm{C}$. Finally, the gels were incubated in destaining/fixing solution [methanol/acetic acid/water (30:10:60)], stained with $0.1 \%$ amido black in $10 \%$ acetic acid for $1 \mathrm{~h}$, and then destained successively in destaining/fixing solution containing $10 \%$ acetic acid and $1 \%$ acetic acid, which revealed clear zones of substrate hydrolysis on a blue background.

\section{Proteolytic processing and activation of mirolysin:}

Mirolysin (proMir and Mircat) was incubated in $50 \mathrm{mM}$ Tris, $0.02 \% \mathrm{NaN}_{3}, \mathrm{pH} 8.0$, at $37^{\circ} \mathrm{C}$ for up to $204 \mathrm{~h}$. At specific time points $(0,1,16,48 \mathrm{~h}$ for proMir and $0,0.25,0.5,1,2,4$, 
$8,16,24,36,48,60,72,84,96,120,156,204 \mathrm{~h}$ for Mircat), aliquots were taken to measure proteolytic activity using Azocoll as a substrate (see the Enzymatic activity assays section), zymography, and SDS-PAGE analysis. Enzymatically inactive muteins (E225A) of both proMir and Mircat served as controls

\section{Purification of mature mirolysin (mMir):}

Mircat at a concentration of $1 \mathrm{mg} / \mathrm{ml}$ was incubated in $50 \mathrm{mM}$ Tris, $2.5 \mathrm{mM} \mathrm{CaCl}_{2}, 0.02 \%$ $\mathrm{NaN}_{3}, \mathrm{pH} 8.0$, at $37^{\circ} \mathrm{C}$, as described above, and processing was monitored by SDS-PAGE. When only one band of molecular weight $31 \mathrm{kDa}$ was visible on the gels, the processing was stopped. The samples were then extensively dialyzed against buffer containing $5 \mathrm{mM}$ Tris, $50 \mathrm{mM} \mathrm{NaCl}, 1 \mathrm{mM} \mathrm{CaCl}_{2}, 0.02 \% \mathrm{NaN}_{3}, \mathrm{pH} 8.0$, and concentrated to a concentration of $1 \mathrm{mg} / \mathrm{ml}$. The obtained $\mathrm{mMir}$ was aliquoted and stored at $-20^{\circ} \mathrm{C}$.

\section{N-terminal sequence analysis:}

Samples were resolved on 4-12\% NuPAGE gels and then electrotransferred in $10 \mathrm{mM}$ CAPS, $10 \%$ methanol, $\mathrm{pH} 11$, onto a PVDF membrane using a mini trans-blot module (Bio-Rad). Protein bands were visualized by CBB G-250 staining, excized, and analyzed by automated Edman degradation using a Procise 494 HT amino acid sequencer (Applied Biosystems, Carlsbad, CA, USA).

\section{Determination of the $K_{d}$ by microscale thermophoresis (MST):}

A Monolith NT.LabelFree instrument (NanoTemper Technologies GmbH, Munich, Germany) was used to analyze the binding interactions between recombinant mirolysin and calcium $\left(\mathrm{Ca}^{2+}\right)$. Calcium at concentrations ranging from 6.1 to $10000 \mu \mathrm{m}$ was incubated with $375 \mathrm{~nm}$ mirolysin (MircatE225A) in assay buffer (5 mM Tris, $50 \mathrm{mM} \mathrm{NaCl}, 0.02 \%$ 
$\mathrm{NaN}_{3}, 0.05 \%$ Pluronic F-127, $\mathrm{pH} 7.5$ ) for $5 \mathrm{~min}$ at $20^{\circ} \mathrm{C}$. The samples were loaded into Monolith NT. Label Free Standard Treated glass capillaries, and an initial fluorescence measurement was taken followed by thermophoresis measurements using $20 \%$ of power of a light-emitting diode (LED) and 20\% MST power, respectively. $K_{d}$ values were calculated using MO.Affinity Analysis software. The experiment was performed in triplicate.

\section{Differential scanning fluorimetry:}

Differential scanning fluorimetry employing the Prometheus NT.48 apparatus (NanoTemper) was used to investigate the effect of $\mathrm{Ca}^{2+}$ concentration on MircatE225A thermal stability. MircatE225A (375 nm) in $50 \mathrm{mM}$ Tris, pH 8.0, was incubated with increasing concentrations of $\mathrm{CaCl}_{2}(0.01,0.1,1$, and $10 \mathrm{mM})$ for $15 \mathrm{~min}$ at $20^{\circ} \mathrm{C}$. The samples were then loaded into nanoDSF standard grade capillaries and then heated from $40^{\circ} \mathrm{C}$ to $95^{\circ} \mathrm{C}$ at a rate of $1^{\circ} \mathrm{C}$ per min. Protein unfolding was monitored by measuring the fluorescence intensity at two emission wavelengths at $330 \mathrm{~nm}$ and $350 \mathrm{~nm}$. Analysis of the obtained data was performed using the control software (NanoTemper), which allowed calculation of the protein $\mathrm{Tm}$ based on the first derivative of the ratio of fluorescence intensity measured at 350 and $330 \mathrm{~nm}$.

\section{Enzymatic activity assays:}

Mirolysin activity was routinely determined in $50 \mathrm{mM}$ Tris ( $\mathrm{pH}$ 8.0) using Azocoll as a substrate. Briefly, $125 \mu \mathrm{l}$ of $15 \mathrm{mg} / \mathrm{ml}$ suspension of substrate in assay buffer was added to the same volume of the enzyme solution in Eppendorf tubes and the mixtures were incubated for $1-2 \mathrm{~h}$ at $37^{\circ} \mathrm{C}$ with shaking. Undigested Azocoll was removed by 
centrifugation $\left(16,100 \times \mathrm{g}, 5 \mathrm{~min}, 4^{\circ} \mathrm{C}\right)$, and the absorbance at $520 \mathrm{~nm}$ was measured using a Spectra MAX microplate reader (Molecular Devices, Sunnyvale, CA, USA). The optimum $\mathrm{pH}$ was determined using the following buffers at a concentration of $50 \mathrm{mM}$ : MES (pH 5.5, 6.0, and 6.5), MOPS (pH 6.5, 7.0, and 7.5), HEPES (pH 7.0, 7.5, and 8.0), Tris ( $\mathrm{pH} 7.5,8.0$, and 8.5), and CAPS ( $\mathrm{pH} 8.5,9.0,9.5$, and 10.0). To test the effect of inhibitors, reducing agents, and divalent metal ions on mirolysin activity, mMir was preincubated with each compound (listed in Table 1) in $50 \mathrm{mM}$ Tris ( $\mathrm{pH}$ 8.0) for $15 \mathrm{~min}$ at room temperature and the residual activity was measured using Azocoll as a substrate. Human albumin, fibrinogen, fibronectin, bovine casein, the human complement proteins C3, C4, and C5 (10 $\mu \mathrm{g})$, and the peptides human cathelicidin LL-37 and bovine insulin $\beta$ chain $(4 \mu \mathrm{g})$ were incubated with mMir at the enzyme/substrate weight ratios $1: 20$ (complement proteins), $1: 100$ (all other proteins), and $1: 1000$ (LL-37 and insulin $\beta$ chain) for $8 \mathrm{~h}$ at $37^{\circ} \mathrm{C}$ in $50 \mathrm{mM}$ Tris, $150 \mathrm{mM} \mathrm{NaCl}, 5 \mathrm{mM} \mathrm{CaCl}_{2}, 0.02 \% \mathrm{NaN}_{3}, \mathrm{pH} 8.0$. Obtained samples were resolved by SDS-PAGE. MircatE225A was used as a negative control.

\section{Determination of mirolysin cleavage specificity:}

To determine mirolysin cleavage specificity, different mammalian proteins and peptides cleaved by mirolysin were examined. Samples were mixed 1:1 (v/v) with 15\% metaphosphoric acid, incubated in ice for $30 \mathrm{~min}$, and centrifuged $(10 \mathrm{~min}, 16,100 \times \mathrm{g}$, $\left.4^{\circ} \mathrm{C}\right)$. Supernatants, free of undigested proteins, were gently collected and lyophilized. The samples were then analyzed by Nano LC-MS/MS using an EASY-nLC II system (Thermo Scientific) connected to a TripleTOF 5600 mass spectrometer (AB SCIEX; Framingham, MA, USA). The mirolysin-digested samples were dissolved in $0.1 \%$ formic acid and loaded 
onto a $0.1 \times 20 \mathrm{~nm} \mathrm{C18}$ trap column and a $0.075 \times 150 \mathrm{~nm} \mathrm{C18}$ analytical column. The peptides were eluted and electro sprayed directly into the mass spectrometer using a 20 min gradient from $5 \%$ to $35 \%$ solvent B ( $0.1 \%$ formic acid in $90 \%$ acetonitrile) at a flow rate of $250 \mathrm{nl} / \mathrm{min}$. An information-dependent acquisition method was employed to automatically run experiments acquiring up to $25 \mathrm{MS} / \mathrm{MS}$ spectra per cycle using a $0.9 \mathrm{~s}$ cycle time and an exclusion window of $6 \mathrm{~s}$. The raw data were converted to MGF files and searched against the SWISS-Prot mammal database (Version 2015-07) using an in-house Mascotsearch engine. No enzyme was specified, and oxidation of methionine was included as a variable modification. Peptide mass tolerance and fragment mass tolerance were set at $10 \mathrm{ppm}$ and $0.2 \mathrm{Da}$, respectively, and the significance threshold (p) was set at 0.01 . Identified peptide sequences were used to reveal the cleavage sites (P1-P1') within substrates digested by mirolysin. The 10-long sequences (P5-P5') were then used to determine mirolysin cleavage specificity using the MEME Suite server (Bailey et al., 2009).

\section{Time- and concentration-dependent LL-37 cleavage by mirolysin:}

LL-37 (4 $\mu \mathrm{g})$ was incubated with mirolysin (mMir) at peptide/enzyme molar ratios varying from $10: 1$ to $10000000: 1$ in $20 \mu 1$ of $50 \mathrm{mM}$ Tris, $150 \mathrm{mM} \mathrm{NaCl}, 2.5 \mathrm{mM} \mathrm{CaCl}_{2}, \mathrm{pH}$ 8.0, for $1 \mathrm{~h}$ at $37^{\circ} \mathrm{C}$. For time dependent analysis, LL-37 was exposed to mirolysin for times ranging from 0 to $120 \mathrm{~min}$ at a molar ratio of 100 000: 1 under the same conditions. The reaction was terminated by the addition of boiling SDS-PAGE sample buffer. After denaturation $\left(5 \mathrm{~min}, 95^{\circ} \mathrm{C}\right)$, samples were subjected to SDS-PAGE analysis. LL-37 incubated with MircatE225A was used as a control. 


\section{Antimicrobial assay:}

To evaluate the antimicrobial activity of LL-37 cleaved by mirolysin, a colony reduction assay using E. coli ATCC 33694 grown in LB was performed. E. coli cells were collected by centrifugation (5000 g, $8 \mathrm{~min}$ ), washed three times with PBS, and resuspended in RPMI

supplemented with $10 \%$ Hank's balanced salt solution) to a final concentration of a $1.1 \times$ 106 colony-forming units (CFU)/ml. LL-37 (20 $\mu \mathrm{m})$, either intact or cleaved by mirolysin, was prepared in $50 \mathrm{mM}$ Tris, $150 \mathrm{mM} \mathrm{NaCl}, 2.5 \mathrm{mM} \mathrm{CaCl}_{2}, \mathrm{pH} 7.5$, and $180 \mu$ of each bacterial suspension was added to Eppendorf tubes. After $1 \mathrm{~h}$ of incubation at $37^{\circ} \mathrm{C}$, aliquots were diluted in 10\% HBSS with RPMI to a final concentration of $103 \mathrm{CFU} / \mathrm{ml}$ and $100 \mu 1$ aliquots of each sample were plated onto LB agar plates. Alternatively, aliquots of bacterial suspension were mixed with different concentrations $(1,0.1$, and $0.01 \mathrm{~nm})$ of mMir and MircatE225A, and the intact LL-37 was then added to a final concentration of 2 $\mu \mathrm{m}$. After $1 \mathrm{~h}$ of incubation, aliquots were plated onto LB agar plates. All experiments were performed in triplicate.

\section{Determination of endotoxin level:}

LL-37 $(2 \mu \mathrm{m})$, intact or cleaved by mirolysin (mMir), was mixed $1: 1(\mathrm{v} / \mathrm{v})$ and then incubated for $5 \mathrm{~min}$ at RT with endotoxin $(0.5 \mathrm{EU} / \mathrm{ml})$ from E. coli 0111 : B4. Intact LL37 incubated with MircatE225A was used as a negative control. The level of free endotoxin was determined by QCL-1000 assay (Lonza, Basel, Switzerland) per the manufacturer's instructions. 


\section{Data analysis:}

All graphing and statistical analysis (Student's t test) was performed using GraphPad Prism. Differences were considered significant when $\mathrm{p}<0.05$.

\subsection{Results:}

Mirolysin is a member of the pappalysin family (M43B) of metalloproteases Bioinformatic analysis revealed that, according to the MEROPS database, mirolysin belongs to family M43, subfamily M43B, represented by pappalysin-1 (PAPPA) [67]. So far, only one protease from subfamily M43B, ulilysin from Methanosarcina acetovirans, has been structurally characterized [68]. Due to its specificity, the metalloprotease was later renamed LysargiNase [69]. Alignment of the CD sequence of mirolysin with five members of family M43B belonging to the three kingdoms of life revealed that mirolysin possesses both an extended zincbinding consensus sequence (ZBCS), HEXXHXXGXXH/D, and a methionine-containing 1,4- $\beta$-turn called Met-turn. These findings identify mirolysin and other members of the M43B family as belonging to a group of metalloproteases called MetZincins, which includes astacins, adamalysins/ADAMs, serralysins, and matrixins. As in the case of ulilysin and PAPPA, mirolysin contains conserved cysteine residues and amino acids that are responsible for the binding of two calcium ions in ulilysin (Figure 4A; $[68,70])$. Ulilysin, the CD of which shares almost $50 \%$ sequence identity with that of mirolysin, is synthesized as a $38 \mathrm{kDa}$ zymogen that undergoes calcium-triggered autoactivation to the mature, $29 \mathrm{kDa}$ protease. Autolytic activation entails removal of the N-terminal prodomain through cleavage of the Ser60- Arg peptide bond. The same peptide bond is conserved in mirolysin (Figure 4A), suggesting that the T. forsythia protease is also synthesized as a proenzyme that undergoes autoprocessing. 


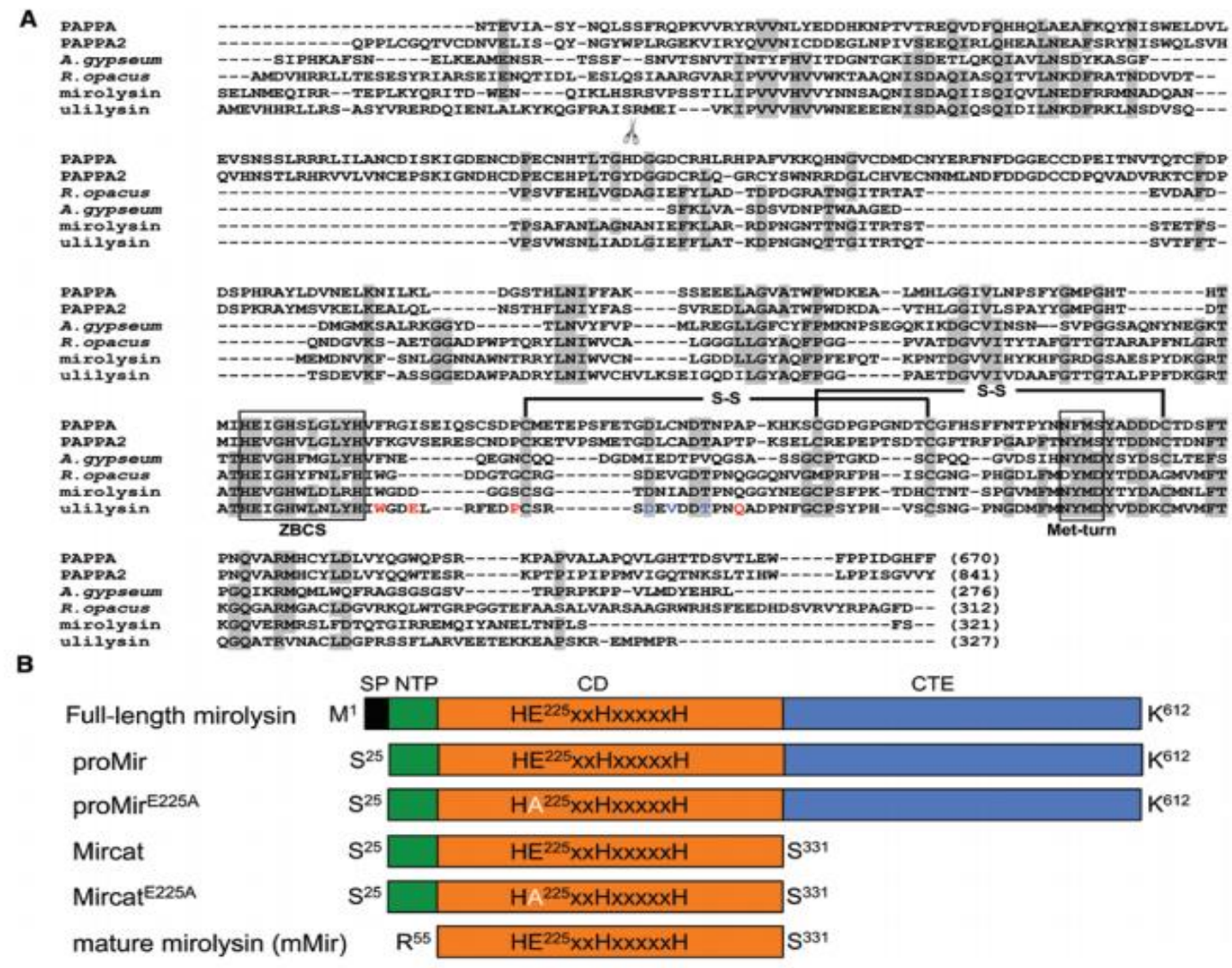

Fig 4: Alignment of mirolysin with other members of the M43B protease family (A) and proteins used in this study (B). (A) Sequence alignment of the catalytic domains of mirolysin (UniProt (UP) accession number: A0A0F7IPS1) and other pappalysins (family M43B) including human PAPPA (UP: Q13219) and PAPPA-2 (UP: Q9BXP8), ulilysin from Archaea (UP: Q8TL28), and proteases from the bacteria A. gypseum (UP: E5QZI4) and R. opacus (GenBank accession number: AII05686.1). Amino acid residues identical in a minimum of four out of six aligned sequences are indicated by black letters on a gray background. Extended zinc-binding consensus sequences (ZBCS) and the Met-turn are boxed. Disulfide bonds identified for human pappalysin-1 (PAPPA) and ulilysin are marked with black lines. The scissors symbol indicates the site of autolytic cleavage during activation of ulilysin. The amino acid residues involved in the binding of two calcium ions by the protease are shown in red and blue fonts. (B) Schematic drawing of the constructs and proteins expressed and purified in this study. SP, signal peptide; NTP, N-terminal profragment; CD, catalytic domain; CTE, C-terminal extension.

Reprinted with the permission. Koneru et al., Biological Chemistry, 2016. 
Expression, purification, and autoprocessing of mirolysin: To verify the zymogenicity of mirolysin, we cloned the coding sequence of mirolysin, without the putative SP (proMir), into the multicloning site of the pGEX-6P-1 vector for expression in E. coli BL21 (DE3) as a fusion protein with an N-terminal glutathione-S-transferase (GST) tag. Both the native form and a catalytically inactive mutein, in which the catalytic residue Glu225 was replaced by Ala (Figure 4B), were expressed. Both recombinant proteins were isolated by affinity chromatography on glutathione Sepharose, with the GST tag removed by oncolumn cleavage with PreScission protease. The recombinant proteins were obtained as a $66 \mathrm{kDa}$ tag-free proteins (Figure 5A, lane 3 in each panel). Of note, only a small amount $(<0.3 \mathrm{mg} / 1$ of culture $)$ of recombinant proteins was obtained, and all attempts to improve the expression yield were unsuccessful. Other KLIKK proteases, including mirolase and karilysin, are synthesized as inactive zymogens that auto process into active enzymes. The same may apply to mirolysin, which possesses an apparent propeptide on the $\mathrm{N}$-terminus that must be removed to activate the protease. To confirm this, we incubated both proMir and proMirE225A at $37^{\circ} \mathrm{C}$ for several hours. SDS-PAGE analysis revealed no change in the molecular mass of the proteins during incubation (Figure 5B), strongly suggesting that, under these conditions (50 mM Tris, $\mathrm{pH} 8.0$ ), promirolysin is stable and does not undergo autoproteolysis. However, since the NTP encompasses only 30 amino acids residues, the change in molecular mass could be too small to be observed by SDS-PAGE. Therefore, we assayed the fractions after different periods of incubation for proteolytic activity using Azocoll as a substrate. Surprisingly, a significant amount of activity was detected even in the sample taken before incubation, and this increased approximately 3 -fold after $1 \mathrm{~h}$ of incubation and stayed at that level after $16 \mathrm{~h}$ and $48 \mathrm{~h}$ of incubation (Figure 5C). As 
expected, no activity was detected in the proMirE225A samples. To, study further the apparent activation of promirolysin, we performed zymography, which allows detection of the activity of zymogenic forms of prometalloproteases, in which latency is exerted not only by "cysteine-switch" [71], but also "aspartate-switch" [45, 66] mechanisms. Interestingly, in addition to a band with a molecular mass equivalent to $66 \mathrm{kDa}$ (promirolysin), the analysis revealed an additional band just below $66 \mathrm{kDa}$ (Figure 5D). 
A

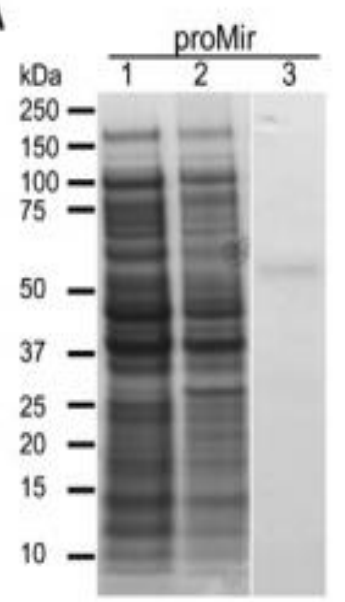

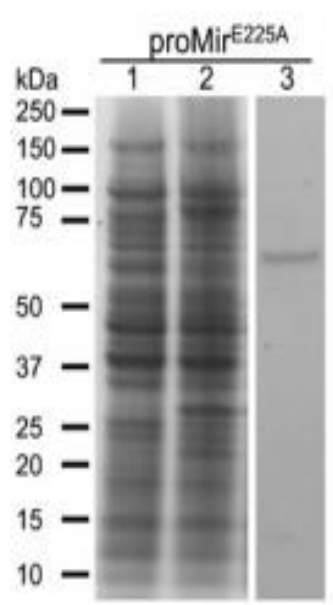

B

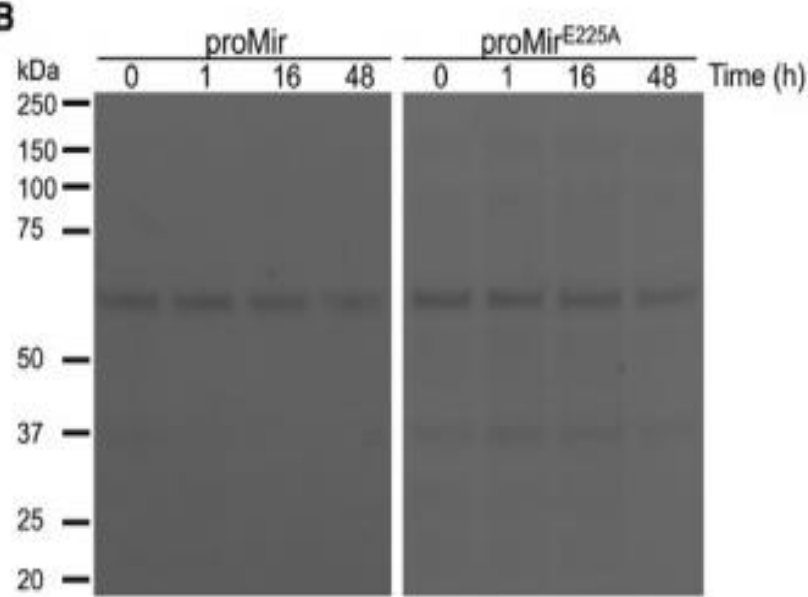

C

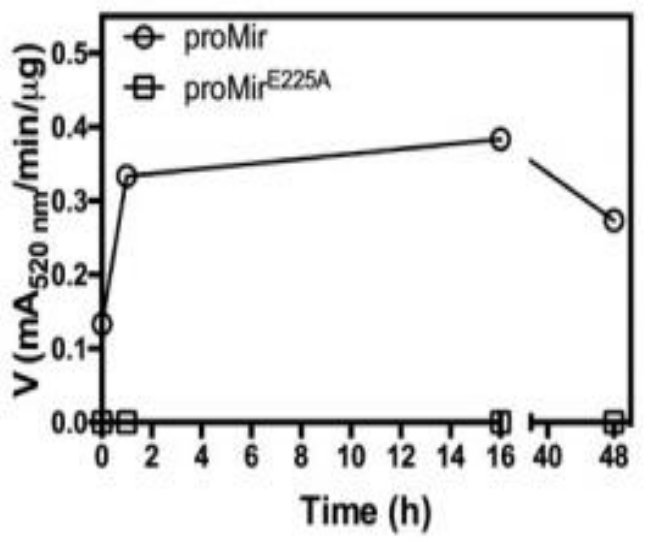

D

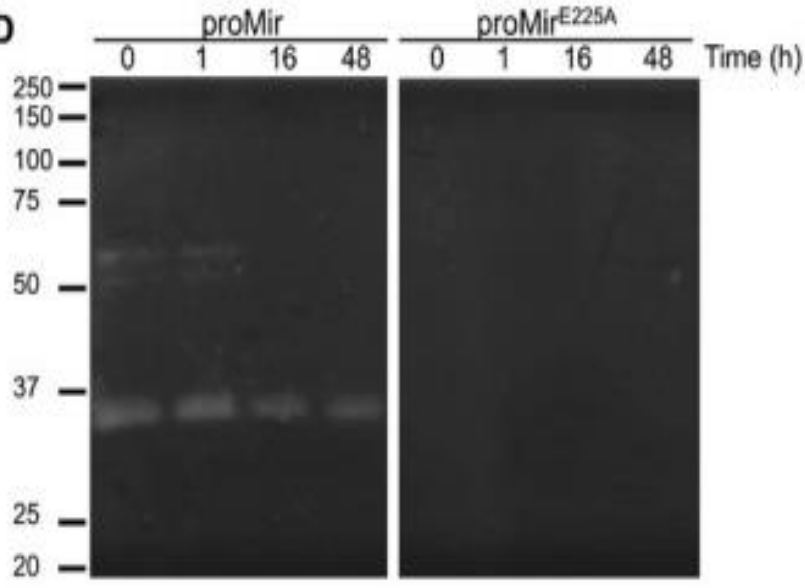

Fig 5: Expression, purification, and autoprocessing of promirolysin. (A) Both promirolysin (proMir) and the active-site-glutamic acid-to-alanine mutein (proMirE225A) were expressed in $E$. coli as a recombinant fusion protein with a GST and purified on a glutathione-Sepharose column with on-column removal of the tag. Lanes 1 and 2, E. coli extracts before and $16 \mathrm{~h}$ after induction of protein expression with IPTG, respectively; lane 3 , the tag-free proMir and proMirE225A $(66 \mathrm{kDa})$ proteins after purification by affinity chromatography with on-column removal of the GST by cleavage with PreScission protease. (B-D) Proteolytic autoprocessing of mirolysin. ProMir and its active site mutein (proMirE225A) were incubated at $0.1 \mathrm{mg} / \mathrm{ml}$ in $50 \mathrm{mM}$ Tris, $\mathrm{pH} \mathrm{8.0,} \mathrm{at} 37^{\circ} \mathrm{C}$. At defined time points, aliquots were taken for SDS-PAGE analysis (B) followed by measurement of activity employing Azocoll as a substrate (C) and zymography with gelatin as a substrate (D).

Reprinted with the permission. Koneru et al., Biological Chemistry, 2016. 
These two bands were detected only in samples taken before incubation and after $1 \mathrm{~h}$ of incubation, while the strong $\sim 31 \mathrm{kDa}$ band corresponding to the fully processed $\mathrm{CD}$ of mirolysin was present in all analyzed samples. Taken together the increase of proteolytic activity observed during autoprocessing (Figure 5C) did not correlate with the results from SDS-PAGE (Figure 5B), indicating that promirolysin was stable during incubation at $37^{\circ} \mathrm{C}$. This discrepancy can be explained by the presence of small fractions of active partially and fully processed protease in the $66 \mathrm{kDa}$ promirolysin preparation.

Purification of mature mirolysin: The findings presented above suggested that mirolysin, similar to karilysin and mirolase, is indeed synthesized as an inactive zymogen that autoprocesses into the mature form consisting of the $\mathrm{CD}$ alone $[72,73]$. To further investigate the maturation of mirolysin, we expressed the protein without the CTE, but with the intact NTP (Figure 4B), which could act as a chaperone and thus be required for proper folding. The recombinant proteins were purified by affinity chromatography on glutathione-Sepharose with simultaneous removal of the GST tag, followed by size exclusion chromatography (SEC) and ion exchange chromatography (only for MircatE225A). The procedure yielded more than $2 \mathrm{mg}$ of purified protein per liter of culture (Figure 6A, lane 4 in each panel). Of note, in clear contrast to MircatE225A, lower bands were visible for Mircat, suggesting that this form of mirolysin is prone to autodegradation. To characterize the process in detail, Mircat was incubated at $37^{\circ} \mathrm{C}$ for $204 \mathrm{~h}$ in $50 \mathrm{mM}$ Tris, $0.02 \% \mathrm{NaN}_{3}, \mathrm{pH} 8.0$, during which time aliquots were taken at specific time points for measurement of proteolytic activity using Azocoll and zymography, as well as SDS-PAGE analysis (Figure 6B, C and E). Mircat (35 kDa) completely processed itself into the mature $31 \mathrm{kDa}$ form of mirolysin (mMir) within $2 \mathrm{~h}$. 
This change in molecular mass correlated with a time-dependent increase in the proteolytic activity against Azocoll (Figure 6E) within the first $30 \mathrm{~min}$ of incubation. Similarly, zymographic analysis of the samples showed complete conversion of the upper band corresponding to Mircat to a lower band equivalent to that of mMir over $2 \mathrm{~h}$ (Figure 6C). This conversion was not associated with an increase in activity as measured by Azocoll degradation, apparently due to autodegradation of mMir that occurred after 1-2 h. After $4 \mathrm{~h}$, the band corresponding to mMir gradually disappeared, and, by the end of the incubation period, had almost completely vanished. The gradual time-dependent decrease in the intensity of the mirolysin band correlated well with a decrease in proteolytic activity and accumulation of degradation products with molecular masses of $10 \mathrm{kDa}$ and lower. The N-terminal sequence analysis of prominent bands at $10 \mathrm{kDa}$ revealed that mirolysin cleaved itself at the Thr-His and Gly-His peptide bonds encompassing the $\mathrm{Zn}$-chelating histidine residues in the conserved HEXXH motif (Figure 4B). The CD (without the CTE) of mirolysin shares almost 50\% sequence identity with ulilysin, including conservation of almost all of the residues required to chelate calcium (Figure 4A). This strongly suggested that mirolysin should also bind calcium, which may affect protein stability and autoproteolysis [74]. To verify this, we monitored the processing of mirolysin in the presence of $2.5 \mathrm{mM} \mathrm{CaCl}_{2}$, which corresponds to the calcium concentration in human serum and gingival crevicular fluid (GCF) [75, 76]. Under these conditions, autoprocessing of mirolysin was much more rapid (Figure 6D). According to SDSPAGE analysis, complete conversion of Mircat into mMir occurred within 15 min, although the activity increased for up to $1 \mathrm{~h}$ in a time-dependent manner (Figure 6E). This may be associated with degradation of the initial cleavage products, including the released NTP. Importantly, 
there was no accumulation of fragments with masses of $10 \mathrm{kDa}$ or lower and the proteolytic activity of mirolysin was stable. After $16 \mathrm{~h}$ of incubation, only one band corresponding to mMir was visible by SDS-PAGE, and its intensity did not change over $204 \mathrm{~h}$ of incubation. This indicated that mMir is very stable in the presence of calcium (Figure 6D). Based on this finding, the homogenous, $31 \mathrm{kDa}$ mMir was obtained from the Mircat sample, incubated overnight for $12-16 \mathrm{~h}$, and subjected to dialysis to remove small molecular mass degradation products. Of note, in all experiments described above, MircatE225A was used as a negative control, as it did not undergo autoprocessing and had no proteolytic activity against Azocoll or as detected by zymographic analysis (data not shown).

Biochemical characterization: Consistent with its similarity to the M43B family of metalloproteases, mirolysin activity was inhibited by treatment with the diagnostic metalloprotease inhibitor, o-phenanthroline, and by EDTA, a general divalent cationchelating compound. As predicted, mirolysin activity was not affected by specific inhibitors of cysteine proteases, E-64 and was only slightly inhibited by the serine protease inhibitor Pefabloc. Also, other inhibitors of these catalytic classes of proteases, leupeptin, iodoacetic acid (IAA), and TLCK, had no effect on mirolysin activity (Table 1). Alignment of mirolysin with other members of the M43B family revealed that all of the conserved cysteine residues involved in the formation of disulfide bridges in pappalysin and ulilysin are also conserved in mirolysin (Figure 4A). Nevertheless, preincubation with reducing agents had almost no effect on enzyme activity (Table 1). 
A

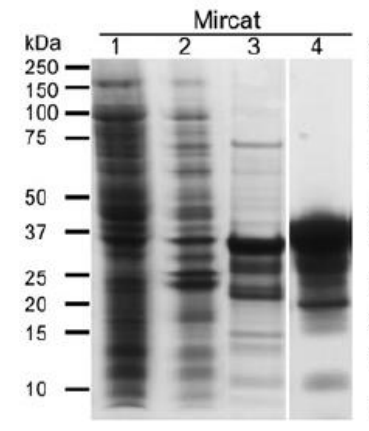

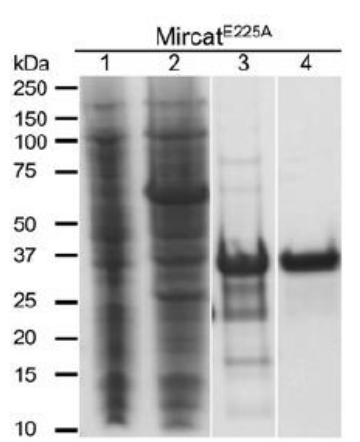

$\mathbf{E}$

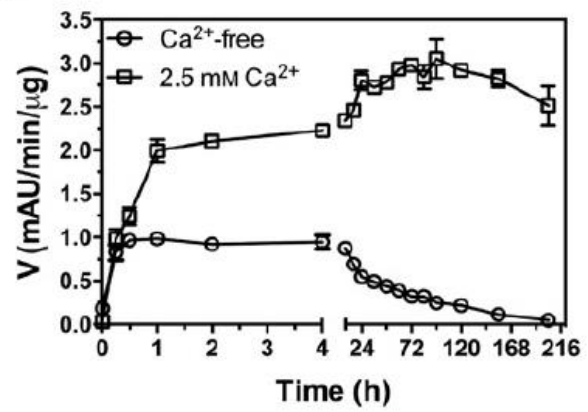

B

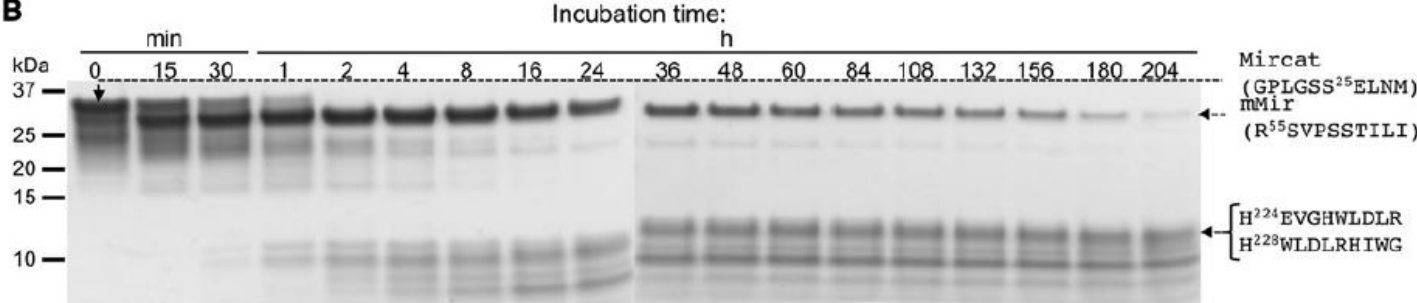

c (zymography)

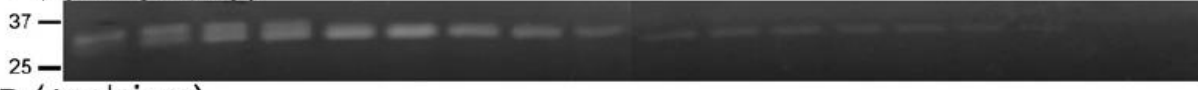

D (+calcium)

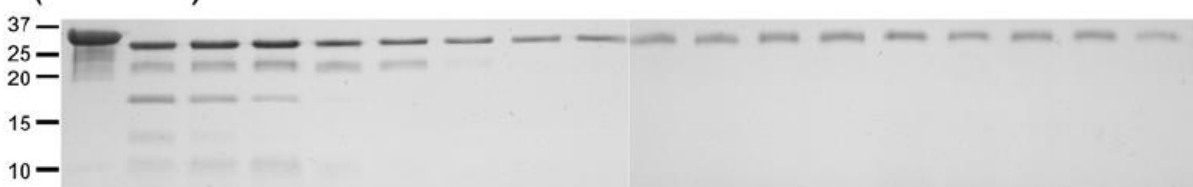

Fig 6: Expression, purification, and the effect of calcium on autoprocessing of mirolysin without C-terminal extension (CTE). (A) Catalytic domain preceded by the profragment of mirolysin and its active site mutein (Mircat and MircatE225A, respectively) were obtained as recombinant proteins and purified by affinity chromatography on glutathione-Sepharose with simultaneous removal of the GST tag by PreScission cleavage followed by SEC and ion exchange chromatography (MircatE225A only). Lanes 1 and 2, E. coli extracts before and $8 \mathrm{~h}$ after induction of protein expression with IPTG, respectively; lanes 3 and 4, proteins after purification by affinity chromatography and SEC followed by ion exchange chromatography for MircatE225A only, respectively. (B-E) Mircat was incubated at $0.5 \mathrm{mg} / \mathrm{ml}$ in $50 \mathrm{~mm}$ Tris, $0.02 \% \mathrm{NaN}_{3}, \mathrm{pH} 8.0$, alone (B) or supplemented with $2.5 \mathrm{~mm} \mathrm{CaCl}_{2}$ (D). At specific time points, aliquots were taken and analyzed by SDS-PAGE (B, D) followed by zymography (C, for incubation in calcium-free buffer only) and measurement of residual activity against Azocoll as a substrate (E). N-terminal sequences determined by Edman degradation are shown on the right.

Reprinted with the permission. Koneru et al., Biological Chemistry, 2016. 
Table 1: The effect of inhibitors, reducing agents, and divalent cations on the proteolytic activity of mirolysin.

\begin{tabular}{|c|c|c|}
\hline Inhibitors and metal ions & Concentration & $\%$ of control \\
\hline \multirow[t]{2}{*}{ EDTA } & $1 \mathrm{~mm}$ & 0 \\
\hline & $10 \mathrm{~mm}$ & 0 \\
\hline \multirow[t]{2}{*}{ Pefabloc } & $10 \mu \mathrm{m}$ & 91 \\
\hline & $100 \mu \mathrm{M}$ & 82 \\
\hline \multirow[t]{2}{*}{ 1,10-Phenanthroline } & $1 \mathrm{~mm}$ & 2 \\
\hline & $10 \mathrm{~mm}$ & 2 \\
\hline \multirow[t]{2}{*}{ lodoacetic acid } & $5 \mathrm{~mm}$ & 130 \\
\hline & $10 \mathrm{~mm}$ & 147 \\
\hline \multirow[t]{2}{*}{$E \cdot 64$} & $5 \mu \mathrm{m}$ & 115 \\
\hline & $10 \mu \mathrm{M}$ & 115 \\
\hline \multirow[t]{4}{*}{$\mathrm{ZnCl}_{2}$} & $0.01 \mathrm{~mm}$ & 112 \\
\hline & $0.1 \mathrm{~mm}$ & 96 \\
\hline & $1 \mathrm{~mm}$ & 24 \\
\hline & $10 \mathrm{~mm}$ & 0 \\
\hline \multirow[t]{4}{*}{$\mathrm{CaCl}_{2}$} & $0.1 \mathrm{~mm}$ & 116 \\
\hline & $1 \mathrm{~mm}$ & 218 \\
\hline & $5 \mathrm{~mm}$ & 230 \\
\hline & $10 \mathrm{~mm}$ & 247 \\
\hline \multirow[t]{2}{*}{ TLCK } & $5 \mathrm{~mm}$ & 91 \\
\hline & $10 \mathrm{~mm}$ & 100 \\
\hline Leupeptin & $50 \mu \mathrm{m}$ & 112 \\
\hline \multirow[t]{2}{*}{ L-cysteine } & $1 \mathrm{~mm}$ & 109 \\
\hline & $10 \mathrm{~mm}$ & 91 \\
\hline \multirow[t]{2}{*}{ DTT } & $1 \mathrm{~mm}$ & 98 \\
\hline & $10 \mathrm{~mm}$ & 74 \\
\hline
\end{tabular}

Mirolysin activity determined at $37^{\circ} \mathrm{C}$ in $50 \mathrm{~mm}$ Tris- $\mathrm{HCl}, \mathrm{pH} 8.0$, using Azocoll as a substrate, was set at $100 \%$.

Reprinted with the permission. Koneru et al., Biological Chemistry, 2016. 
We also examined the effect of divalent cations on mirolysin activity. At a high concentration $(10 \mathrm{mM}), \mathrm{Zn}^{2+}$ inhibited enzyme activity, while $\mathrm{Ca}^{2+}$ at concentrations ranging from 1-10 $\mathrm{mM}$ enhanced the activity 2 -fold (Table 1 ). This increase in activity corroborated the results from analysis of mirolysin processing. To investigate calcium binding by mirolysin in more detail, we determined the dissociation constant $\left(K_{d}\right)$ for the interaction between mirolysin and $\mathrm{Ca}^{2+}$ and studied the effect of calcium on enzyme stability using microscale thermophoresis (MST) [77] and differential scanning fluorimetry (DSF) techniques, respectively. The $K_{d}$ of the interaction was determined to be at $0.89 \mathrm{mM}$ (Figure 7A), and melting temperatures $(\mathrm{Tm})$ were calculated to demonstrate the effect of $\mathrm{Ca}^{2+}$ ions on MircatE225A stability. As shown in Figure 7B, calcium increased the Tm in a concentration-dependent manner, but the observed changes were negligible, with only a $1.5^{\circ} \mathrm{C}$ increase in the $T m$ in the presence of $10 \mathrm{mM} \mathrm{CaCl}_{2}$, suggesting that $\mathrm{Ca}^{2+}$ exerts no major effect on the structural stability of mirolysin. Mirolysin was active at $\mathrm{pH}$ values ranging from 6 to 9 , and activity was dependent on the buffer composition, despite using buffers with the same molarity (50 mM; Figure 7C). This could be explained by differences in the ionic strength of the buffers, as calculated using software developed by Bob Beynon (https://www.liverpool.ac.uk/ buffers/buffercalc.html). For example, the ionic strength of buffers at $\mathrm{pH} 7.5$ is 0.027 for HEPES, 0.035 for MOPS, and 0.042 for Tris, which correlates with the observed differences in activity. 

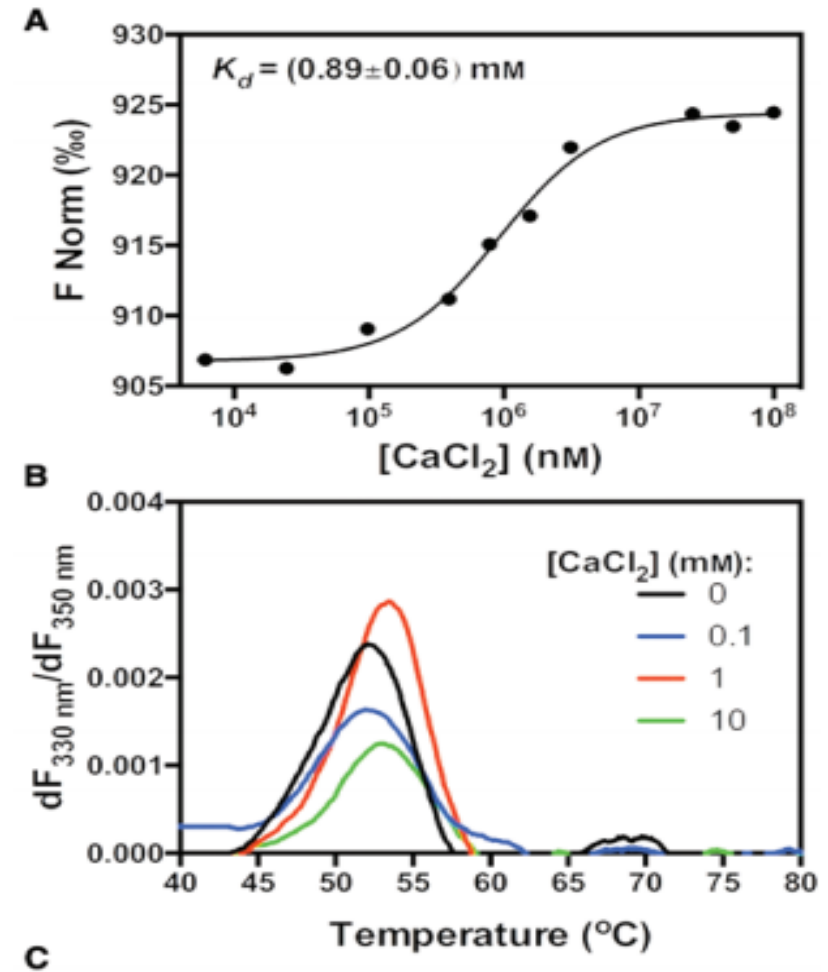

C

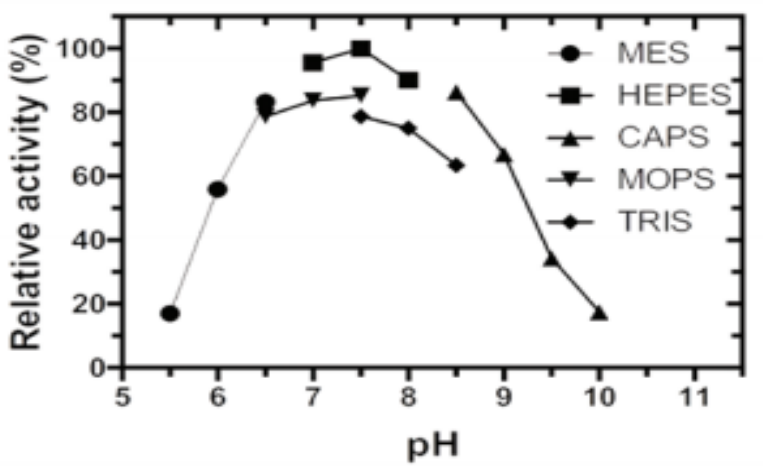

Fig 7: Determination of the dissociation constant $\left(K_{d}\right)$ of mirolysin in the presence of calcium, the effect of calcium on thermal stability, and the optimum pH. (A) The dissociation constant $\left(K_{d}\right)$ was determined using microscale thermophoresis. MircatE225A was titrated with increasing concentrations of $\mathrm{CaCl}_{2}$. The binding data were fitted, and the $K_{d}$ values were determined. The results are presented as the mean \pm SD from three experiments. (B) The effect of increasing concentrations of calcium on the Tm of MircatE225A was evaluated by differential scanning fluorimetry. Briefly, protein samples in the presence of increasing concentrations of $\mathrm{CaCl}_{2}$ were gradually heated and fluorescence was recorded at two emission wavelengths, 330 and $350 \mathrm{~nm}$. The Tm was calculated based on the plots of first derivative of the ratio of two measured fluorescence values against temperature. (C) Activity of mirolysin (mMir) was determined in buffers with different $\mathrm{pH}$ values. The activity measured in $50 \mathrm{mM}$ HEPES, pH 7.5 was set to $100 \%$.

Reprinted with the permission. Koneru et al., Biological Chemistry, 2016. 
Determination of mirolysin specificity: As mentioned previously, the name of the archaeal metalloprotease ulilysin was changed to LysargiNase in order to better describe the specificity of the enzyme, which is restricted to Xaa-Lys and Xaa-Arg peptide bonds [69]. To determine whether mirolysin shows the same specificity, mMir was incubated with the following proteinaceous substrates: bovine casein and human albumin, fibrinogen, fibronectin, complement proteins (factors $\mathrm{C} 3, \mathrm{C} 4$, and $\mathrm{C5}$ ), and the peptides human cathelicidin LL-37 and bovine insulin $\beta$-chain. The reaction was stopped by boiling in SDS-PAGE sample buffer, and the digestion products were separated by SDS-PAGE (Figure 8A). Mirolysin cleaved all of the analyzed substrates except albumin. Two types of proteolysis were identified: complete and limited. The latter was observed only for complement proteins. To determine mirolysin specificity, peptides generated by the enzyme were identified by mass spectrometry, thus allowing the determination of cleavage sites within the polypeptide chains of the substrates. Based on these results, we mapped the enzymatic specificity of mirolysin using Weblogo (Figure 8B). Like LysargiNase, mirolysin cleaved preferentially peptide bonds with arginine and lysine at the $\mathrm{P} 1$ ' position. Interestingly, unlike LysargiNase, mirolysin also cleaved Xaa-His peptide bonds. The limited proteolysis of the $\alpha$-chains of C3 and C5 could lead to release of anaphylatoxins. To examine this, we determined the $\mathrm{N}$-terminal sequence of truncated $\alpha$-chains of C3 and C5 (Figure 8B). The analysis revealed that, indeed, both proteins were cleaved at the Nterminus. However, the cleavage of $\mathrm{C} 3$ led to the formation of $\mathrm{C} 3 \mathrm{a}$ desArg (without $\mathrm{C}$ terminal arginine), while C5 was truncated 127 residues downstream of the C5a peptide. The efficient cleavage of complement factors by mMir corroborates the observation of efficient inactivation of complement functions by mirolysin [65]. 

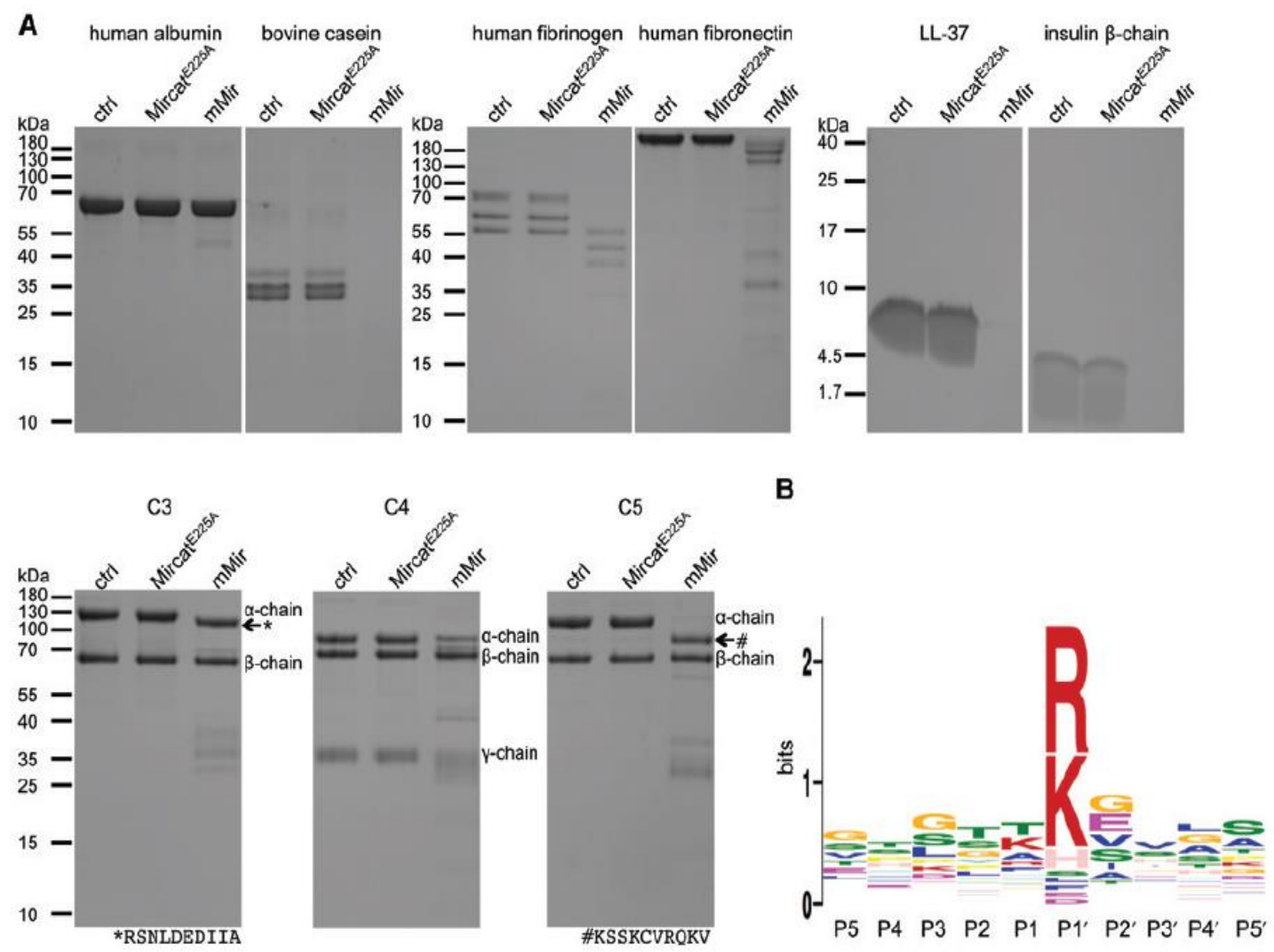

Fig 8: Mirolysin hydrolyzes a broad range of substrates and cleaves peptide bonds at arginine and lysine. (A) The proteins human albumin, fibrinogen, fibronectin, and bovine casein, the human complement proteins $\mathrm{C} 3, \mathrm{C} 4$, and $\mathrm{C} 5(10 \mu \mathrm{g})$, and the peptides human cathelicidin LL-37 and bovine insulin $\beta$-chain $(4 \mu \mathrm{g})$ were incubated in $50 \mathrm{mM}$ Tris, $150 \mathrm{mM}$ $\mathrm{NaCl}, 2.5 \mathrm{mM} \mathrm{CaCl}_{2}, 0.02 \% \mathrm{NaN}_{3}, \mathrm{pH} 7.5$, at $37^{\circ} \mathrm{C}$ for $8 \mathrm{~h}$ alone (control, ctrl) or with mMir at a enzyme : substrate weight ratio of $1: 20$ (complement proteins), $1: 100$ (other proteinaceous substrates), and 1:1000 (peptides). Substrates incubated with MircatE225A served as a negative control. The identity of the bands indicated by arrows was determined by $\mathrm{N}$-terminal sequencing. The obtained sequences are shown below the gels. (B) The digestive peptides resulting from cleavage of substrates by mirolysin were identified by mass spectrometry, thus allowing the determination of cleavage sites within the substrate polypeptide chains. Based on these results, the mirolysin cleavage motif was generated employing MEME (Multiple Em for Motif Elicitation).

Reprinted with the permission. Koneru et al., Biological Chemistry, 2016. 
Mirolysin abolishes the biological activities of LL-37: LL-37 is thought to play a crucial role in maintaining homeostasis in the periodontium [78]. Therefore, we monitored the concentration- and time dependent cleavage of LL-37 by mirolysin. Mirolysin cleaved LL37 very efficiently, and, after $1 \mathrm{~h}$ of incubation at a 1:100 000 molar ratio of enzyme/substrate, no native LL-37 remained in the sample (Figure 9A). Accumulated product(s) with lower molecular mass peptides ( $<3.4 \mathrm{kDa}$ ) (Figure 9B) was completely degraded during incubation for $1 \mathrm{~h}$ at a 1: 1000 (enzyme/substrate) molar ratio (Figure 9A). LL-37 was not affected by the catalytically inactive mirolysin mutein, MircatE225A. To assess the bactericidal potency of LL-37 after incubation with mirolysin, we performed an antimicrobial assay employing E. coli ATCC 3369 as a target. After just 10 min of incubation with mirolysin, the bactericidal activity of LL-37 against $E$. coli was reduced by $60 \%$, and was entirely gone after $1 \mathrm{~h}$ (Figure 9C). 

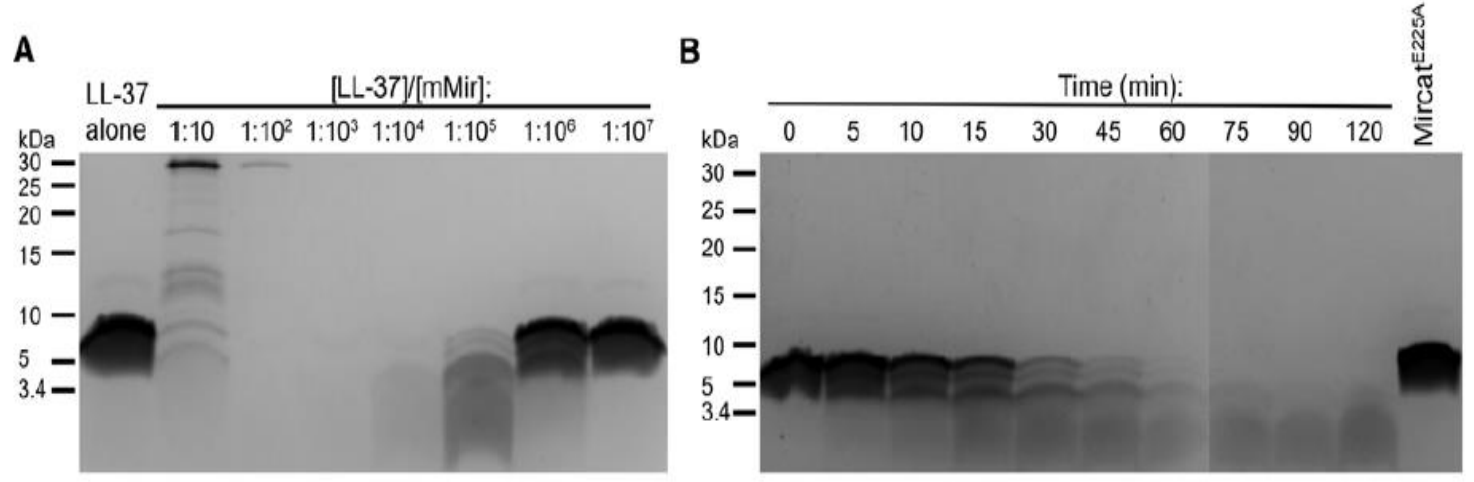

C

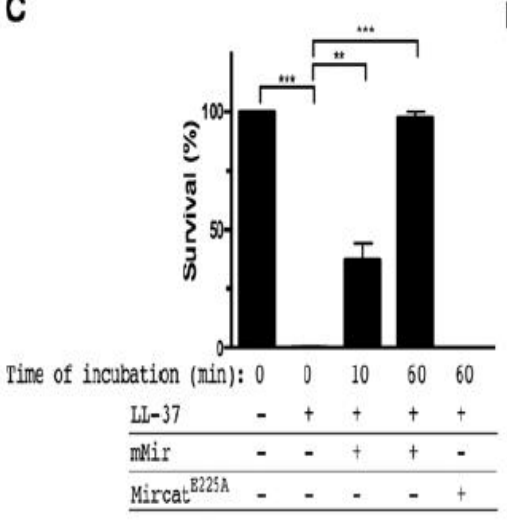

D

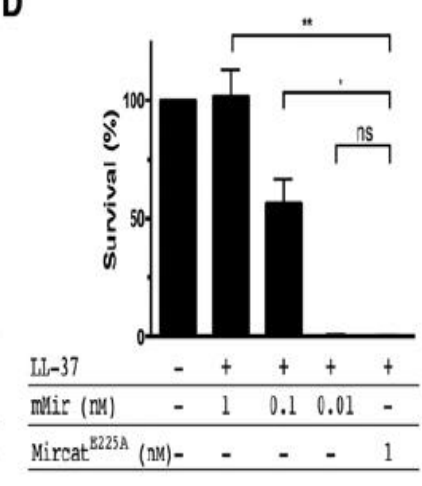

E

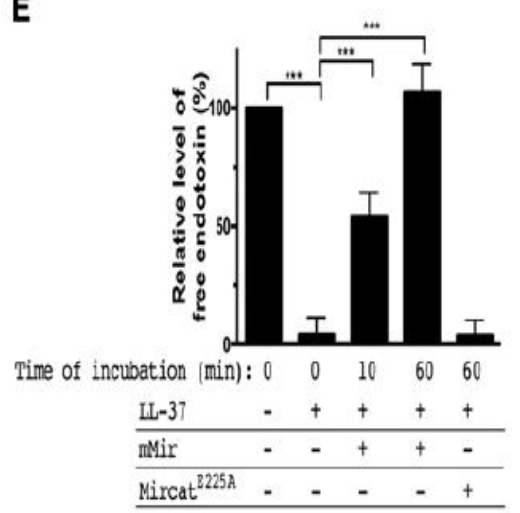

Fig 9: Mirolysin degrades LL-37 in a concentration- and time-dependent manner, abolishing its antimicrobial activity. (A, B) LL-37 was incubated with mature mirolysin (mMir) at different substrate : enzyme molar ratios (concentration-dependent proteolysis) for $1 \mathrm{~h}$ (A) or at a constant 100,000:1 substrate : enzyme molar ratio for different time intervals (timedependent proteolysis) (B) in $50 \mathrm{mM}$ Tris, $150 \mathrm{mM} \mathrm{NaCl}, 2.5 \mathrm{mM} \mathrm{CaCl}_{2}, 0.02 \% \mathrm{NaN}_{3}$, pH 7.6, at $37^{\circ} \mathrm{C}$. The reaction was terminated by boiling with SDS-PAGE sample buffer, and samples were subjected to SDS-PAGE. LL-37 incubated with MircatE225A served as a negative control. (C) LL-37 was incubated alone or with mirolysin (mMir) at a molar ratio of $100000: 1$ for 10 and $60 \mathrm{~min}$, then mixed with bacteria (E. coli ATTCC 25922), incubated for $2 \mathrm{~h}$ at $37^{\circ} \mathrm{C}$, and plated onto agar plates to determine the numbers of colony-forming units (CFU). Percentage survival was calculated and compared to bacteria grown without antimicrobial peptide LL-37 (100\% survival). (D) Bacteria were mixed with mMir at concentrations of $0.01,0.1$, and $1 \mathrm{nM}$ or MircatE225A (control), then LL-37 was added, and after incubation for $2 \mathrm{~h}$ at $37^{\circ} \mathrm{C}$ the mixtures were plated onto agar plates to determine the numbers of CFU. Percentage survival was calculated and compared to bacteria treated with MircatE225A (no survival). (E) LL-37, intact or cleaved by $\mathrm{mMir}$, was mixed and then incubated for $5 \mathrm{~min}$ at room temperature with endotoxin from E. coli 0111 : B4. Intact LL-37 incubated with MircatE225A was used as a negative control. The level of the Limulus test reactive endotoxin was determined and compared to endotoxin without LL-37 (100\%). *p $<0.05 ; * * p<0.01 ; * * * p<0.001$.

Reprinted with the permission. Koneru et al., Biological Chemistry, 2016. 
Of note, the inactive mirolysin mutein MircatE225A exerted no effect on the antimicrobial activity of the peptide. T. forsythia is naturally resistant to LL-37, but the dental plaque is also inhabited by other species of bacteria, many of which are susceptible to LL-37 [79]. Therefore, we hypothesized that secreted mirolysin could protect bacteria dwelling together with $T$. forsythia in the dental plaque. To verify this, mirolysin at different concentrations was added to a suspension of $E$. coli, which was then immediately treated with LL-37. MircatE225A served as a negative control. Mirolysin at a $1 \mathrm{nM}$ concentration completely protected E. coli against the antimicrobial activity of LL-37. At a concentration of $0.1 \mathrm{nM}$, mirolysin increased E. coli survival to approximately 50\%, but at lower concentrations $(0.01 \mathrm{nM})$ the enzyme had no protective effect. The inactive form of the enzyme had no effect on E. coli viability at any concentration (Figure 9D). In addition to the antimicrobial activity, LL-37 exerts potent anti-inflammatory activity, which is mediated through direct binding to lipopolysaccharide (LPS). To determine how cleavage of LL-37 by mirolysin affects the ability of the peptide to neutralize LPS, we used a commercially available kit based on Limulus amebocyte lysate. Intact LL-37 prevented LPS from activation of a protease zymogen, Factor C, which is the first step in clotting induction. This ability was completely lost after preincubation of the peptide with mirolysin, which led to degradation of the peptide. Abrogation of the ability of LL-37 to neutralize LPS was dependent on mirolysin activity, since the catalytically inactive mutein of mirolysin had no effect (Figure 9E). 


\subsection{Discussion:}

Peptidases (proteases) are widely distributed among prokaryotes, so it is not surprising that bacterial proteases are involved in processes such as nutrient acquisition, degradation of misfolded proteins, regulation of gene expression, and post-translational modification of proteins. Proteolysis is irreversible, so bacterial proteases must be tightly controlled in both a spatial and temporal manner. The first is achieved by compartmentalization of synthesized proteins, which are directed to the periplasm or extracellular milieu by different secretory pathways. In the case of prepromirolysin, a SP directs the protein to the SEC translocon. During translocation to the inner membrane, the SP is cleaved off and promirolase folds in the periplasm. The conserved CTD serves as a signal for transport by the T9SS [29], which moves mirolysin across the outer membrane to the extracellular milieu. During the journey through the periplasm, mirolysin is maintained as an inactive zymogen by the N-terminal profragment (NTP). The NTP, however, seems to provide stable latency only in the absence of calcium. In bacteria, similar to eukaryotes, calcium concentrations within the cell are tightly regulated. Although, there are no data available for T. forsythia, calcium levels were measured in the model bacteria, E. coli. In E. coli, as well as in other tested bacteria, the cytoplasmic $\mathrm{Ca}^{2+}$ concentration is kept constant at 1 $\mu \mathrm{M}$. The periplasmic concentration may vary depending on the extracellular concentration, but, nevertheless, it is maintained in the range of $60-300 \mu \mathrm{m}[80,81]$. The determined $K_{d}$ value for interaction of mirolysin with calcium is $890 \mu \mathrm{M}$, which suggested that mirolysin could not bind calcium in subcellular compartments of T. forsythia (cytoplasm and periplasm), but only after secretion into the extracellular milieu, GCF, where the calcium concentration is around $2.5 \mathrm{mM}$. Thus, such regulation could prevent unwanted activation 
of secretory proteases in the periplasm. Mirolysin is the third KLIKK protease to be characterized; the first two were karilysin and mirolase. All of these proteases bind calcium, but, interestingly, $\mathrm{Ca}^{2+}$ exerts a different effect on each enzyme. In karilysin, $\mathrm{Ca}^{2+}$ increases thermal stability, in mirolase, it is essential for enzyme activity, and, in mirolysin, it facilitates autoactivation of promirolysin and prevents autoproteolytic degradation of the mature enzyme. As a result, calcium concentration within the subcellular compartments may be a global regulator of KLIKK protease activity. Despite sharing almost 50\% identity of the amino acid sequence with the $\mathrm{CD}$ of ulilysin, mirolysin possesses some unique features. First, both proteases bind calcium, but this binding results in different effects. $\mathrm{Ca}^{2+}$ is essential for ulilysin activity, while it only increases the activity of mirolase and provides resistance to autoproteolysis. Second, although both ulilysin and mirolysin show strong preference for lysine or arginine at the $\mathrm{P} 1$ ' position, ulilysin, similar to trypsin, slightly prefers lysine (52\%) to arginine (40\%). In mirolysin, the opposite is true: $49 \%$ of cleavage occurred before arginine and only $33 \%$ in front of lysine. Moreover, mirolysin also cleaved Xaa-His peptide bonds (8\%). However, it needs to be kept in mind that mirolysin specificity was determined based on only 39 cleavage sites compared to 1917 unique cleavage sites determined for ulilysin [69]. Two disulfide bridges spanning the CD are conserved in PAPPA and ulilysin $[68,82]$. Those cysteine residues are also present in mirolysin (Figure 1A), but they are either not engaged in disulfide bridges or these bridges are not structurally important, since protein reduction with DTT has little effect on mirolysin activity. The former assumption is corroborated by the fact that M43B protease from Rhodococcus opacus lacks the cysteine residues that form these disulfide bridges (Figure 1A). Furthermore, despite the presence of numerous cysteine residues, disulfide 
bridges are absent in $T$. forsythia and $P$. gingivalis proteins with structures known at atomic resolution. This is likely a structural and functional adaptation to the anaerobic, reducing environment niche occupied by periodontal pathogens. The human cathelicidin LL-37 is considered as a crucial antimicrobial peptide responsible for the maintenance of homeostasis in the periodontium [83]. Levels of LL-37 are increased in patients suffering from periodontitis compared to healthy controls [84], and genetic deficiency of LL-37 results in rapid development of severe periodontitis [78]. Thus, hydrolysis of LL-37 by mirolysin may contribute to the natural resistance of $T$. forsythia to this peptide. During LL-37 degradation, mirolysin may act synergistically with karilysin and mirolase, which also cleave LL-37. Mirolysin alone, at concentrations as low as $1 \mathrm{~nm}$, fully protected E. coli against LL-37. Thus, it is tempting to speculate that mirolysin could provide protection to LL-37 against periodontal pathogens inhabiting subgingival biofilm with $T$. forsythia. In addition to its bactericidal activity, LL-37 also possesses potent immunoregulatory properties mediated by binding and neutralizing the proinflammatory activity of LPS (endotoxin) [85]. LPS is a component of the outer membrane of Gramnegative bacteria, which are the most predominant bacteria in dental plaques. Therefore, degradation of LL-37 by mirolysin, which abolishes the ability of the peptide to bind LPS, may result in increased inflammation at the site of infection, thus contributing to development of periodontitis. In dental plaques, which are bathed in GCF composed of almost $70 \%$ human serum, T. forsythia is exposed to the bactericidal activity of the complement system. Complement activation contributes to bacterial death, either directly by assembly of a membrane attacking complex (MAC) on the bacterial surface, or indirectly through the release of potent anaphylatoxins (C3a and $\mathrm{C} 5 \mathrm{a})$, which recruit and 
activate neutrophils and macrophages to kill bacteria [86]. Anaphylatoxin activity is regulated by serum carboxypeptidase, which removes the $\mathrm{C}$-terminal arginine, resulting in the formation of desArg forms of these potent mediators. This leads to the loss of almost $90 \%$ and $100 \%$ of the biologic activity of C3a and C5a, respectively [87]. For many years, C3a was considered a proinflammatory mediator. However, it has been recently shown that C3a possesses both pro- and anti-inflammatory properties, the latter being exerted through blocking the mobilization of neutrophils from bone marrow into the blood stream and suppressing the production of proinflammatory cytokines by these cells [88]. In this context, it is important to emphasize that mirolysin efficiently generated C3a des Arg devoid of anti-inflammatory properties, which cannot counterbalance the activity of C5a released by $T$. forsythia proteases [89]. This may contribute to excessive, sustained inflammation at the site of infection, the environment in which periodontal pathogens thrive [90]. Apart from the proteolysis-mediated disruption of two major bactericidal systems present in the oral cavity, mirolysin is also able to efficiently degrade other physiologically relevant human proteins, including fibrinogen and fibronectin. Thus, mirolysin could interfere with clotting at the site of infection, but this is more likely to facilitate the degradation of proteins abundant in GCF, which generates a pool of peptides indispensable for the growth of asaccharolytic bacteria [91]. Taken together, our findings regarding the expression and biochemical characterization of mirolysin identify it as a specific protease that preferentially hydrolyzes Xaa-Arg and Xaa-Lys peptide bonds. Based on its high level of proteolytic activity and cleavage of complement proteins and LL-37, mirolysin may not only provide nutrients for the asaccharolytic consortium of periodontal pathogens, but also protect itself, as well as other pathogens in dysbiotic subgingival 
biofilm, against the human innate immune system. Confirmation of this hypothesis is currently the subject of ongoing research in our laboratory. 


\section{CHAPTER 3}

\section{CONSTRUCTION OF THE NOVEL MIROLYSIN MUTANTS FOR THE CYSTALLOGRAPHY ANALYSIS}

3.1 Introduction: Tannerella forsythia is an anaerobic gram negative pathogen often associated with a chronic form of periodontitis. The virulence properties, synergistic relation with other bacteria of the polymicrobial community and implications in the progression of the inflammatory disease makes the study of underlying virulence mechanisms of this pathogen imperative $[40,64,91]$. The proteolytic virulence factors identified in T. forsythia so far include PrtH a cysteine protease and the recently identified KLIKK group of proteases. Till to date only three (PrtH, karilysin, mirolase) of the above mentioned proteolytic enzymes have been characterized [29, 45, 46]. As discussed in the previous chapter the biochemical and biological characterization of an effector protein of T9SS, mirolysin of the KLIKK group of proteases was successfully accomplished. In this study, we would like to further investigate the structure-function relations contributing to zymogenicity of promirolysin by designing new constructs for the crystallography analysis of the mirolysin protein. These structural studies will not only help us to design specific targets for the development of new protease inhibitors but also help in understanding the mechanism of the enzyme latency. Due to the amino acid similarity of ulilysin with mirolysin, the sequence of the already crystallized structure of ulilysin was taken into consideration for designing the new constructs. Total eight constructs of mirolysin were 
designed, constructed and transformed into E.coli BL21 (DE3) for the expression and purification of the protein, which was intended to be used for crystallization. Unfortunately, due to the formation of inclusion bodies the expressed mirolysin protein was obtained in the insoluble form.

\subsection{Materials and Methods:}

Chemical Reagents and strains: Primers were designed using a clone manager software and were ordered from Sigma. A phusion site directed mutagenesis kit (Thermo Scientific) was used to introduce the required mutations. E. coli strains used in this study were NEBalpha and BL21 (DE3) from New England Biolabs, Rosetta from Novagen, and Arctic Express from Agilent.

SDS PAGE: sample preparation: $\mathrm{x} \mu \mathrm{l}$ of the sample was taken into tube and $\mathrm{dH}_{2} \mathrm{O}$ was added to a final volume of $30 \mu 1$. To this volume $10 \mu \mathrm{l}$ of loading dye (4X) with $\beta$ Mercaptoethanol (BME) added at volume ratio 10:1 and the mixtures were boiled at $100^{\circ} \mathrm{C}$ for 5 min. Gel Electrophoresis: The obtained samples were separated in 4-12\% Bis Tris gels at $150 \mathrm{~V}$ for $1 \mathrm{~h}$ in $1 \mathrm{xMES}$ Buffer at room temperature.

Mutagenesis: Eight mirolysin mutants (Figure 10B) were prepared by using phusion site directed mutagenesis kit and appropriate primers (Table 2). The master plasmid (pGeX6P1 vector with the mirolysin gene) used in chapter 2 was taken as a template for mutagenesis. 


\section{A}

$>$ full-length mirolysin

MKKI ILS ILASALWINGYSQRTCGSELNMEQIRRTEPLKYQRITDWENQIKLHSRSVPSSTILIP VVVHVVYNNSAQNISDAQI ISQIQVLNEDFRRMNADQANT PSAFANLAGNANIEFKLARRDPNGN TTNGITRTSTSTETFSMEMDNVKFSNLGGNNAWNTRRYLNIWVCNLGDDLLGYAQFPFEFQTKPN TDGVVIHYKHFGRDGSAESPYDKGRTATHEVGHWLDLRH IWGDDGGSCSGTDNIADT PNQGGYNE GCPSFPKTDHCTNTS PGVMFMNYMDYTYDACMNLFTKGQVERMRSLFDTQTGIRREMQ IYANELT NPLSFSITGPSEFCDNAIYKIANLPTGTTVQWSTSMSGNPYPLIANNSPQTNQCTLYNVYNCSAD IF I LAK IYQGASHMVTLSKKI IVKDNSTVQKGRYVQEECTFYGVHHPS ITGELIDGANF LYQGCM TRIYLDNMYRKTIEFTGS IPPLYWYYVESQKMLLLQLPLGSGGIPFTFKVKGGCQEKTLLFFSRT GNRNVIFTLSPNPATDAVTLQLTETDEVSGLSVLSTERSAYEIQIWSGMRMLRSFRTNEPTFQIP MAGLPAGLYFVRVVKNGQTYTQKLIKK

B

\begin{tabular}{|c|c|c|c|}
\hline \multicolumn{4}{|c|}{ SP PD CATALYTIC DOMAIN C-TERMINAL EXTENSION } \\
\hline${ }^{25}$ SELN & $\mathrm{HExxH}$ & $\lambda$ & KLIKK \\
\hline${ }^{13} \mathrm{LWIN}$ & HExxH & 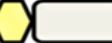 & KLIKK \\
\hline${ }^{13}$ LWIN & $\mathrm{HAxxH}$ & $\Lambda$ & KLIKK \\
\hline MKKI & HEXXH & GIRR $^{332}$ & \\
\hline${ }^{13} \mathrm{LWIN}$ & $\mathrm{HEx \times H}$ & GIRR $^{332}$ & \\
\hline${ }^{60} \mathrm{STIL}$ & $\mathrm{HAxxH}$ & $\mathrm{TGIR}^{331}$ & \\
\hline${ }^{60}$ STIL & HExxH & TGIR $^{331}$ & \\
\hline MKKI & HExxH & TGIR $^{331}$ & \\
\hline MKKI & HExxH & TGPS $^{353}$ & \\
\hline
\end{tabular}

Fig 10: Mirolysin amino acid sequence (A) and the scheme of novel mirolysin mutants (LK1-LK8) generated in this study (B). 
Table 2: List of primers used to generate mirolysin mutants

\begin{tabular}{|c|c|}
\hline Name of the mutant. & $\begin{array}{l}\text { Sequence of the Primer } \\
\qquad\left(5^{\prime}-3^{\prime}\right)\end{array}$ \\
\hline LK1 and LK2 & $\begin{array}{l}\text { F:TTATGGATCAATGGCTATTCACAACGGACATGTGGTTCT } \\
\text { GAGTTGAATATGGAACF2:5'- } \\
\text { TCTGAGTTGAATATGGAACAAATCCGGCGGACAG-3' } \\
\text { R:ACCACATGTCCGTTGTGAATAGCCATTGATCCATAAGG } \\
\text { ATCCCAGGGGCCCCTGGR2:5'- } \\
\text { GGATCCCAGGGGCCCCTGGAAC-3' }\end{array}$ \\
\hline LK3/1 ${ }^{\text {st }}$ mutation & $\begin{array}{l}\text { F:CCCAAACAGGTATCAGACGTTAAATGCAGATTTATGCG } \\
\text { R:CGCATAAATCTGCATTTAACGTCTGATACCTGTTTGGG }\end{array}$ \\
\hline $\mathrm{LK} 3 / 2^{\text {nd }}$ mutation & $\begin{array}{l}\text { F:ATGAAGAAAATCATTCTGTCCATCCTGGCTTCTGCATTA } \\
\text { TGGATCAATGGCTATTCACAACGGACATG } \\
\text { R:CGCATAAATCTGCATTTAACGTCTGATACCTGTTTGGG }\end{array}$ \\
\hline LK4 & $\begin{array}{l}\text { F:CCCAAACAGGTATCAGACGTTAAATGCAGATTTATGCG } \\
\text { R:CGCATAAATCTGCATTTAACGTCTGATACCTGTTTGGG }\end{array}$ \\
\hline LK5/1 ${ }^{\text {st }}$ mutation & $\begin{array}{l}\text { F:GATACCCAAACAGGTATCAGATGAGAAATGCAGATTTA } \\
\text { TGCG } \\
\text { R:CGCATAAATCTGCATTTCTCATCTGATACCTGTTTGGGT } \\
\text { ATC }\end{array}$ \\
\hline LK $5 / 2^{\text {nd }}$ mutation & $\begin{array}{l}\text { F:TCCACAATTCTGATCCCGGTTGTAGTACATG } \\
\text { R:GGGCCCCTGGAACAGAACTTCC }\end{array}$ \\
\hline LK6/1 $1^{\text {st }}$ mutation & $\begin{array}{l}\text { F:GATACCCAAACAGGTATCAGATGAGAAATGCAGATTTA } \\
\text { TGCG } \\
\text { R:CGCATAAATCTGCATTTCTCATCTGATACCTGTTTGGGT } \\
\text { ATC }\end{array}$ \\
\hline LK6/2 $2^{\text {nd }}$ mutation & $\begin{array}{l}\text { F:TCCACA ATTCTG ATCCCGGTTGTAGTACATG } \\
\text { R:GGGCCCCTGGAACAGAACTTCC }\end{array}$ \\
\hline LK $7 / 1^{\text {st }}$ mutation & $\begin{array}{l}\text { F:GATACCCAAACAGGTATCAGATGAGAAATGCAGATTTA } \\
\text { TGCG } \\
\text { R:CGCATAAATCTGCATTTCTCATCTGATACCTGTTTGGGT } \\
\text { ATC }\end{array}$ \\
\hline LK $7 / 2^{\text {nd }}$ mutation & $\begin{array}{l}\text { F:ATGAAGAAAATCATTCTGTCCATCCTGGC } \\
\text { R:GGGCCCCTGGAACAGAACTTCC }\end{array}$ \\
\hline LK8/1 $1^{\text {st }}$ mutation & $\begin{array}{l}\text { F:CCATTACAGGCCCTTCGTAATTTTGTGACAATGCG } \\
\text { R:CGCATTGTCACAAAATTACGAAGGGCCTGTAATGG }\end{array}$ \\
\hline $\mathrm{LK} 8 / 2^{\text {nd }}$ mutation & $\begin{array}{l}\text { F:ATGAAGAAAATCATTCTGTCCATCCTGGC } \\
\text { R:GGGCCCCTGGAACAGAACTTCC }\end{array}$ \\
\hline
\end{tabular}


Expression and purification of the mirolysin mutants: The expression plasmid pGEX6P1 encoding recombinant proteins (LK1-LK8) was transformed into E. coli strain BL21 (DE3) (New England Biolabs, Ipswich, MA). Transformed E. coli hosts were grown in LB medium at $37^{\circ} \mathrm{C}$ to an $\mathrm{OD}_{600 \mathrm{~nm}}$ ranging from 0.75 to 1 and cooled for 30 min at $4{ }^{\circ} \mathrm{C}$, and then expression of recombinant proteins was induced by the addition of $0.125 \mathrm{mM}$ isopropyl-1-thio- $\beta$-D-galactopyranoside (IPTG). After growing for $16 \mathrm{~h}$ at $20^{\circ} \mathrm{C}$, cells were harvested by centrifugation $\left(15 \mathrm{~min}, 6000 \times \mathrm{g}, 4^{\circ} \mathrm{C}\right)$, re-suspended in PBS $(15 \mathrm{ml}$ per pellet from 11 of culture), and subsequently lysed by sonication (cycle of $15 \times 3 \mathrm{~s}$ pulses at a power output of $70 \%$ per pellet from 11 of culture). The cell lysates were clarified by centrifugation $\left(1 \mathrm{~h}, 50,000 \times \mathrm{g}, 4^{\circ} \mathrm{C}\right)$, filtered through a $0.45 \mu \mathrm{m}$ syringe filter, and loaded onto a glutathione-Sepharose 4 Fast Flow column (bed volume, $5 \mathrm{ml}$ ) equilibrated with PBS at $4^{\circ} \mathrm{C}$. Further, $10 \mathrm{ml}$ of PBS containing $100 \mu \mathrm{l}$ of PreScision protease stock solution (1 U/ml) was applied to the column and incubated for $40 \mathrm{~h}$ at $4^{\circ} \mathrm{C}$. The RreScission cleaved protein sample was then collected as $1 \mathrm{ml}$ fractions. The remaining bound proteins were later eluted using $50 \mathrm{mM}$ Tris- $\mathrm{HCl}, \mathrm{pH} 8.0$, supplemented with $10 \mathrm{mM}$ reduced glutathione. Protein concentration in each fraction was determined by measurement of absorbance at $280 \mathrm{~nm}$ using a Nanodrop spectrophotometer. The purity of the proteins was verified by SDS-PAGE electrophoresis using 4-12\% Bis Tris gels (Invitrogen, Thermo fisher scientific). Gels were stained with simply blue safe stain (Novex life technologies). 


\subsection{Results:}

Expression of the mirolysin mutants in the insoluble form: Based on alignment with ulilysin, mirolysin WT was extended and/or truncated at both $\mathrm{N}$ - and $\mathrm{C}$-terminus resulting in generation of eight different mirolysin mutants (LK1-LK8). The designed constructs were later expressed in E. coli BL21 (DE3) as a fusion protein with an N-terminal glutathione-S-transferase (GST) tag. All the 8 proteins were overexpressed inside $E$. coli cells after induction of protein expression with IPTG (data shown only for LK4, LK5, LK6 in Figure 11). But all the proteins was in insoluble form due to the formation of inclusion bodies as it was not present in the supernatant of the cell lysate after sonication and centrifugation. 


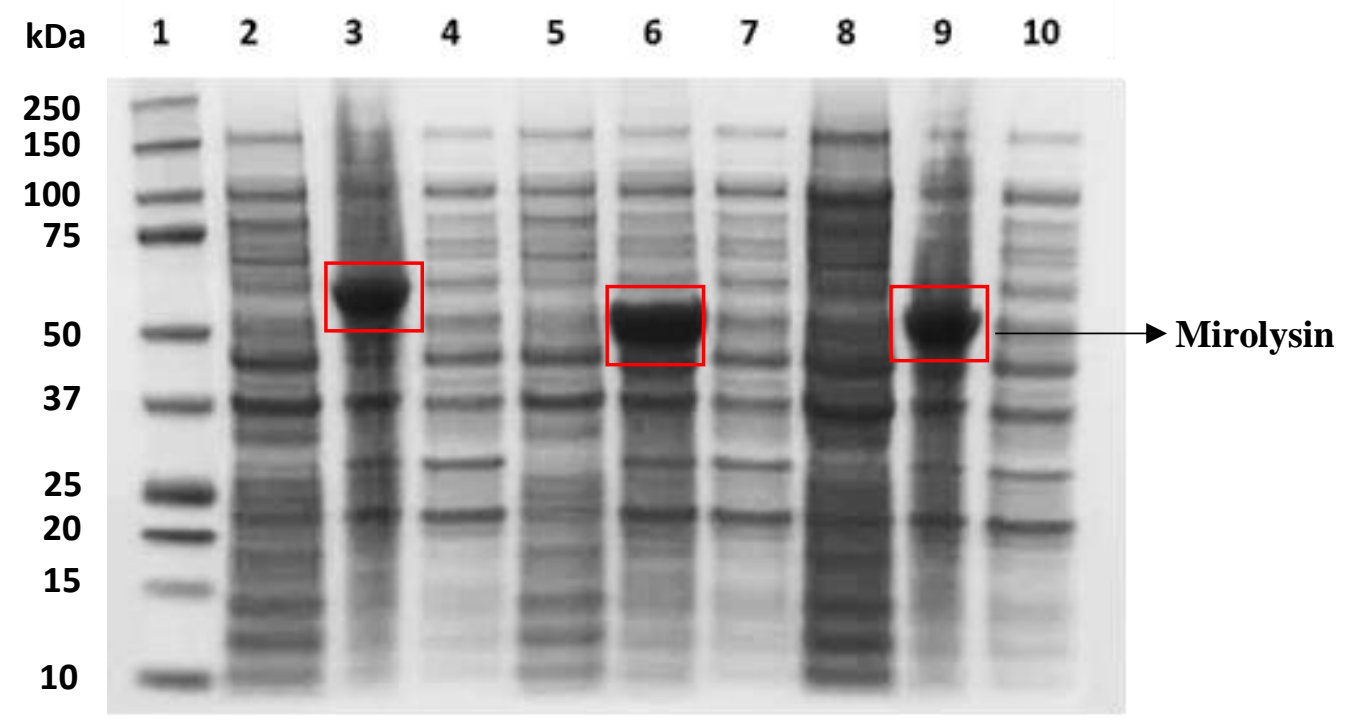

Fig 11: Expression of the recombinant mirolysin mutants: 1) Molecular weight marker, 2) E. coli culture of LK4 before IPTG induction 3,4) cell debris and supernatant after sonication and centrifugation of E. coli LK4 after protein expression induction with IPTG, respectively - rewrite rest 4) The supernatant of LK4 after sonication and centrifugation, 5) E. coli culture of LK5 before IPTG induction 6) LK5 E. coli cell debris after sonication and centrifugation 7) The supernatant of LK5 after sonication and centrifugation, 8) E. coli culture of LK6 before IPTG induction 9) LK E. coli cell debris of 
3.4 Discussion: Structural characterization of mirolysin was essential for the study of enzyme latency and in the identification of structure based design of specific targets to develop inhibitors against the enzyme in future. Taking the similarity of the amino acid sequence between ulilysin and mirolysin into consideration and the previous successful attempts of the crystallization of ulilysin, different mirolysin mutants (LK1-LK8) were designed and created in order to obtain protein for the crystallographic analysis. The fusion proteins were successfully expressed in the BL21 E. coli strain but only in the insoluble form as inclusion bodies. To prevent the formation of inclusion bodies several approaches were tried: protein expression by lactose based autoinduction, adding detergents to the cell suspension before the sonication, growing of bacteria at lower temperatures and using different $E$. coli expression strains, like Arctic and Rosetta for the expression of the protein in the soluble form. All these attempts failed to prevent formation of inclusion bodies. The conventional procedure is refolding of the recombinant protein from the inclusion bodies. The refolding consist of two general steps: solubilization of the inclusion bodies using denaturing agents such as $6 \mathrm{M}$ guanidine hydrochloride, $8 \mathrm{M}$ urea and then renaturation of the solubilized proteins. We were not inclined towards this procedure as it is difficult to validate the proper folding of the recombinant protein after renaturation. Hence, in further experiments we would like to proceed by different optimizations and designing another mirolysin mutants. 


\section{CHAPTER 4}

\section{UNDERLYING MECHANISMS AND IMPORTANT AMINO ACID RESIDUES IN C-TERMINAL DOMAIN OF RgpB GINGIPAIN ESSENTIAL FOR THE TRANSLOCATION OF THE PROTEIN ACROSS OUTERMEMBRANE}

4.1 Introduction: $P$. gingivalis is an anaerobic, haem acquiring, gram negative, keystone pathogen corresponding to the etiology and progression of the periodontitis. Till to date several virulence factors have been identified and extensively studied with respect to $P$. gingivalis. Among these identified virulence factors 'gingipains' which belong to the group of extracellular proteases are considered as one of the major virulence factors of P.gingivalis. These extracellular proteolytic enzymes are secreted through a unique Type IX secretion system (T9SS), which is also found widespread within the phylum of Bacteriodetes (T. forsythia, Prevotella intermedia, Parabacteroides distasonis). All the proteins secreted through T9SS possess a conserved C-terminal domain (CTD), which is essential for their translocation from the periplasm across the outer membrane [50, 92-94]. The similar system is found with respect to KLIKK proteases of T. forsythia, which also comprises of the CTD within the structure of proteins [64]. In case of $\operatorname{RgpB}$, the CTD is later cleaved off at the outer membrane and the protein is released into the extracellular medium and/or attached to the outer membrane. Having, this common feature of the CTD as an export signal in secretion of the major virulence factors by two of the primary 
pathogens has built a curiosity to investigate and study the significance and underlying mechanism. In the recent studies the structure of the recombinant CTD of RgpB gingipain was published which revealed the CTD as a stable dimer with their strands swapped [95]. Hence, in this study we would like to expand the previous data by showing that the energy released during the process of dimerization after CTD cleavage at the outer membrane is essential for the export of the protein to the bacteria outer surface for the attachment. Identification of specific amino acids that prevent the function of the CTD by causing hindrance to the dimer formation was our primary aim in the current study. Taking the crystal structure of rCTD of RgpB and PorZ (PG1604), which in contrast to the general proposition doesn't undergo the cleavage of CTD during the translocation across the outer membrane [96], 4 single point mutations (A637R, G699R, A719R, R721E) were proposed on the CTD of RgpB that might prevent the export of the protein from the periplasm. The gene constructs bearing mutations were electroporated into P.gingivalis strains to proceed with purification and characterization studies. Mutations of glycine to arginine (G699R) and alanine to arginine (A719R) prevented the export of RgpB towards outer membrane, which was confirmed through cumulative data from a gingipain activity assay, the phenotype on the blood agar plate and western blot analysis. Also, with respect to RgpB gingipain the native form with the prodomain (ProRgpB) and the recombinant form of its Ig-CTD with the factor Xa cleavage site (IEGRAA) inserted, with and without mutations (A719R, R721E), were purified. These purified proteins will be used to check the formation of the dimer after cleaving with factor $\mathrm{Xa}$ through crystallization and microcalorimetry. 


\subsection{Materials and Methods:}

Chemical Reagents: The Mutagenesis kit used in this study was Quick Change Lightening Site Directed Mutagenesis Kit from Agilent. The matrix for affinity chromatography included Nickel Sepharose 6 fast flow and Glutathione Sepharose fast flow that were purchased from GE Health Care. Primers were designed using the clone manager software and ordered from Sigma. The other reagents used in this study were Protein inhibitor Cocktail (P8465) and TLCK (T2754) from Sigma, 4,4-Dithiopyridine from Acros Organics, Precision plus Kaleidoscope standard molecular weight marker from BioRad.

\section{Mutagenesis and strain construction:}

Mutants construction with W83 $\Delta$ RgpA strain: A quick change lightening site directed mutagenesis kit was used to mutate the wild type plasmid p6HRgpBt-A [95] with A637R, G699R, A719R, R721E using the primers shown in Table 1. Later the plasmid was electroporated into the W83 $\triangle \mathrm{RgpA} P$. gingivalis strain for chromosomal integration of the mutated regions into the $P$. gingivalis genome via a double homologous recombination event. The mutants were further verified by DNA sequencing of the pertinent regions of the genome from PCR products. Total 4 mutants were made for the purpose of selection and characterization. 
A

>full length RgpB

MKKI.

NQLPFIFDVACVN

GDFLYNVPCFAEALMRAQKDGKPTGTVA I IAST INQSWAS PMRGQDEMNE I LCEKHPNN IKRTFGGVTMNGMFAMVEKYKKDGEKMLDTWTVFGDPS LLVRTLVPTKMQVTAPANISA SAQTFEVACDYNGAIATLSDDGDMVGTA IVKDGKAI I KLNES IADETNLTLTVVGYNKV TVIKDVKVEGTS IADVANDKPYTVAVSGKTITVESPAAGLTIFDMNGRRVATAKNRMVF EAQNGVYAVRIATEGKTYTEKVIVK

B

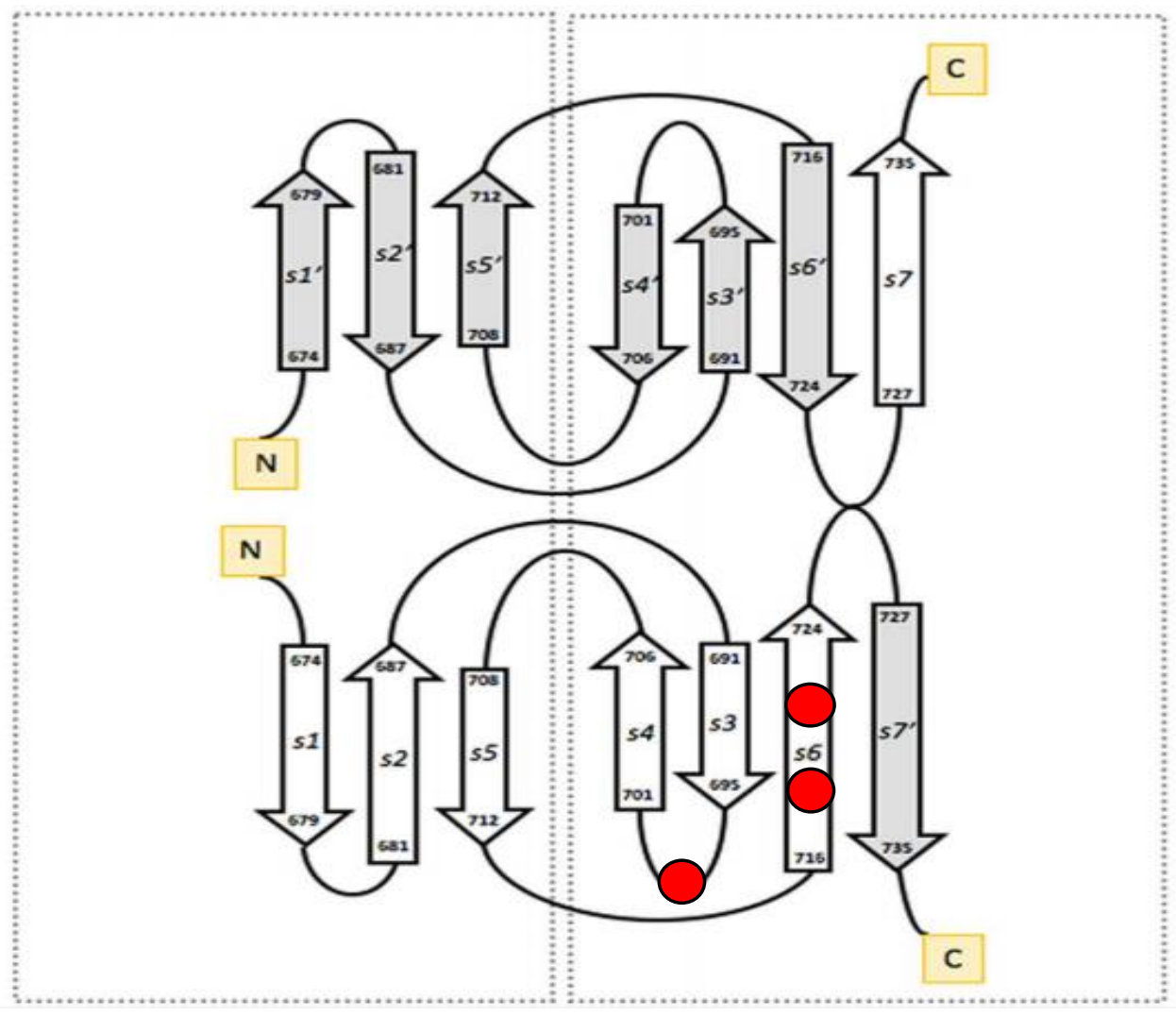

Fig 12: The location of predicted mutations on the CTD of RgpB in P.gingivalis.

A) The location of mutations A637R, G699R, A719R, R721E the rgpB gene sequence.

B) The location of mutations G699R, A719R, R721E on rCTD structure topology. 
Mutant construction with W83 $\Delta$ PorN ( $\Delta$ PG0266): A quick change lightening site directed mutagenesis kit was used to mutate the wild type plasmid pRgpB662iXa6HC449A [95] with A719R and R721E using the primers in Table 3. Later the plasmid was electroporated into the W83 $\triangle$ PorN $P$. gingivalis strain for chromosomal integration of the mutated regions into the $P$. gingivalis genome via a double homologous recombination event. Resistant colonies were selected using antibiotic selective media. The mutants were further verified by DNA sequencing of the pertinent regions of the genome from PCR product. 
Table 3: List of primers used in this study.

\begin{tabular}{|l|l|}
\hline Primers names & Primer sequence \\
\hline RgpBA719R_F & CAAAACGGCGTGTATCGCGTTCGCATCGCTACTGAAGGC \\
\hline RgpBA719R_R & GCCTTCAGTAGCGATGCGAACGCGATACACGCCGTTTTG \\
\hline RgpBR721E_F & CAAAACGGCGTGTATGCCGTTGAGATCGCTACTGAAGGC \\
\hline RgpBR721E_R & GCCTTCAGTAGCGATCTCAACGGCATACAC \\
\hline RgpBA637R_F & CAAATTAAATGAGAGTATCCGTGATGAAACGAACTTG \\
\hline RgpBA637R_R & CAAGTTCGTTTCATCACGGATACTCTCATTTAATTTG \\
\hline RgpBG699R_F & GATCTTCGATATGAACCGCCGTGTAGCTACTG \\
\hline RgpBG699R_R & CAGTAGCTACACGACGGCGGTTCATATCGAAGATC \\
\hline
\end{tabular}


Table 4: List of the P.gingivalis strains used in this study.

\begin{tabular}{|l|l|}
\hline Strain names & Ref \\
\hline W83 & {$[95]$} \\
\hline$\Delta$ RgpA & {$[95]$} \\
\hline$\Delta$ RgpA/RgpB A637R & This study \\
\hline$\Delta$ RgpA/RgpB G699R & This study \\
\hline$\Delta$ RgpA/RgpB A719R & This study \\
\hline$\Delta$ RgpA/RgpB R721E & This study \\
\hline$\Delta$ PorN ( $\Delta$ PG0266) & {$[95]$} \\
\hline W83 $\Delta$ PorNRgpB662iXa6H C449 A719R & This study \\
\hline W83 $\Delta$ PorNRgpB662iXa6HC449A R721E & This study \\
\hline W83 $\Delta$ PorNRgpB662iXa6H C449A & {$[95]$} \\
\hline
\end{tabular}


Expression and purification of a recombinant protein: The plasmid pRgp662iXa [95] and $\mathrm{pRgP} 665 \mathrm{~s} X \mathrm{a}$ [95] expression vectors encoding recombinant fusion proteins alone (Wild Type) and with mutations (r662iXaA719R/ R721E, r665sXaA719R/R721E) were transformed into E. coli strain BL21 (DE3) (New England Biolabs, Ipswich, MA). Transformed E. coli hosts were grown in $\mathrm{LB}$ medium at $37^{\circ} \mathrm{C}$ to an $\mathrm{OD}_{600}$ ranging from 0.75 to 1 and cooled for $30 \mathrm{~min}$ at $4{ }^{\circ} \mathrm{C}$, and expression of recombinant proteins was induced by the addition of $0.125 \mathrm{mM}$ isopropyl-1-thio- $\beta$-D-galactopyranoside (IPTG). After culture for $16 \mathrm{~h}$ at $20^{\circ} \mathrm{C}$, cells were harvested by centrifugation $\left(15 \mathrm{~min}, 6,000 \times \mathrm{g}, 4^{\circ} \mathrm{C}\right)$, resuspended in PBS (15 $\mathrm{ml}$ per pellet from 11 of culture), and subsequently lysed by sonication (cycle of $1 \times 15 \mathrm{~s}$ pulses at a power output of $70 \%$ per pellet from 11 of culture). The cell lysates were clarified by centrifugation $\left(1\right.$ hour, $\left.50,000 \times \mathrm{g}, 4^{\circ} \mathrm{C}\right)$, filtered through a $0.45 \mu \mathrm{m}$ syringe filter, and loaded onto a glutathione-Sepharose 4 Fast Flow column (bed volume, $5 \mathrm{ml}$ ) equilibrated with PBS at $4^{\circ} \mathrm{C}$. Later $10 \mathrm{ml}$ of PBS containing $100 \mu \mathrm{l}$ of Prescision protease stock solution $(1 \mathrm{U} / \mathrm{ml})$ was applied to the column and incubated for $40 \mathrm{~h}$ at $4^{\circ} \mathrm{C}$. GST was then eluted using $50 \mathrm{mM}$ Tris- $\mathrm{HCl}, \mathrm{pH}$ 8.0, supplemented with 10 $\mathrm{mM}$ reduced glutathione. Protein concentration was determined by measurement of absorbance at $280 \mathrm{~nm}$ using a Nanodrop spectrophotometer. The purity of the proteins was verified by SDS-PAGE electrophoresis using 4-12\% Bis-Tris gels (Invitrogen, Thermo fisher scientific). Gels were stained with simply blue safe stain (Novex life technologies). 
Expression and the purification of native proteins: Strains $\Delta 266$ ProRgpB $662 \mathrm{iXa}$ C449A, 2266 ProRgpB 662iXa C449A A719R, 2266 ProRgpB 662iXa C449A R721E were grown to late exponential phase $\left(\mathrm{OD}_{600}=1.2-1.3\right)$ and bacterial cells were collected by centrifugation $(8,000 \times \mathrm{g}, 30 \mathrm{~min})$ from a 21 culture. Cells were washed and resuspended (15 $\mathrm{ml}$ per pellet from 11 of culture) in $\mathrm{Ni}^{2+}$-Sepharose binding buffer $(20 \mathrm{mM}$ sodium phosphate buffer, $500 \mathrm{mM} \mathrm{NaCl}, 20 \mathrm{mM}$ imidazole, $\mathrm{pH}$ 7.4, supplemented with $0.02 \%$ $\mathrm{NaN}_{3}, 1.5 \mathrm{mM}$ 4,4-dithiodipyridine, $1.5 \mathrm{mM}$ TLCK, and Protein inhibitor cocktail (5 ml cocktail/500 $\mathrm{ml}$ bacteria sample)) and lysed by sonication (cycle of $1 \mathrm{x} 10 \mathrm{~s}$ pulses at a power output of $20-30 \%$ per pellet from 11 of culture. Insoluble cell debris were removed by ultracentrifugation $\left(100,000 \times \mathrm{g}, 1 \mathrm{~h}, 4{ }^{\circ} \mathrm{C}\right)$ and clarified supernatant was applied onto a column with $\mathrm{Ni}^{2+}$-Sepharose 6 Fast Flow matrix (1.5 ml) (GE Healthcare) pre-equilibrated with Nickel Sepharose binding buffer. After extensive washing (with Nickel Sepharose binding Buffer supplemented with 40mM imidazole), bound proteins were eluted with Nickel Sepharose binding buffer supplemented with $500 \mathrm{mM}$ imidazole. Final purification of ProRgpB variants was accomplished by size exclusion chromatography on a Superdex 200 column equilibrated with $20 \mathrm{mM}$ Tris, $50 \mathrm{mM} \mathrm{NaCl}, 5 \mathrm{mM} \mathrm{CaCl}_{2}$, and $0.02 \% \mathrm{NaN}_{3}$, pH 7.5 using the ÄCTA Purifier system. Fractions containing ProRgpB were pooled together, concentrated by ultrafiltration (30 kDa cut-off membrane) and dialyzed against $20 \mathrm{mM}$ BisTris, $150 \mathrm{mM} \mathrm{NaCl}, 5 \mathrm{mM} \mathrm{CaCl} 2$, and $\mathrm{pH} 6.8$ with $0.02 \% \mathrm{NaN}_{3}$. Protein concentration of the final samples was determined by BCA Assay (Sigma, St Louis, MO, USA). Gels were stained with simply blue safe stain (Novex life technologies, LC6065). 
Gingipain activity assay: The Gingipain activity assay was performed to measure the gingipain activity in culture samples. The amidolytic activities of Rgp and Kgp gingipains were assessed by hydrolysis of chromogenic substrates: Bz-Arg-pNA (for Rgp) and AcLys-pNA (for Kgp) respectively (Bachem). In a 96-well plate, samples (in triplicates) were pre-incubated in assay buffer (200 mM Tris- $\mathrm{HCl}, 100 \mathrm{mM} \mathrm{NaCl}, 5 \mathrm{mM} \mathrm{CaCl}_{2}, \mathrm{pH} 7.6$; freshly supplemented with L-cysteine to $10 \mathrm{mM}$ ) for $2 \mathrm{~min}$ at $37^{\circ} \mathrm{C}$ prior to the addition of specific substrate to the final concentration of $0.5 \mathrm{mM}$. The total volume in the well after adding the substrate was to be $200 \mu$ l. After incubation the substrate was added to the well and the rate of formation of p-nitroanilide (pNA) was measured as an increase of absorbance at $405 \mathrm{~nm}$ at $37^{\circ} \mathrm{C}$ for $5 \mathrm{~min}$ on a spectrophotometer (SpectraMax M5, Molecular Devices). Enzymatic analysis was performed for whole cell cultures adjusted to OD600 - 1.0, cells alone and media alone. Equal volumes of samples of all the strains were applied (10 $\mu 1$ for Kgp and $5 \mu 1$ for Rgp assay) and specific activity was measured as a function of density, and time per $\mu \mathrm{l}(\mathrm{mOD} / \mathrm{min} / \mu \mathrm{l})$. Later, total $\mathrm{Rgp} / \mathrm{Kgp}$ activity in the W83 $\triangle$ RgpA strain served as a positive control and was taken as $100 \%$, allowing relative cross-comparison between independent experiments and statistical analysis.

SDS PAGE: Sample Prep: $\mathrm{x} \mu \mathrm{l}$ of the sample was taken into and ependorff and $\mathrm{dH}_{2} 0$ was added to it to make a final volume of $30 \mu$. To this volume TLCK was added at a final concentration of $2 \mathrm{mM}$ and incubated at room temperature for $10 \mathrm{~min}$. Later $10 \mu \mathrm{l}$ of loading dye (NuPAGE LDS Sample Buffer) was added to the sample and heated at $100^{\circ} \mathrm{C}$ for $5 \mathrm{~min}$. Finally $1 \% \mathrm{BME}$ was added to the sample and reheated at $100^{\circ} \mathrm{C}$ for $10 \mathrm{~min}$.

Gel Electrophoresis: 4-12\% Bis-Tris gel was run with the prepared samples at 150V for 1 $\mathrm{h}$ in 1x MES Buffer at room temperature. 
Western Blot: After the SDS-PAGE gels were immediately transferred onto a nitrocellulose membrane and were run at $100 \mathrm{~V}$ for $1 \mathrm{~h}$. Later the membranes were stained using Ponceau S (Sigma) to check if the transfer was done properly. The stain was then removed by washing the membranes with washing buffer $(20 \mathrm{mM}$ Tris, $0.5 \mathrm{M} \mathrm{NaCl}, 0.1 \%$ Tween 20, pH 7.5). These membranes were then blocked with 5\% skim dry milk and left on shaker for $1 \mathrm{~h}$ at $37^{\circ} \mathrm{C}$. Later the membranes were washed and incubated with primary antibodies (incubated in blocking solution for $30 \mathrm{~min}$ at room temp before adding) at 1 : 20,000 for Rgp (GP1 Rabbit IgG polyclonal) and 1 : 1,000 for Kgp (monoclonal 7B9F10F6) at room temperature for $1 \mathrm{~h}$ on shaker. After that the membranes were washed again and left for incubation with secondary antibodies (incubated in blocking solution for $30 \mathrm{~min}$ at room temperature before adding) at $1: 10,000$ for Rgp (Rabbit IgG A3687 Sigma) and $1: 20,000$ for Kgp (IgG mouse A4312 Sigma) at room temperature for $1 \mathrm{~h}$. Finally, after washing the membranes they were developed with the alkaline phosphatase substrate (Bio-Rad Cat. \#170-6432) to visualize the bands of interest. 


\subsection{Results:}

Expression and purification of recombinant and native proteins: The three native proteins in W83 P.gingivalis ( $\triangle$ PorN RgpB6H 662iXa C449A WT, $\Delta$ PorN RgpB6H 662iXa C449A A719R, $\Delta$ PorN RgpB 662iXa C449A R721E) with a molecular weight of 75-80 kDa and 6 recombinant proteins in BL21 E.coli (IgSFCTD 662iXA WT, IgSFCTD 662iXa, IgSFCTD 662iXA R721E, IgSFCTD 665sXa WT, IgSFCTD 665sXa A719R, IgSFCTD 665sXa R721E) with a molecular weight of $20 \mathrm{kDa}$ were expressed and purified in homogenous forms (Figure 13). These proteins comprise of insertions and substitutions with a Factor Xa (IEGRAA) cleavage site between the Ig and CTD domains. This site when cleaved with Factor Xa will simulate the cleavage of CTD at the outer membrane in case of $P$. gingivalis. The result in case of wild type without mutations is expected to form a CTD dimer while with the mutations (A719R and R721E) that are proposed to prevent dimerization of the CTD. The proteins without mutations will be taken as a positive control. This hypothesis will be later checked on size exclusion chromatography and microcalorimetry for further confirmation. 


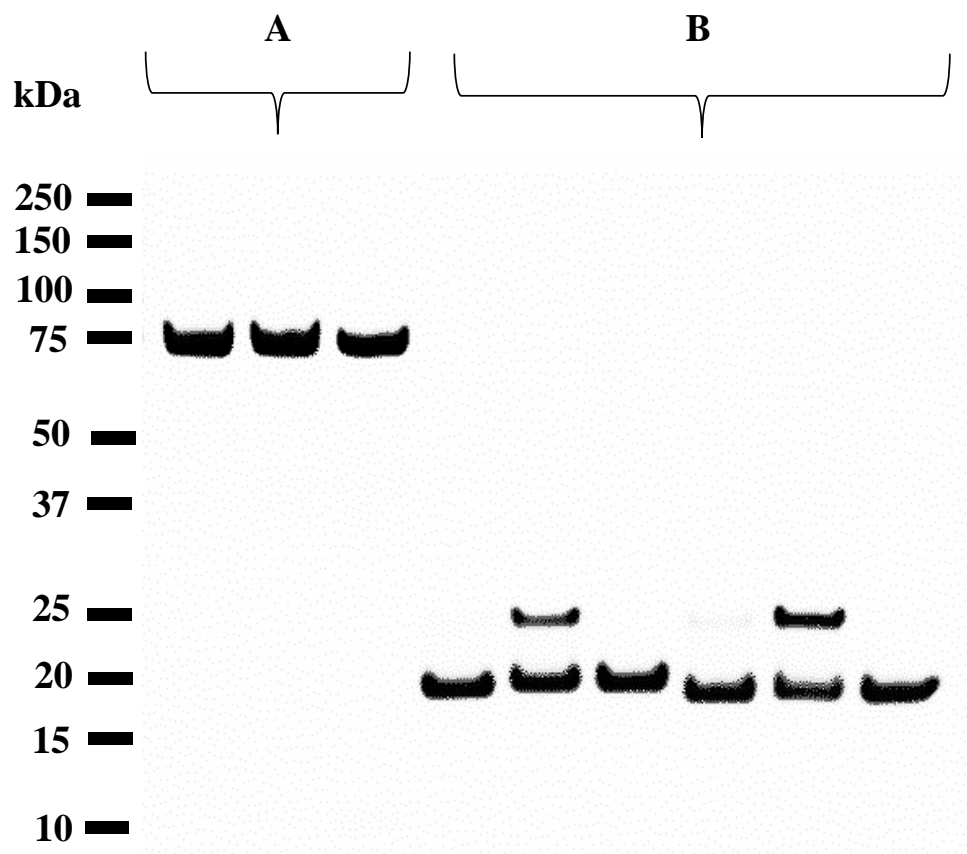

Fig 13: Purified proRgpB native proteins and its recombinant fragment, Ig-CTD tandem. A) The purified native proteins after gel filtration by Superdex 200 prep grade Hiload 16/60. B) The purified recombinant (IgSFCTD) proteins after gel filtration by Superdex 75 prep grade Hiload 16/60. 1) Molecular weight marker, 2) $\Delta$ PorN RgpB6H 662iXa C449A WT, 3) $\Delta$ PorN RgpB6H 662iXa C449A A719R, 4) $\Delta$ PorN RgpB 662iXa C449A R721E, 5) IgSFCTD 662iXA WT, 6) IgSFCTD 662iXa, 7) IgSFCTD 662iXA R721E, 8) IgSFCTD 665sXa WT, 9) IgSFCTD 665sXa A719R, 10) IgSFCTD 665sXa R721E. 
Characterization of the $\Delta \operatorname{RgpA}$ mutants with point mutations: Four point mutations A637R, G699R, A719R, R721E were separately introduced into the master plasmid. After confirming the sequence the 4 plasmids carrying a single amino acid mutation were electroporated into the W83 $\Delta$ RgpA strain and plated on blood agar plates with selective antibiotics (Chloramphenicol+Tetracycline). The selected colonies were sequenced to confirm correctness of the gene-swap and were then cultured for further characterization by gingipain activity assay and western blots to find if any of the four mutations were capable of hampering the ability of the CTD to export the protein across the outer membrane. The parenteral strain W83 $\triangle$ RgpA and wild type strain W83 were taken as the positive controls in each experiment.

\section{a.) Phenotype on the Blood Agar Plates:}

All the 4 mutants $(\Delta \mathrm{RgpA}$ /A637R, $\Delta \mathrm{RgpA} / \mathrm{G} 699 \mathrm{R}, \quad \Delta \mathrm{RgpA} / \mathrm{A} 719 \mathrm{R}$, $\Delta \mathrm{RgpA} / \mathrm{R} 721 \mathrm{E})$ along with the parenteral strain $(\triangle \mathrm{RgpA})$ and the wild type strain (W83) were cultured in the liquid media till they reached stationary phase $\left(\mathrm{OD}_{600^{-}}\right.$ 1.5) under the anaerobic conditions. Later all the 6 strains were plated on the blood agar plates and left for incubation in the anaerobic jar at $37^{\circ} \mathrm{C}$. Every single day the plates were observed for the change in the pigmentation dependent on the release

of gingipains (Kgp, RgpA, RgpB) activity. Apparently, the wild type and parenteral strains appeared dark in pigmentation from day 2 while the bacteria with A637R mutation showed partial dark pigmentation. However, in case of bacteria possessing other mutations including G699R, A719R and R721E colonies initially appeared grayish-white in color but turned dark by the end of the $5^{\text {th }}$ day. Since, 
gingipains are the factors, which are responsible for the dark pigmentation the results clearly depict the possibility of one of the gingipains (RgpB or Kgp) not being secreted. The slow progression of the pigmentation could be due to the secretion of only low amount of gingipains. Here we assume the lack of dark pigmentation in the beginning could be due to the absence of RgpB secretion while the eventual dark pigmentation is due to the presence of only Kgp (Figure 14).

A

B

C

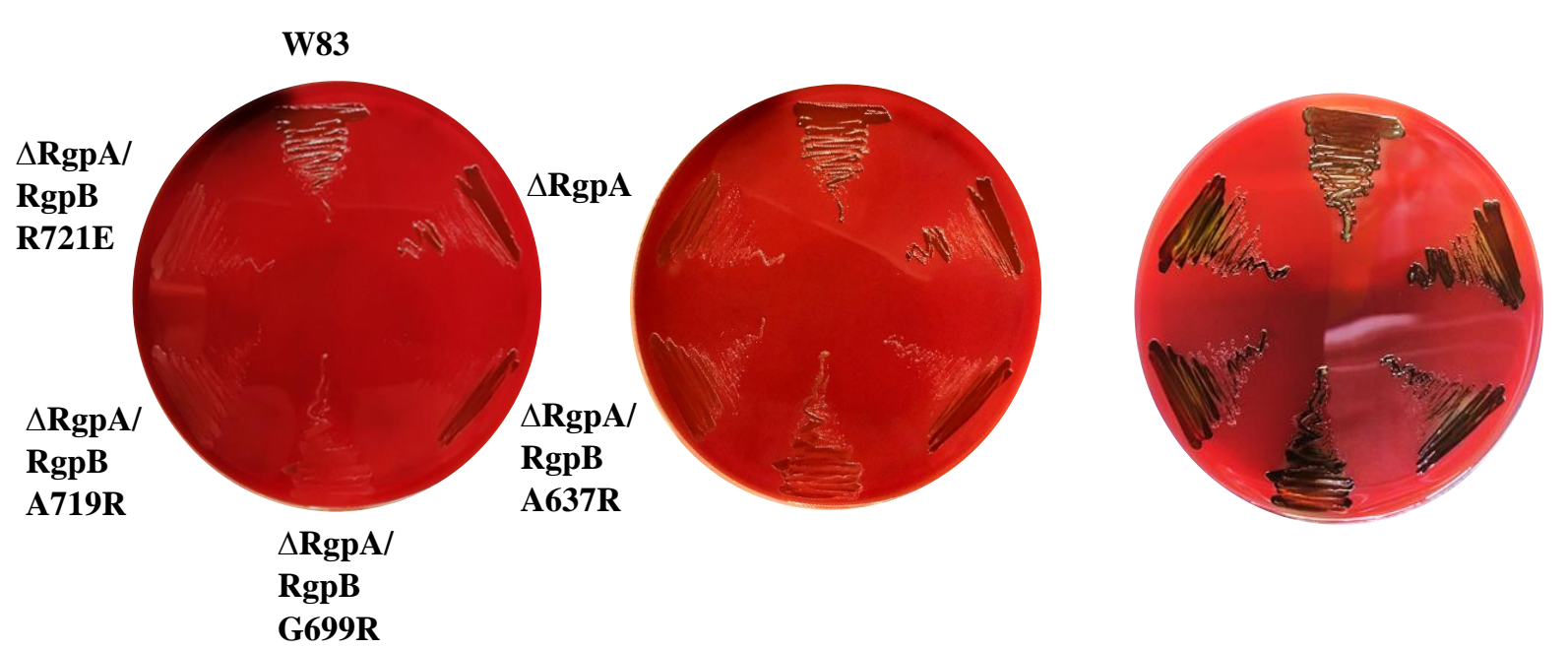

Fig 14: Phenotype of the $P$. gingivalis strains on Blood Agar Plate.

P. gingivalis strains W83, $\Delta$ RgpA, $\Delta$ RgpA/RgpBA637R, $\Delta$ RgpA/RgpBG699R, $\triangle \mathrm{RgpA} / \mathrm{RgpBA} 719 \mathrm{R}, \Delta \mathrm{RgpA} / \mathrm{RgpBR} 721 \mathrm{E}$ were plated on a blood agar plate without antibiotic and incubated in the anaerobic jar at $37^{\circ} \mathrm{C}$ for 1 week. The color transition on the plate was visualized on A) Day 2 B) Day 4 and C) Day 6. 
b.) Gingipain activity assay: The activity of gingipains was measured in all mutant strains, including the $\triangle \operatorname{rgpA}$ mutant (RagAC), and shown in relation to the activity expressed by the $\triangle \operatorname{rgp} A$, of which the activity was arbitrarily taken as $100 \%$. We observed a complete knock down of the Rgp activity in strains carrying G699R and A719R mutations within $\operatorname{rgpB}$, while there was a very minimal activity expressed by A637R and R721E mutant strains. In contrast, the Kgp activity was almost same in all mutant strains with a very small difference in comparison to the parental strain indicating a minimal effect on expression, processing, activation and secretion of Kgp (Figure 15). This data was concurrent to the phenotype changes on the plate which is yet to be confirmed by western blots analysis of subcellular localization of RgpB in all mutant strains. 


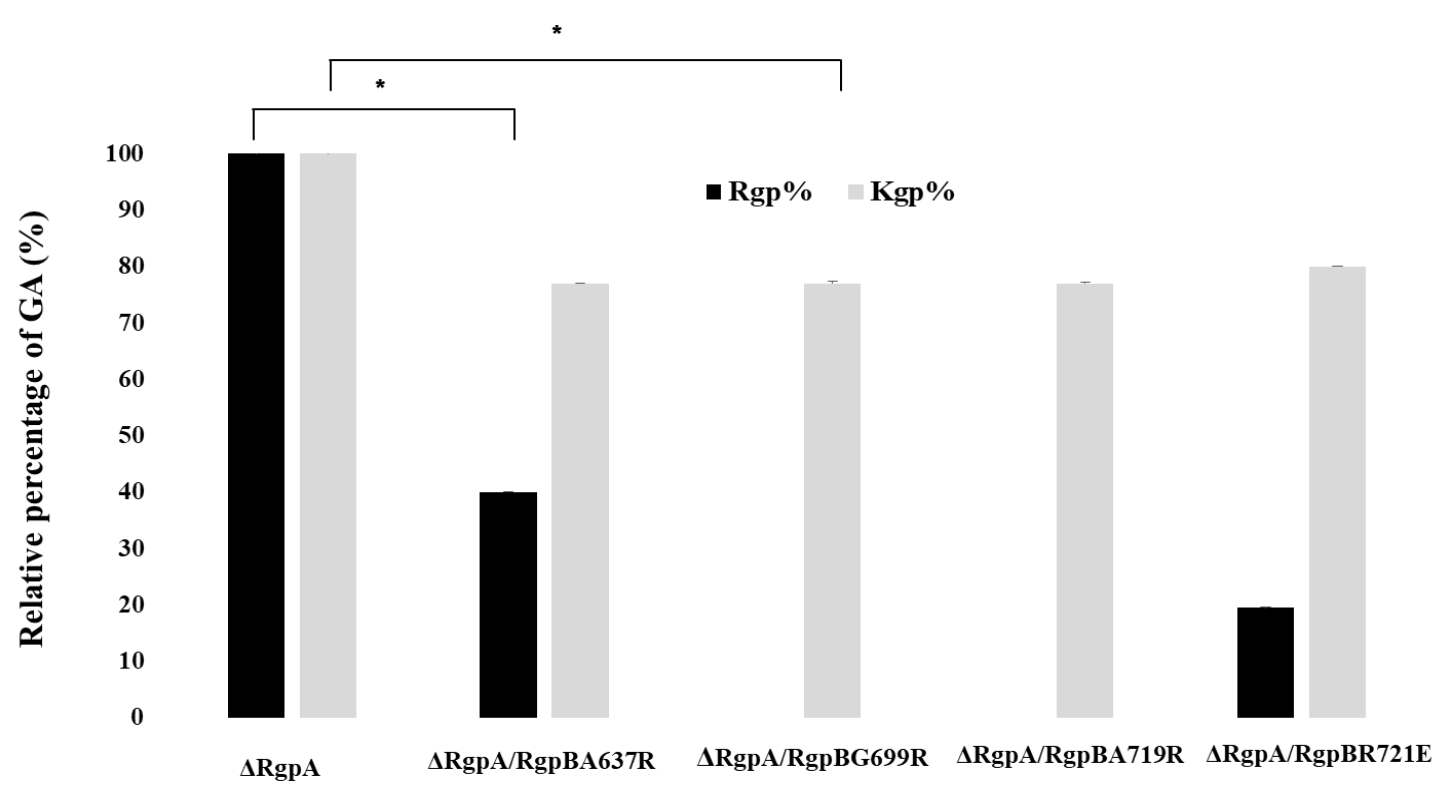

Fig 15: Gingipain activity assay.

Cultures of all the $P$. gingivalis strains W83, $\Delta$ RgpA, $\Delta$ RgpA/RgpBA637R, $\triangle \mathrm{RgpA} / \operatorname{RgpBG} 699 \mathrm{R}, \Delta \mathrm{RgpA} / \operatorname{RgpBA} 719 \mathrm{R}, \Delta \mathrm{RgpA} / \mathrm{RgpBR} 721 \mathrm{E}$ were grown till the late exponential phase. The whole culture samples were collected and adjusted to $\mathrm{OD}_{600}$ 1.0. Later the samples were assayed for Arg- $\mathrm{X}$ and Lys- $\mathrm{X}$ activity using the chromogenic substrates as described in the methods.

* $\mathrm{p}<0.005$ 
c.) Western Blot analysis: The initial analysis was done with the whole culture, cells alone and media alone. Antibodies against Kgp and Rgp were used to check if the proteins were actually produced within the bacteria. W83 and $\Delta \mathrm{RgpA}$ strains were taken as a positive control in this experiment. In case of Kgp the expression was normal in all the 4 mutants (A637R, G699R, A719R, and R721E) and similar to the positive control with respect to expression level and processing. In contrast the expression of $\operatorname{RgpB}$ varied in all 4 mutants compared to the positive control. RgpB in case of the A637R was unprocessed and non-glycosylated (Figure 16). These posttranslational modifications usually happen when a mutein is exported across the outer membrane and the CTD is cleaved off. The minimal amount of the gingipain activity present might be due to the partial leakage of processed RgpB left intact with the cells. It can be appreciated as the faint band between $37 \mathrm{kDa}$ and $50 \mathrm{kDa}$. Similarly, also in case of the R721E mutant strain a band $(\sim 50 \mathrm{kDa})$ apparently processed porRgpB leaked into the media. In contrast to the above two mutant strains, mutations in G699R and A719R caused accumulation of the unprocessed form of RgpB which complies with the results of the lack of gingipain activity and hindered in time pigmentation of colonies grown on the agar blood plate. 

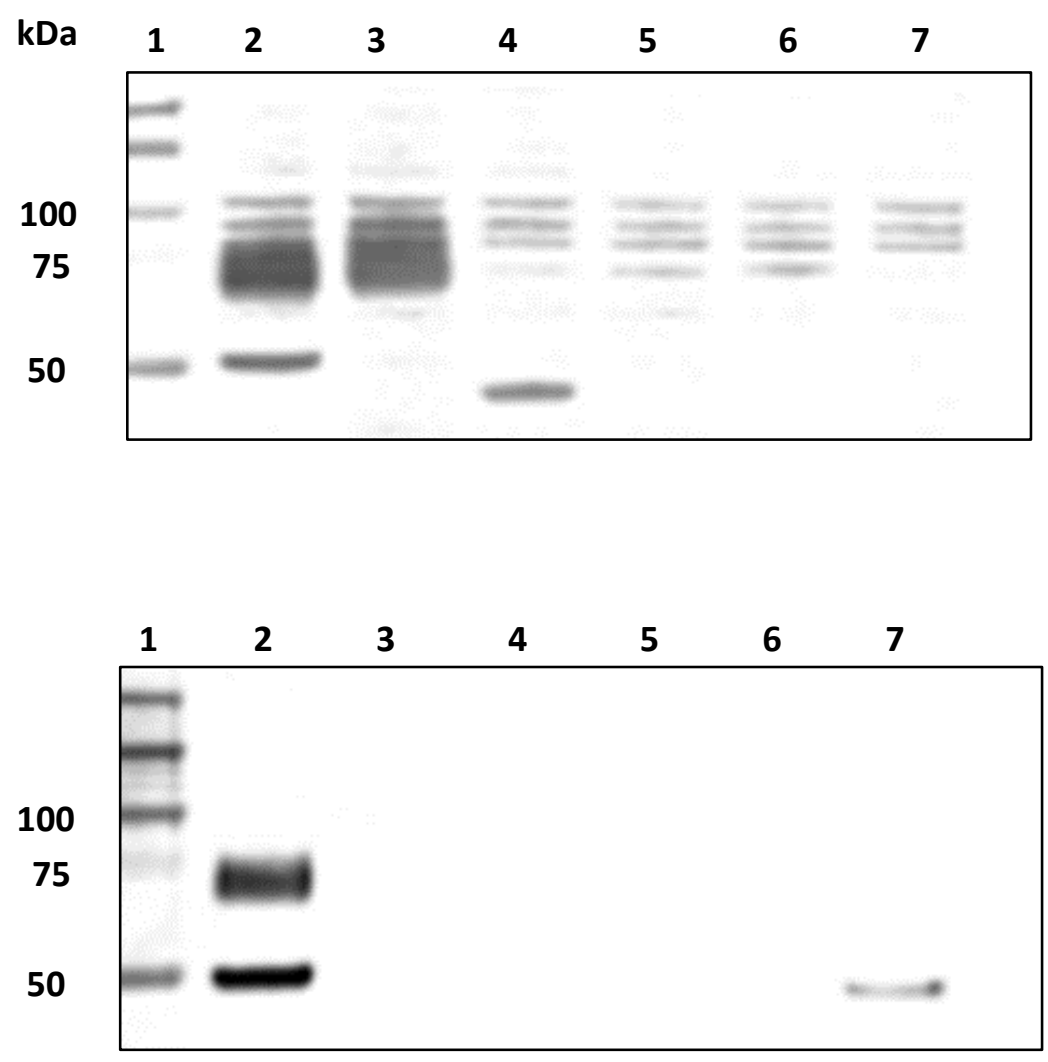

B

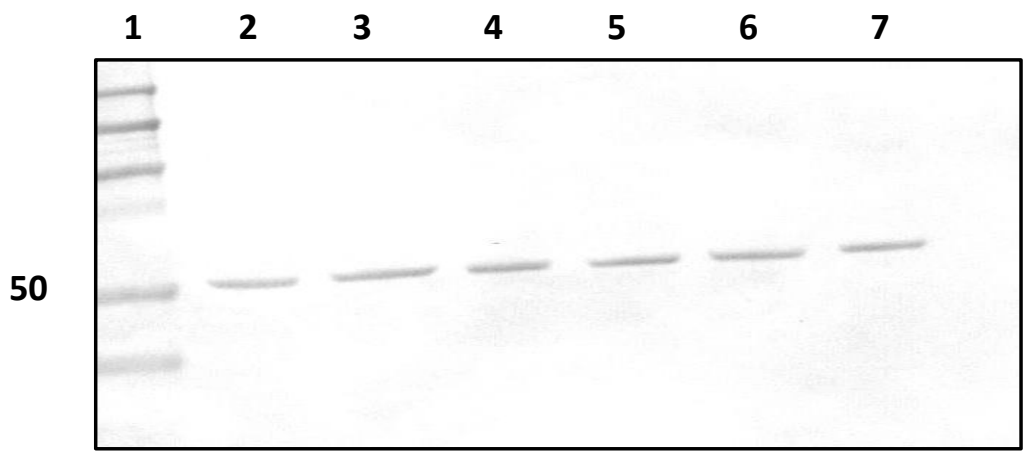

C

Fig 16: Comparison of RgpB phenotype expressed by wild-type $P$. gingivalis W83 and the mutant strains. The liquid cultures of all the strains were grown till late exponential phase and samples were collected with an adjusted $\mathrm{OD}_{600}$ 1.0. The samples of whole culture, cells only and the supernatant/media only from the culture sample of adjusted $\mathrm{OD}_{600}$ were subjected to SDS-PAGE and then transferred onto a nitrocellulose membrane. Later the membranes were incubated with the anti-Kgp and anti-Rgp antibodies to visualize the processing of the gingipains within these strains. A) Rgp antibodies against samples of cells only, B) Rgp antibodies against the samples of media only, C) Kgp antibodies against the samples of whole cell culture. 1) Molecular weight marker, 2) W83 strain, 3) $\Delta$ RgpA strain, 4) $\Delta \operatorname{RgpA} / \operatorname{RgpBA637R,~5)~} \Delta \operatorname{RgpA} / \operatorname{RgpBG699R,~6)~}$ $\triangle \operatorname{RgpA} / \operatorname{RgpBA719R} 7) \Delta \operatorname{RgpA} / \operatorname{RgpBR721E}$. 
4.4 Discussion: Gingipains are the major virulence factors identified in $P$. gingivalis which is the keystone pathogen associated with the adult periodontitis. The structure of these proteins possess the conserved CTD that is found essential for their secretion through T9SS. Similarly, the newly identified proteolytic enzymes named KLIKK proteases of $T$. forsythia bearing the CTD within their structure are also found to be secreted through this system. Taking into account the significance of CTD in the translocation of the major virulence factors in $P$. gingivalis and other Gram-negative pathogens the study of its underlying mechanism has become essential. In this study the first step was to identify the specific amino acids that were crucial for this property of the CTD. To investigate the function of the CTD, the PorZ (PG1604) structure was taken into consideration and 4 pointmutations were proposed on the CTD of RgpB in the background of the RgpA-knockout P. gingivalis strain. Out of the 4 mutations G699R and A719R successfully prevented the export of ProRgpB without causing hindrance to expression, processing and secretion of Kgp. These observations were deduced from the phenotype characterization of the mutant strains in comparison with the wild type and the parenteral strains. Although, the A637R and R721E mutations were partially successful in preventing the translocation of the protein, minimal activity was detected in the mutant strains and corroborated by western blot analysis showing a lower band equivalent to the processed form of RgpB. From, this data we can infer that mutation within the swapped strands of CTD could have blocked the formation of the dimer. Also, there is a possibility that altering the amino acids especially the positive and negative charges around the domain could have possibly altered the structure of the CTD especially with the hydrophobic and hydrophilic nature of the domain. To understand the reason behind this structural instability we wanted to investigate the 
hypothesis of CTD dimerization for which the native and recombinant proteins were purified with and without mutations. In, further studies these proteins with the factor Xa the Factor Xa cleavage site engineered between Ig and CTD domains of these RgpB variants will be cleaved by FXa. Measuring the energy changes using microcalorimetry during this very specific proteolytic event which might prove the phenomenon of dimerization as a driving mechanism pertinent to the inherent function of the CTD in protein secretion via T9SS. Recent studies have reported a similar phenomenon of proteins dimerization in the periplasm of Gram-negative bacteria (Salmonella enterica serovar Typhimurium and Borrelia burgdorferi) through a domain located at the C-terminus of proteins forming a dimer [97]. Hence, these studies will certainly help in future to understand the mechanism of T9SS in P.gingivalis. 


\section{CHAPTER 5}

\section{CONCLUSION AND FUTURE PERSPECTIVES}

Periodontitis is the chronic inflammatory disease driven by the dysbiotic subgingival bacterial plaque. Proteolytic enzymes of the primary periodontal pathogens $(P$. gingivalis, T. forsythia, T. denticola) that belong to polymicrobial community of the oral cavity predominantly contribute in progression of the disease. Although, several inhibitors were designed against these proteases, till to date there is no single successful inhibitor that is profoundly efficient, in impeding the virulent properties of the bacteria. One of the reasons could be the lack in identification of specific targets, which on inhibition might result in minimization of the disease progression. Hence, characterization of the new virulence factors, especially the proteases of primary pathogens associated with the disease, has become imperative. Proteases are considered as the main targets for drug or vaccine discovery. A strong correlation between gingival protease activity and periodontal inflammation demands the need for identification of new inhibitors. Among them, extracellular proteases (ECPs) has become the main focus of study due to their differential expression in many pathophysiological processes. Although, several inhibitors were designed previously the success rate ranged from minimum to none. Lack of enzyme specificity and redundancy of functions of the proteolytic enzymes were some of the associated reasons. Hence, it has become imperative to identify specific targets, which are 
common in most of the pathogens associated with the disease that will aid in identification of inhibitors as future therapeutics [54, 94, 98-100].

In recent years putative virulence factors named KLIKK proteases were identified within the genome of the $T$. forsythia (one of the most understudied microrganism among the primary group of pathogens which include $P$. gingivalis, T. forsythia, T. denticola). Among, the KLIKK proteases karilysin and mirolase are well characterized. Hence, as a first approach in Chapter 2 we characterized yet another putative enzyme belonging to the KLIKK group of proteases, named as mirolysin. In the initial study the enzyme was expressed in E. coli as the full-length protein and the catalytic domain alone with the active and inactive forms and later purified using affinity chromatography. Further, the pure protein was biochemically characterized unveiling the property of autolytic processing by the cleavage of the N-terminal prodomain. This processing of the proprotein has resulted in the increased activity of the enzyme and aided in the maintenance of the stable form. This can be closely related to a similar mechanism found in $P$. gingivalis where the prodomain is used in maintaining the latency of the enzyme within the periplasm. This can only be confirmed by the structural studies of mirolysin forms with the N-terminal prodomain. From, the results of biological characterization the enzyme was found capable of cleaving several physiological substrates, like fibrinogen, insulin, fibronectin and LL37.

Due to the arginine specificity of the mirolysin enzyme was checked for the cleavage of PAR2 receptors on neutrophils. PAR2 receptors also called as Protease Activated Receptors belong to G-protein couple receptors that play an important role in inflammation. In the oral cavity they are found predominantly on neutrophils as signaling receptors. They are activated by the proteolytic cleavage at an arginine residue. Calcium 
immobilization experiments similar to that described in the previous paper on gingipains were performed on neutrophils with mirolysin [101-110]. Samples of the active mirolysin were taken for the test with the inactive mirolysin as a negative control and trypsin as a positive control. The signal with positive control trypsin has shown significant activation of neutrophils while there was no signal during incubation with the active and inactive catalytic domains of mirolysin. The lack of activation might be due to the low content of the active enzyme in our preparation of mirolysin. Indeed, when the enzyme was titrated with macroglobulin for the measurement of active site concentration we inferred that only $3 \%$ of the enzyme was active. This shows that we applied mirolysin at only $1 / 3$ of concentration of the positive control trypsin. Hence, active site enzyme concentration will be taken into consideration for all future experiments.

The unsuccessful attempts with the crystallization of the mirolysin protein for structural studies in chapter 2 has led to the work in Chapter 3 with the designing of new constructs to obtain the pure protein for the purpose of crystallization. These studies are anticipated to provide information pertaining to the mechanism of enzyme latency and its functions. Due to the formation of inclusion bodies the protein was not expressed in the soluble form. Hence, this work can be further proceeded by optimizing the conditions and by designing new constructs.

Although, several new pathogens were identified and studied pertaining to their virulence and synergism in periodontal diseases, the primary pathogens $(P$. gingivalis, $T$. forsythia, T. denticola) still seem to play a predominant role in asserting the virulence and colonization in the host. The common feature that is identified among the proteolytic enzymes secreted through T9SS by the primary pathogens include the C-terminal domain. 
Therefore, in chapter 4 we tried to focus on understanding the role of the CTD in virulence factor secretion. The CTD is the common domain present in all major virulence factors secreted through T9SS in these primary periodontal pathogens. Based on the crystal structure of the rCTD of RgpB gingipain resolved in the previous studies we hypothesized that the phenomenon of CTD dimerization is essential in the function of the CTD in secretion. As an export signal the CTD aids in the translocation of the cargo proteins through T9SS. Cleavage of the CTD at the outer membrane (OM) is required for these proteins to translocate across the OM. In case of PorZ (PG1604) this cleavage of CTD is not detected and is present in the secreted protein during translocation. The four point mutations, which were designed based of the rCTD of RgpB and PorZ (PG1604) highresolution atomic structure, successfully prevented the export of the RgpB gingipain across the OM. This certainly provides the knowledge which amino acids residues within the CTD that are essential for the export of cargo proteins. Although, A637R and R721E mutants have shown partial leakage of the processed protein, the G699R and A719R mutations completely blocked secretion causing accumulation of the protein in the periplasm in the unprocessed, inactive form. Also the recombinant Ig-CTD and native full-length RgpB were purified with and without mutations to check the phenomenon of dimerization. Results, from the preliminary experiments using glutaraldehyde cross linking revealed the formation of dimer in case of wild type IgCTD proteins and absence in the formation with A719R and R721E mutations (data not shown). In further experiments these proteins with the factor Xa cleavage site will be analyzed using microcalorimetry for the dimerization propensity of the CTD released by cleavage with factor Xa. The other observation inferred from the data of A637R suggests that alteration of amino acids could have disrupted the 
surface charge, which might destabilize the structure of the CTD domain. This in turn could have resulted in the partial processing of the enzyme as observed in the results. 


\section{REFERENCES}

1. Oral health in America: a report of the Surgeon General. J Calif Dent Assoc, 2000. 28(9): p. 685-95.

2. Petersen, P.E. and H. Ogawa, The global burden of periodontal disease: towards integration with chronic disease prevention and control. Periodontol 2000, 2012. 60(1): p. 15-39.

3. Abusleme, L., et al., The subgingival microbiome in health and periodontitis and its relationship with community biomass and inflammation. Isme j, 2013. 7(5): p. 1016-25.

4. $\quad$ Eke, P.I., et al., Prevalence of periodontitis in adults in the United States: 2009 and 2010. J Dent Res, 2012. 91(10): p. 914-20.

5. $\quad$ Frencken, J.E., et al., Global epidemiology of dental caries and severe periodontitis - a comprehensive review. J Clin Periodontol, 2017. 44 Suppl 18: p. S94-s105.

6. Hernandez, M., et al., Host-pathogen interactions in progressive chronic periodontitis. J Dent Res, 2011. 90(10): p. 1164-70.

7. Hyde, S., et al., Prevention of tooth loss and dental pain for reducing the global burden of oral diseases. Int Dent J, 2017. 67 Suppl 2: p. 19-25.

8. Benedyk, M., et al., Gingipains: Critical Factors in the Development of Aspiration Pneumonia Caused by Porphyromonas gingivalis. Journal of Innate Immunity, 2016. 8(2): p. 185-198.

9. Gao, S.G., et al., Presence of Porphyromonas gingivalis in esophagus and its association with the clinicopathological characteristics and survival in patients with esophageal cancer. Infectious Agents and Cancer, 2016. 11.

10. Tonetti, M.S. and T.E. Van Dyke, Periodontitis and atherosclerotic cardiovascular disease: consensus report of the Joint EFP/AAP Workshop on Periodontitis and Systemic Diseases. J Clin Periodontol, 2013. 40 Suppl 14: p. S24-9.

11. Gogeneni, H., et al., Increased infection with key periodontal pathogens during gestational diabetes mellitus. J Clin Periodontol, 2015. 42(6): p. 506-12.

12. Potempa, J., P. Mydel, and J. Koziel, The case for periodontitis in the pathogenesis of rheumatoid arthritis. Nature Reviews Rheumatology, 2017. 13(10): p. 606-620.

13. Branschofsky, M., et al., Secondary trauma from occlusion and periodontitis. Quintessence Int, 2011. 42(6): p. 515-22.

14. Gabrilska, R.A. and K.P. Rumbaugh, Biofilm models of polymicrobial infection. Future Microbiol, 2015. 10(12): p. 1997-2015.

15. Genco, R.J. and W.S. Borgnakke, Risk factors for periodontal disease. Periodontol 2000, 2013. 62(1): p. 59-94.

16. Hajishengallis, G. and R.J. Lamont, Dancing with the Stars: How Choreographed Bacterial Interactions Dictate Nososymbiocity and Give Rise to Keystone Pathogens, Accessory Pathogens, and Pathobionts. Trends Microbiol, 2016. 24(6): p. 477-89. 
17. Lamont, R.J. and G. Hajishengallis, Polymicrobial synergy and dysbiosis in inflammatory disease. Trends Mol Med, 2015. 21(3): p. 172-83.

18. Wright, C.J., et al., Microbial interactions in building of communities. Mol Oral Microbiol, 2013. 28(2): p. 83-101.

19. Suzuki, N., M. Yoneda, and T. Hirofuji, Mixed red-complex bacterial infection in periodontitis. Int J Dent, 2013. 2013: p. 587279.

20. Tan, K.H., et al., Porphyromonas gingivalis and Treponema denticola exhibit metabolic symbioses. PLoS Pathog, 2014. 10(3): p. e1003955.

21. Zhu, Y., et al., Porphyromonas gingivalis and Treponema denticola synergistic polymicrobial biofilm development. PLoS One, 2013. 8(8): p. e71727.

22. Potempa, J. and R.N. Pike, Corruption of Innate Immunity by Bacterial Proteases. Journal of Innate Immunity, 2009. 1(2): p. 70-87.

23. Potempa, J., et al., Gingipains, the major cysteine proteinases and virulence factors of Porphyromonas gingivalis: Structure, function and assembly of multidomain protein complexes. Current Protein \& Peptide Science, 2003. 4(6): p. 397-407.

24. Potempa, J. and J. Travis, Porphyromonas gingivalis proteinases in periodontitis, a review. Acta Biochimica Polonica, 1996. 43(3): p. 455-465.

25. Dashper, S.G., et al., Virulence factors of the oral spirochete Treponema denticola. J Dent Res, 2011. 90(6): p. 691-703.

26. Fenno, J.C., et al., The opdB locus encodes the trypsin-like peptidase activity of Treponema denticola. Infect Immun, 2001. 69(10): p. 6193-200.

27. Ishihara, K., et al., Characterization of the Treponema denticola prtP gene encoding a prolyl-phenylalanine-specific protease (dentilisin). Infect Immun, 1996. 64(12): p. 5178-86.

28. Schroder, N.W., et al., Involvement of lipopolysaccharide binding protein, CD14, and Toll-like receptors in the initiation of innate immune responses by Treponema glycolipids. J Immunol, 2000. 165(5): p. 2683-93.

29. Ksiazek, M., et al., KLIKK proteases of Tannerella forsythia: putative virulence factors with a unique domain structure. Front Microbiol, 2015. 6: p. 312.

30. Pei, J. and N.V. Grishin, Prediction of a caspase-like fold in Tannerella forsythia virulence factor PrtH. Cell Cycle, 2009. 8(9): p. 1453-5.

31. Eichinger, A., et al., Crystal structure of gingipain R: an Arg-specific bacterial cysteine proteinase with a caspase-like fold. Embo Journal, 1999. 18(20): p. 54535462.

32. Li, N. and C.A. Collyer, Gingipains from Porphyromonas gingivalis - Complex domain structures confer diverse functions. Eur J Microbiol Immunol (Bp), 2011. 1(1): p. 41-58.

33. McAlister, A.D., et al., Gingipain enzymes from Porphyromonas gingivalis preferentially bind immobilized extracellular proteins: a mechanism favouring colonization? J Periodontal Res, 2009. 44(3): p. 348-53.

34. O'Brien-Simpson, N.M., et al., Role of RgpA, RgpB, and Kgp proteinases in virulence of Porphyromonas gingivalis W5O in a murine lesion model. Infect Immun, 2001. 69(12): p. 7527-34.

35. Potempa, J., et al., Gingipains, the major cysteine proteinases and virulence factors of Porphyromonas gingivalis: structure, function and assembly of multidomain protein complexes. Curr Protein Pept Sci, 2003. 4(6): p. 397-407. 
36. Sroka, A., et al., Degradation of host heme proteins by lysine-and arginine-specific cysteine proteinases (gingipains) of Porphyromonas gingivalis. Journal of Bacteriology, 2001. 183(19): p. 5609-5616.

37. Benedyk, M., et al., Gingipains: Critical Factors in the Development of Aspiration Pneumonia Caused by Porphyromonas gingivalis. J Innate Immun, 2016. 8(2): p. 185-98.

38. Eichinger, A., et al., Crystal structure of gingipain R: an Arg-specific bacterial cysteine proteinase with a caspase-like fold. Embo j, 1999. 18(20): p. 5453-62.

39. Lourbakos, A., et al., Arginine-specific protease from Porphyromonas gingivalis activates protease-activated receptors on human oral epithelial cells and induces interleukin-6 secretion. Infect Immun, 2001. 69(8): p. 5121-30.

40. Sharma, A., Virulence mechanisms of Tannerella forsythia. Periodontol 2000, 2010. 54(1): p. 106-16.

41. Sroka, A., et al., Degradation of host heme proteins by lysine-and arginine-specific cysteine proteinases (gingipains) of Porphyromonas gingivalis. J Bacteriol, 2001. 183(19): p. 5609-16.

42. Travis, J., et al., Porphyromonas gingivalis proteinases as virulence factors in the development of periodontitis. J Periodontal Res, 1997. 32(1 Pt 2): p. 120-5.

43. Yongqing, T., et al., The lysine-specific gingipain of Porphyromonas gingivalis : importance to pathogenicity and potential strategies for inhibition. Adv Exp Med Biol, 2011. 712: p. 15-29.

44. Jusko, M., et al., A metalloproteinase mirolysin of Tannerella forsythia inhibits all pathways of the complement system. Molecular Immunology, 2013. 56(3): p. 311311.

45. Karim, A.Y., et al., A novel matrix metalloprotease-like enzyme (karilysin) of the periodontal pathogen Tannerella forsythia ATCC 43037. Biological Chemistry, 2010. 391(1): p. 105-117.

46. Ksiazek, M., et al., Mirolase, a novel subtilisin-like serine protease from the periodontopathogen Tannerella forsythia. Biological Chemistry, 2015. 396(3): p. 261-275.

47. Jusko, M., et al., A Metalloproteinase Mirolysin of Tannerella forsythia Inhibits All Pathways of the Complement System. J Immunol, 2015. 195(5): p. 2231-40.

48. Gorasia, D.G., et al., Porphyromonas gingivalis Type IX Secretion Substrates Are Cleaved and Modified by a Sortase-Like Mechanism. PLoS Pathog, 2015. 11(9): p. e1005152.

49. Green, E.R. and J. Mecsas, Bacterial Secretion Systems: An Overview. Microbiol Spectr, 2016. 4(1).

50. Lasica, A.M., et al., The Type IX Secretion System (T9SS): Highlights and Recent Insights into Its Structure and Function. Front Cell Infect Microbiol, 2017. 7: p. 215.

51. Nguyen, K.A., J. Travis, and J. Potempa, Does the importance of the C-terminal residues in the maturation of RgpB from Porphyromonas gingivalis reveal a novel mechanism for protein export in a subgroup of Gram-Negative bacteria? J Bacteriol, 2007. 189(3): p. 833-43. 
52. de Diego, I., et al., The outer-membrane export signal of Porphyromonas gingivalis type IX secretion system (T9SS) is a conserved C-terminal beta-sandwich domain. Scientific Reports, 2016. 6.

53. Slakeski, N., et al., C-terminal domain residues important for secretion and attachment of RgpB in Porphyromonas gingivalis. J Bacteriol, 2011. 193(1): p. 132-42.

54. Fox, C.H., New considerations in the prevalence of periodontal disease. Curr Opin Dent, 1992. 2: p. 5-11.

55. Hugoson, A., B. Sjodin, and O. Norderyd, Trends over 30 years, 1973-2003, in the prevalence and severity of periodontal disease. J Clin Periodontol, 2008. 35(5): p. 405-14.

56. Armitage, G.C., Periodontal diagnoses and classification of periodontal diseases. Periodontol 2000, 2004. 34: p. 9-21.

57. Otomo-Corgel, J., et al., State of the science: chronic periodontitis and systemic health. J Evid Based Dent Pract, 2012. 12(3 Suppl): p. 20-8.

58. Hajishengallis, G. and R.J. Lamont, Beyond the red complex and into more complexity: the polymicrobial synergy and dysbiosis (PSD) model of periodontal disease etiology. Mol Oral Microbiol, 2012. 27(6): p. 409-19.

59. Holt, S.C. and J.L. Ebersole, Porphyromonas gingivalis, Treponema denticola, and Tannerella forsythia: the "red complex", a prototype polybacterial pathogenic consortium in periodontitis. Periodontol 2000, 2005. 38: p. 72-122.

60. Guo, Y., K.A. Nguyen, and J. Potempa, Dichotomy of gingipains action as virulence factors: from cleaving substrates with the precision of a surgeon's knife to a meat chopper-like brutal degradation of proteins. Periodontol 2000, 2010. 54(1): p. 15-44.

61. Ishihara, K., Virulence factors of Treponema denticola. Periodontol 2000, 2010. 54(1): p. 117-35.

62. Nakajima, T., et al., Isolation and identification of a cytopathic activity in Tannerella forsythia. Biochem Biophys Res Commun, 2006. 351(1): p. 133-9.

63. Sato, K., et al., Identification of a new membrane-associated protein that influences transport/maturation of gingipains and adhesins of Porphyromonas gingivalis. $\mathrm{J}$ Biol Chem, 2005. 280(10): p. 8668-77.

64. Tomek, M.B., et al., The S-layer proteins of Tannerella forsythia are secreted via a type IX secretion system that is decoupled from protein O-glycosylation. Molecular Oral Microbiology, 2014. 29(6): p. 307-320.

65. Jusko, M., et al., A Metalloproteinase Mirolysin of Tannerella forsythia Inhibits All Pathways of the Complement System. Journal of Immunology, 2015. 195(5): p. 2231-2240.

66. Lopez-Pelegrin, M., et al., A novel mechanism of latency in matrix metalloproteinases. J Biol Chem, 2015. 290(8): p. 4728-40.

67. Rawlings, N.D., A.J. Barrett, and R. Finn, Twenty years of the MEROPS database of proteolytic enzymes, their substrates and inhibitors. Nucleic Acids Res, 2016. 44(D1): p. D343-50.

68. Tallant, C., et al., Molecular analysis of ulilysin, the structural prototype of a new family of metzincin metalloproteases. J Biol Chem, 2006. 281(26): p. 17920-8. 
69. Huesgen, P.F., et al., LysargiNase mirrors trypsin for protein C-terminal and methylation-site identification. Nat Methods, 2015. 12(1): p. 55-8.

70. Overgaard, M.T., et al., Complex of pregnancy-associated plasma protein-A and the proform of eosinophil major basic protein. Disulfide structure and carbohydrate attachment. J Biol Chem, 2003. 278(4): p. 2106-17.

71. Shimokawa Ki, K., et al., Matrix metalloproteinase (MMP)-2 and MMP-9 activities in human seminal plasma. Mol Hum Reprod, 2002. 8(1): p. 32-6.

72. Karim, A.Y., et al., A novel matrix metalloprotease-like enzyme (karilysin) of the periodontal pathogen Tannerella forsythia ATCC 43037. Biological chemistry, 2010. 391(1): p. 105-117.

73. Ksiazek, M., et al., Mirolase, a novel subtilisin-like serine protease from the periodontopathogen Tannerella forsythia. Biological chemistry, 2015. 396(3): p. 261-275.

74. Staniec, D., et al., Calcium regulates the activity and structural stability of Tpr, a bacterial calpain-like peptidase. Journal of Biological Chemistry, 2015. 290(45): p. 27248-27260.

75. Koregol, A.C., et al., Analysis of inorganic ions in gingival crevicular fluid as indicators of periodontal disease activity: A clinico-biochemical study. Contemporary clinical dentistry, 2011. 2(4): p. 278.

76. CRACOVIENSIA, F.M., Serum potassium, sodium and calcium levels in healthy individuals - literature review and data analysis. Folia medica Cracoviensia, 2014. 54(1): p. 53-70.

77. Jerabek-Willemsen, M., et al., Molecular interaction studies using microscale thermophoresis. Assay Drug Dev Technol, 2011. 9(4): p. 342-53.

78. Putsep, K., et al., Deficiency of antibacterial peptides in patients with morbus Kostmann: an observation study. Lancet, 2002. 360(9340): p. 1144-9.

79. Ouhara, K., et al., Susceptibilities of periodontopathogenic and cariogenic bacteria to antibacterial peptides, \{beta $\}$-defensins and LL37, produced by human epithelial cells. J Antimicrob Chemother, 2005. 55(6): p. 888-96.

80. Dominguez, D.C., Calcium signalling in bacteria. Mol Microbiol, 2004. 54(2): p. 291-7.

81. Jones, H.E., I.B. Holland, and A.K. Campbell, Direct measurement of free Ca(2+) shows different regulation of $\mathrm{Ca}(2+)$ between the periplasm and the cytosol of Escherichia coli. Cell Calcium, 2002. 32(4): p. 183-92.

82. Tallant, C., et al., Molecular analysis of ulilysin, the structural prototype of a new family of metzincin metalloproteases. Journal of biological chemistry, 2006. 281(26): p. 17920-17928.

83. Hosokawa, I., et al., Innate immune peptide LL-37 displays distinct expression pattern from beta-defensins in inflamed gingival tissue. Clin Exp Immunol, 2006. 146(2): p. 218-25.

84. Turkoglu, O., et al., Gingival crevicular fluid levels of cathelicidin LL-37 and interleukin-18 in patients with chronic periodontitis. J Periodontol, 2009. 80(6): p. 969-76.

85. Golec, M., Cathelicidin LL-37: LPS-neutralizing, pleiotropic peptide. Ann Agric Environ Med, 2007. 14(1): p. 1-4. 
86. Potempa, M. and J. Potempa, Protease-dependent mechanisms of complement evasion by bacterial pathogens. 2012.

87. Bajic, G., et al., Human C3a and C3a desArg anaphylatoxins have conserved structures, in contrast to C5a and C5a desArg. Protein Science, 2013. 22(2): p. 204-212.

88. Coulthard, L.G. and T.M. Woodruff, Is the complement activation product C3a a proinflammatory molecule? Re-evaluating the evidence and the myth. The Journal of Immunology, 2015. 194(8): p. 3542-3548.

89. Jusko, M., et al., A metalloproteinase mirolysin of tannerella forsythia inhibits all pathways of the complement system. The Journal of Immunology, 2015. 195(5): p. 2231-2240.

90. Hajishengallis, G., Complement and periodontitis. Biochemical pharmacology, 2010. 80(12): p. 1992-2001.

91. Tanner, A.C. and J. Izard, Tannerella forsythia, a periodontal pathogen entering the genomic era. Periodontol 2000, 2006. 42: p. 88-113.

92. Travis, J., et al., Porphyromonas gingivalis proteinases as virulence factors in the development of periodontitis. Journal of Periodontal Research, 1997. 32(1): p. 120125.

93. Veillard, F., et al., Gingipain aminopeptidase activities in Porphyromonas gingivalis. Biological Chemistry, 2012. 393(12): p. 1471-1476.

94. Wilensky, A., et al., Porphyromonas gingivalis Gingipains Selectively Reduce CD14 Expression, Leading to Macrophage Hyporesponsiveness to Bacterial Infection. Journal of Innate Immunity, 2015. 7(2): p. 127-135.

95. de Diego, I., et al., The outer-membrane export signal of Porphyromonas gingivalis type IX secretion system (T9SS) is a conserved C-terminal beta-sandwich domain. Sci Rep, 2016. 6: p. 23123.

96. Lasica, A.M., et al., Structural and functional probing of PorZ, an essential bacterial surface component of the type-IX secretion system of human oralmicrobiomic Porphyromonas gingivalis. Scientific Reports, 2016. 6.

97. Tan, K., et al., Insights into PG-binding, conformational change, and dimerization of the OmpA C-terminal domains from Salmonella enterica serovar Typhimurium and Borrelia burgdorferi. Protein Sci, 2017. 26(9): p. 1738-1748.

98. Craik, C.S., M.J. Page, and E.L. Madison, Proteases as therapeutics. Biochem J, 2011. 435(1): p. 1-16.

99. Cudic, M. and G.B. Fields, Extracellular proteases as targets for drug development. Curr Protein Pept Sci, 2009. 10(4): p. 297-307.

100. Laugisch, O., et al., Periodontal pathogens affect the level of protease inhibitors in gingival crevicular fluid. Mol Oral Microbiol, 2012. 27(1): p. 45-56.

101. Cottrell, G.S., et al., Protease-activated receptor 2: activation, signalling and function. Biochem Soc Trans, 2003. 31(Pt 6): p. 1191-7.

102. Cseri, J., et al., A purinergic signal transduction pathway in mammalian skeletal muscle cells in culture. Pflugers Arch, 2002. 443(5-6): p. 731-8.

103. Fu, H., et al., The mechanism for activation of the neutrophil NADPH-oxidase by the peptides formyl-Met-Leu-Phe and Trp-Lys-Tyr-Met-Val-Met differs from that for interleukin-8. Immunology, 2004. 112(2): p. 201-10. 
104. Grynkiewicz, G., M. Poenie, and R.Y. Tsien, A new generation of Ca2+ indicators with greatly improved fluorescence properties. J Biol Chem, 1985. 260(6): p. 344050 .

105. Jenkins, A.L., et al., The response to thrombin of human neutrophils: evidence for two novel receptors. J Cell Sci, 1995. 108 ( Pt 9): p. 3059-66.

106. Liu, D., et al., Altered calcium-induced exocytosis in neutrophils from allergic patients. Int Arch Allergy Immunol, 2004. 134(4): p. 281-7.

107. Lourbakos, A., et al., Cleavage and activation of proteinase-activated receptor-2 on human neutrophils by gingipain-R from Porphyromonas gingivalis. FEBS Lett, 1998. 435(1): p. 45-8.

108. Lourbakos, A., et al., Activation of protease-activated receptors by gingipains from Porphyromonas gingivalis leads to platelet aggregation: a new trait in microbial pathogenicity. Blood, 2001. 97(12): p. 3790-3797.

109. Sage, S.O., et al., Rapid kinetics of agonist-evoked changes in cytosolic free Ca2+ concentration in fura-2-loaded human neutrophils. Biochem J, 1990. 265(3): p. 915-8.

110. Smolen, J.E. and S.J. Stoehr, Micromolar concentrations of free calcium provoke secretion of lysozyme from human neutrophils permeabilized with saponin. $\mathrm{J}$ Immunol, 1985. 134(3): p. 1859-65. 


\section{CURRICULUM VITAE}

Lahari Koneru

lahari23koneru@gmail.com

\section{QUALIFICATIONS:}

2007-2012: Bachelor of Dental Surgery.

2013- 2017: Interdisciplinary PhD (expected).

\section{PUBLICATIONS}

- Veillard F, Potempa B, Guo Y, Ksiazek M, Sztukowska MN, Houston JA, Koneru L, Nguyen KA, Potempa J. (2015) Purification and characterization of recombinant His-tagged RgpB gingipain from Porphymonas gingivalis. Biol. Chem. 396: 377384. doi: 10.1515/hsz-2014-0304.

- de Diego-Martinez, I., Ksiazek, M., Mizgalska, D., Koneru L., Golik, P., Szmigielski, B., Nowak, M., Nowakowska, Z., Potempa, B., Nguyen, K.A., Enghild, J.J., Thøgersen, I., Dubin, G., Gomis-Ruth F.X. \& Potempa, J (2016) The outer-membrane export signal of Porphyromonas gingivalis type IX secretion system (T9SS) is a conserved C-terminal $\beta$-sandwich domain. Sci. Rep. 6: 23123. doi: $10.1038 /$ srep23123.

- Koneru L, Ksiazek, M., Waligorska, I., Straczek, A., Lukasik, M., Madej, M., Thøgersen, I.B., Enghild, J.J., Potempa J. (2017) Mirolysin, a LysargiNase from Tannerella forsythia, proteolytically inactivates the human cathelicidin, LL-37. (2016) Mirolysin, a LysargiNase from Tannerella forsythia, proteolytically inactivates a human cathelicidin, LL37. Biol. Chem. 398: 395-409. doi: 10.1515/hsz-2016-0267. 


\section{PRESENTATIONS AND PARTICIPATIONS:}

- Poster Presentation on 'Purification and Characterization of ProRgpB CTD Mutants in Porphyromonas gingivalis' in 2016 Summer Research Program (Research Louisville!) held at University of Louisville, Kentucky, U.S.A.

- Poster Presentation on 'Characterization of a novel metallopeptidase mirolysin of Tannerella forsythia' in $\mathbf{2 3}^{\text {rd }}$ Annual Midwest Microbial Pathogenesis Conference, University of Illinois at Urbana- Champaign, Illinois, U.S.A.

- Poster presentation on 'Mirolysin - A novel member of KLIKK family of proteases and potential virulence factor of Tannerella forsythia' in $\mathbf{2 0 1 5}$ Summer Research Program (Research Louisville!) at University of Louisville, Kentucky, U.S.A.

- Poster presentation on 'Characterization of a novel metallopeptidase mirolysin of Tannerella forsythia' in PgLONDON2015, $2^{\text {nd }}$ International conference on porphyromonas gingivalis and related species in Oral and Systemic Diseases at Queen Mary University of London, U.K.

- Poster Presentation on 'Characterization of a novel metallopeptidase mirolysin of Tannerella forsythia' in 2014 Summer Research Program (Research Louisville!) held at University of Louisville, Kentucky, U.S.A.

- Paper Presentation on 'Saliva as a Diagnostic Tool in Periodontics' at $\mathbf{1}^{\text {st }} \mathbf{A . P}$ IDA U.G Conference held on12th October 2012 in Vishnu Dental College, Bheemavaram, India.

- Participated in All India Dental student Conference, held on Jan2011, Vijayawada, Andhra Pradesh, India.

- Participated in Art of Dental Materials inter- state program held on $22^{\text {nd }}$ Nov 2011 at St. Joseph Dental College, Eluru, India .

- State level CDE Programme held on $18^{\text {th }}$ march 2011 by Department of Periodontics \& Implantology at St. Joseph Dental College, Eluru, India.

- Participated in State Level CDE Programme on 'The Special Child Management \&Hospital Based Pediatric Dentistry' held on 12 Dec 2009 Eluru, Andhra Pradesh, India. 